\title{
Comparison of a Work-Based Window Method to NTE Method for Reporting In-Use Emissions
}

\author{
Nathan Music \\ West Virginia University
}

Follow this and additional works at: https://researchrepository.wvu.edu/etd

\section{Recommended Citation}

Music, Nathan, "Comparison of a Work-Based Window Method to NTE Method for Reporting In-Use Emissions" (2011). Graduate Theses, Dissertations, and Problem Reports. 4759.

https://researchrepository.wvu.edu/etd/4759

This Thesis is protected by copyright and/or related rights. It has been brought to you by the The Research Repository @ WVU with permission from the rights-holder(s). You are free to use this Thesis in any way that is permitted by the copyright and related rights legislation that applies to your use. For other uses you must obtain permission from the rights-holder(s) directly, unless additional rights are indicated by a Creative Commons license in the record and/ or on the work itself. This Thesis has been accepted for inclusion in WVU Graduate Theses, Dissertations, and Problem Reports collection by an authorized administrator of The Research Repository @ WVU. For more information, please contact researchrepository@mail.wvu.edu. 
Comparison of a Work-Based Window Method to NTE Method for Reporting In-Use Emissions Nathan Music

\author{
Thesis submitted to the \\ College of Engineering and Mineral Resources \\ at West Virginia University \\ in partial fulfillment of the requirements \\ for the degree of \\ Master of Science \\ in \\ Mechanical Engineering \\ Gregory Thompson, Ph.D., Chair \\ Benjamin Shade, Ph.D. \\ Scott Wayne, Ph.D.
}

Department of Mechanical and Aerospace Engineering

\author{
Morgantown, West Virginia
}

2011

Keywords: (Emissions, In-Use Testing, PEMS, Work-based Window)

Copyright 2011. Nathan S. Music 


\section{Abstract \\ Comparison of a Work-Based Window Method to NTE Method for Reporting In-Use Emissions}

\section{Nathan S. Music}

Heavy-duty on-road diesel engines currently sold in the United States are subjected to emission certification over the Federal Test Procedure and Supplemental Emissions Test in an engine test cell as well as in-use testing in real world environments using portable emissions measurement systems (PEMS). The current method for analyzing in-use emissions is based on the Not-To-Exceed (NTE) region of engine operation. With this method, emissions are reported only when the engine is operating in the NTE region for a minimum of thirty seconds. The downfall to this method is that any engine operation outside of this region is neglected. An alternative method for measuring in-use emissions is based on a work approach previously proposed by Shade. This method integrates power produced by the engine over time to create work windows; the integration duration can be defined using a pre-specified work level. One such work level could be the work that the engine was exercised over during the Federal Test Procedure. The emissions produced during this window are then summed and divided by the work to produce brake specific emission levels for each window. By basing this analysis on work produced by the engine instead of time an engine spends in a certain region of operation, almost no point of engine operation is neglected and the majority of all emissions produced during the test are accounted for.

A study using in-use compliance data from seven vehicles representing diverse vocations was used to compare the currently implemented NTE method of in-use emissions measurement and a proposed work-based window method for measuring brake specific emissions of $\mathrm{CO}, \mathrm{CO}_{2}$, 
NOx, THC, and PM emissions. Analysis of this data showed that without any exclusions applied to either method, the work-window method resulted in an average percent difference of $162 \%$ higher $\mathrm{CO}, 12 \%$ higher $\mathrm{CO}_{2}, 94 \%$ higher NOx, and $186 \%$ higher THC emissions when compared to the average NTE results. Average PM results from the work-window method, however, showed a $122 \%$ lower level than the NTE method. Due to limitations associated with the NTE method, it was determined that the work-based window method may still provide better representation of actual in-use emissions despite the higher calculated brake specific emission levels. 


\section{Acknowledgements}

Special thanks goes to all those involved in the in-use testing program that provided the data used for this study. Especially to Brad Ralston, Brock Merritt, Chris Beers, and Kurt Yankalonis who put in countless hours in the field working to complete the project despite constant technical difficulties and schedule set-backs. Also, to my committee chairperson, Dr. Thompson, and my committee members Dr. Shade, Dr. Wayne, and Dr. Nuszkowski, I would like to thank them for their continued guidance during my graduate research. I would also like to thank Oscar Delgado for his help with the programming portion of my research. 


\section{Table of Contents}

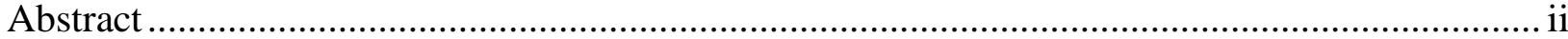

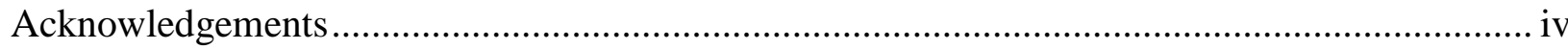

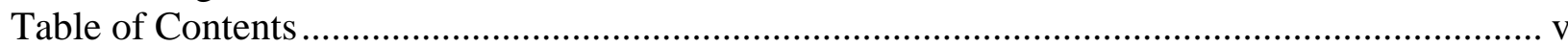

List of Figures …............................................................................................................. vii

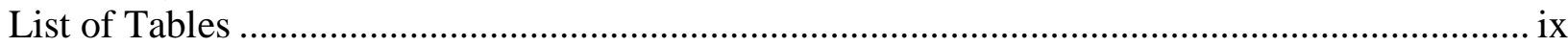

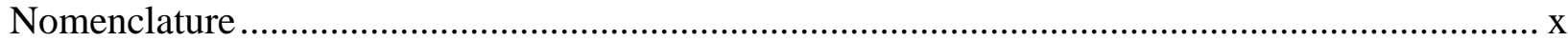

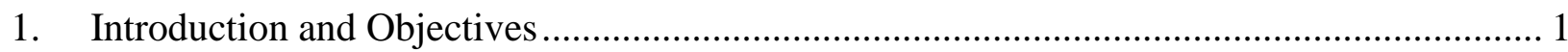

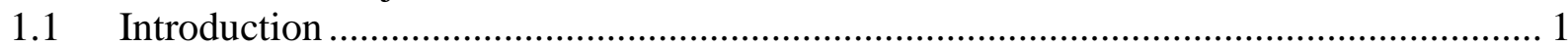

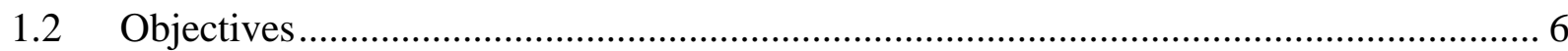

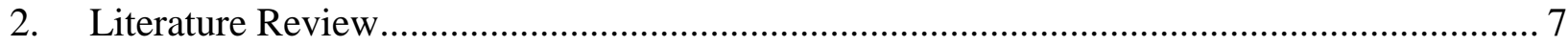

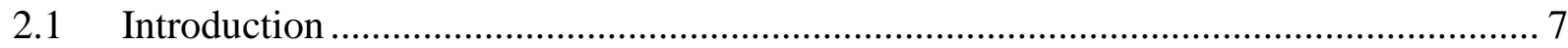

2.2 Air Quality and Emissions Regulatory History.................................................... 8

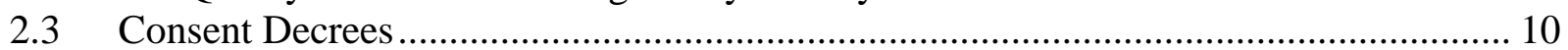

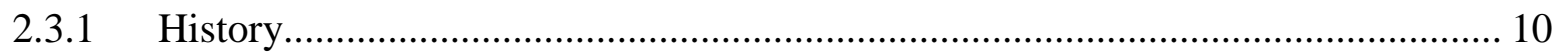

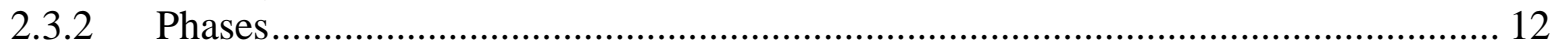

2.4 Differences between In-Use Testing and Laboratory Emissions Measurement ............ 14

2.5 Portable Emissions Measurement Systems ............................................................... 19

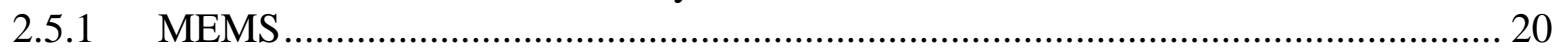

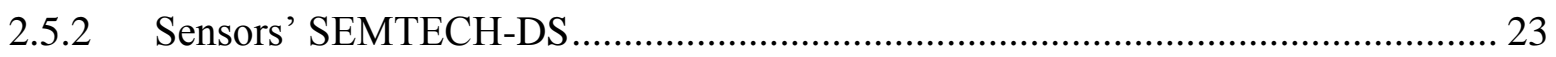

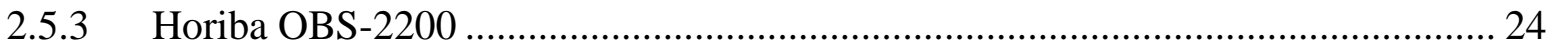

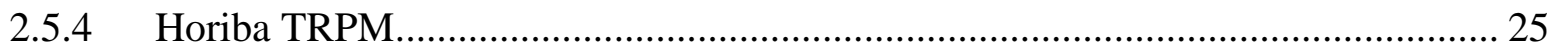

2.5.5 Sensors' SEMTECH PPMD ........................................................................ 27

2.6 Not-To-Exceed Zone ............................................................................................ 28

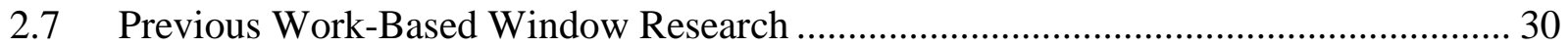

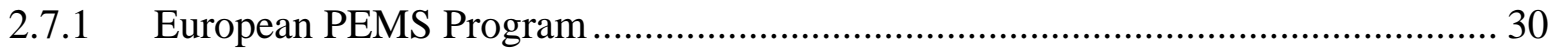

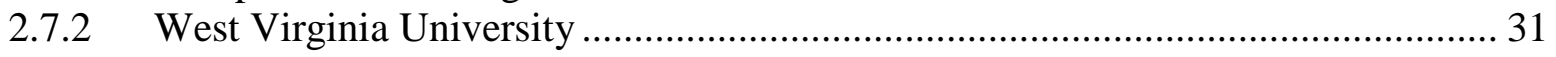

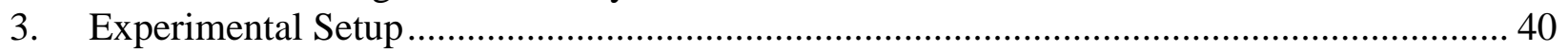

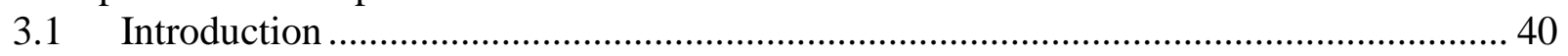

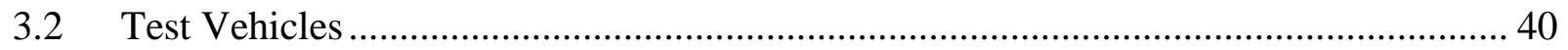

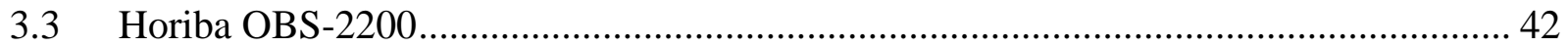

3.3.1 Carbon Monoxide/ Carbon Dioxide Analyzer .................................................. 43

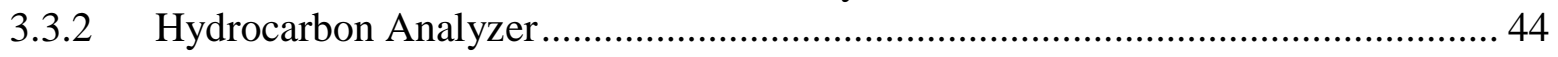

3.3.3 Oxides of Nitrogen Analyzer ...................................................................... 44

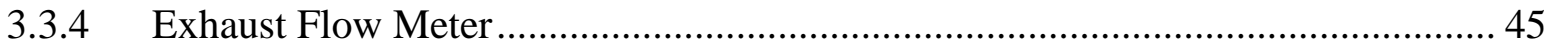

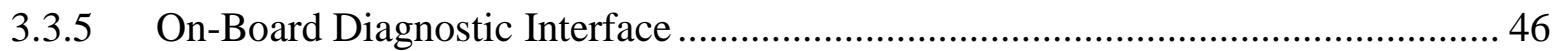

3.3.6 Auxiliary Components ............................................................................. 47

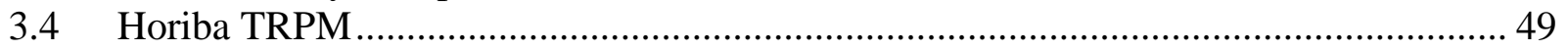

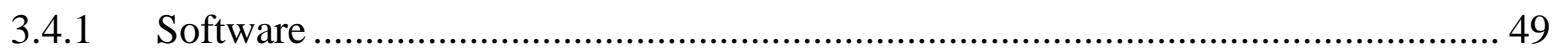

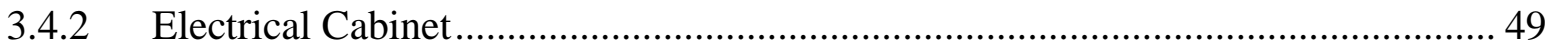

3.4.3 Mechanical Cabinet .................................................................................... 50

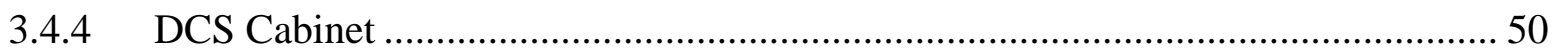

3.4.5 Sample Probe and Miniature Dilution Tunnel .............................................. 50

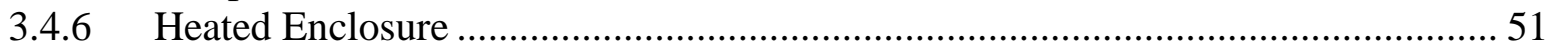

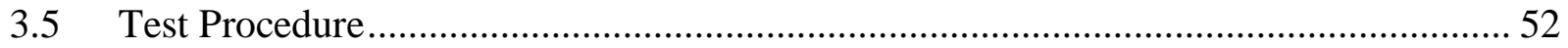


3.5.1 Equipment Calibration and Maintenance Schedule .......................................... 52

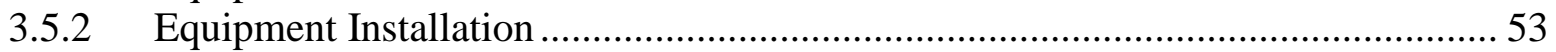

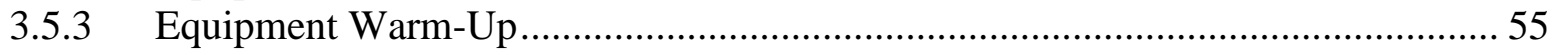

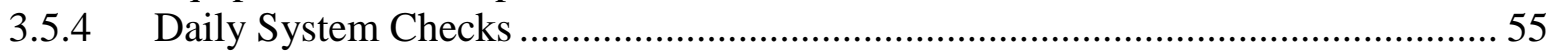

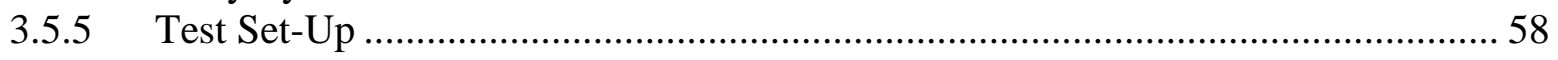

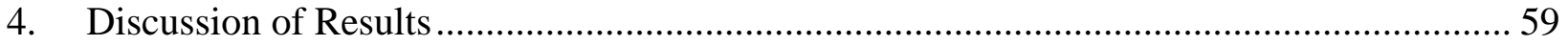

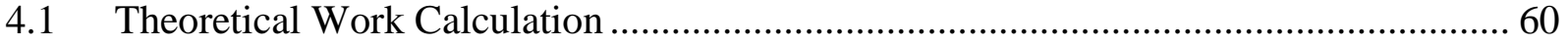

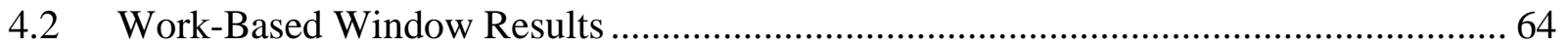

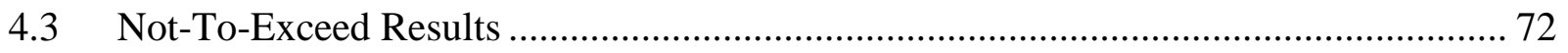

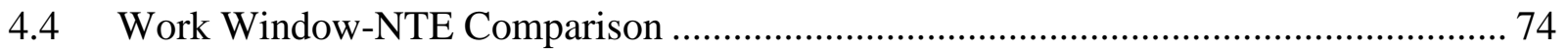

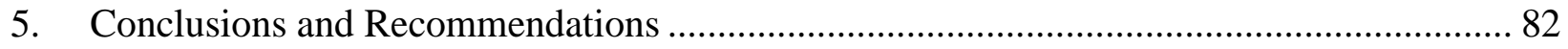

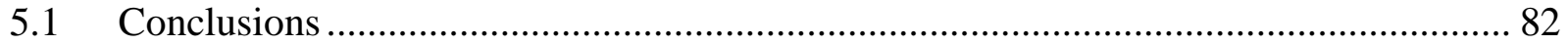

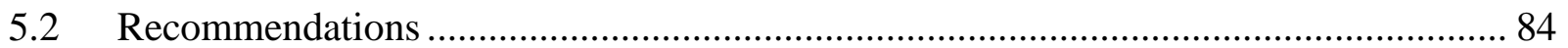

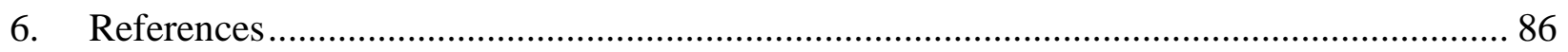

7. Appendix A- Matlab Program to Determine FTP Theoretical Work ............................... 88

8. Appendix B- Matlab Program to Generate Work-Windows …...................................... 90

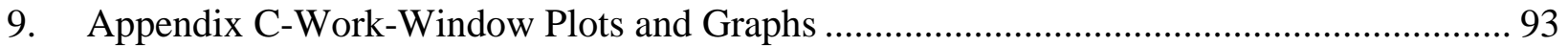

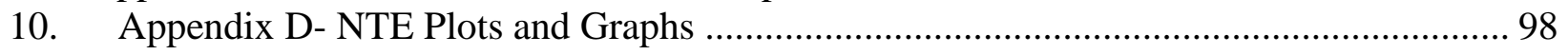




\section{List of Figures}

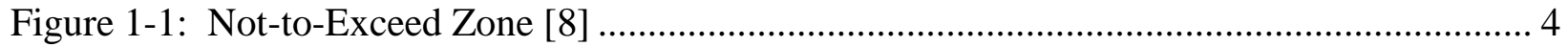

Figure 2-1: Example of Engine Test Cell Configuration [17] ................................................ 16

Figure 2-2: Federal Test Procedure for Heavy Duty Engines [18] .......................................... 17

Figure 2-3: MEMS Data Acquisition Unit Installed on a Test Vehicle [9] ............................. 21

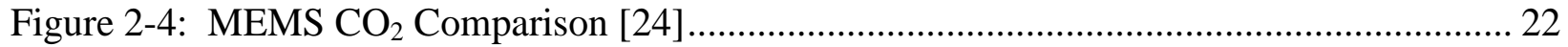

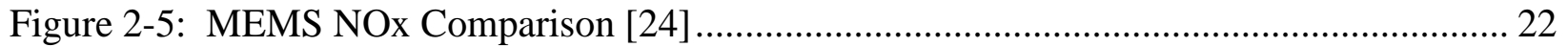

Figure 2-6: SEMTECH-DS Main Unit [22] .......................................................................... 24

Figure 2-7: Horiba OBS System as Installed on a Test Vehicle .............................................. 25

Figure 2-8: Prototype Horiba TRPM Installed on a Test Vehicle .......................................... 27

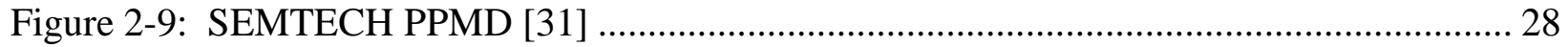

Figure 2-10: Diagram of the Not-To-Exceed Region [8] ..................................................... 30

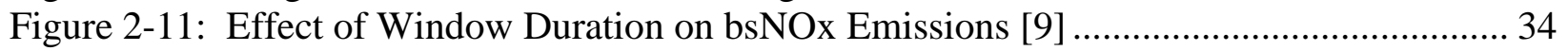

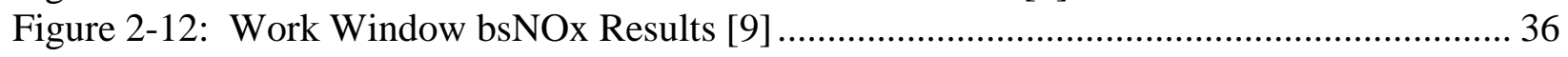

Figure 2-13: 30 Second NTE Window bsNOx Results [9]................................................. 37

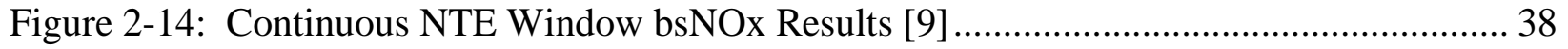

Figure 3-1: Schematic of the OBS-2200 System [27] ......................................................... 42

Figure 3-2: Heated NDIR Analyzer Configuration [27] ..................................................... 43

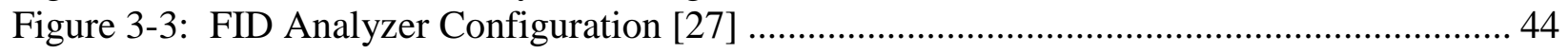

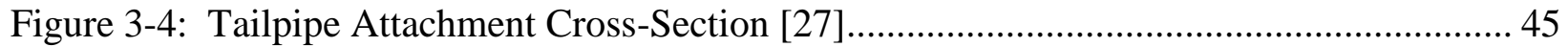

Figure 3-5: Internal Components of TRPM Heated Enclosure ............................................ 52

Figure 3-6: Equipment Installed on a Test Vehicle ........................................................... 54

Figure 3-7: OBS System Check Result Window [27] .......................................................... 56

Figure 3-8: TRPM Pressure Transducer Calibration Sequence Window [32] .......................... 57

Figure 3-9: TRPM Sample Flow Rate Check Window [32] ................................................. 58

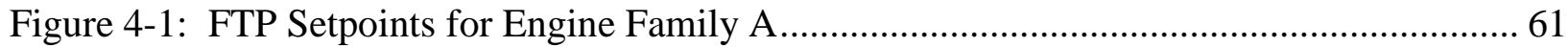

Figure 4-2: FTP Setpoints for Engine Family B ............................................................. 61

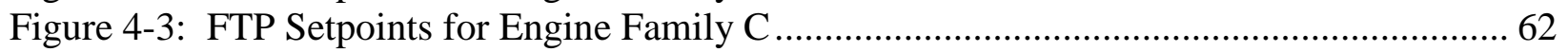

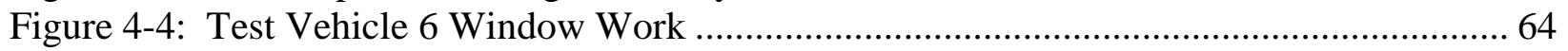

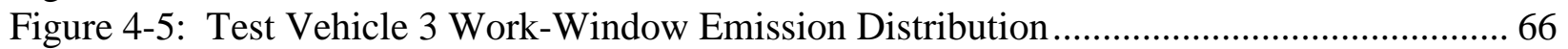

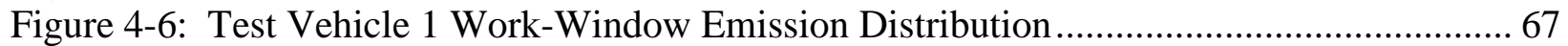

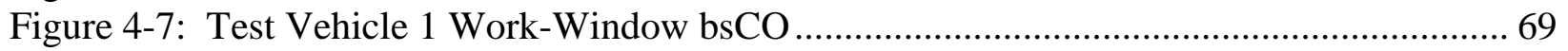

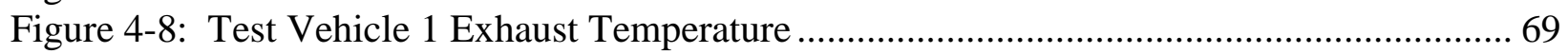

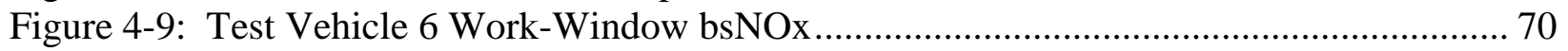

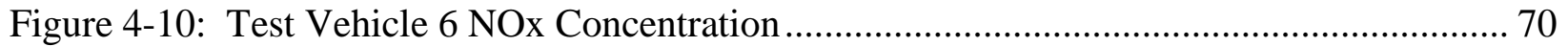

Figure 4-11: Test Vehicle 7 NTE Event Distribution ............................................................. 73

Figure 4-12: CO Comparison of Work-Window to NTE ...................................................... 76

Figure 4-13: CO2 Comparison of Work-Window to NTE .................................................... 76

Figure 4-14: NOx Comparion of Work-Window to NTE .................................................... 77

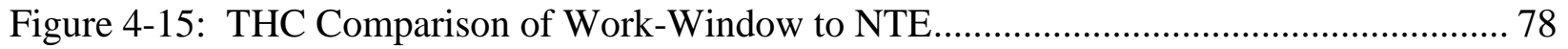

Figure 4-16: PM Comparison of Work-Window to NTE.................................................... 79

Figure 9-1: Work-Window Gaseous Emission Distribution for TV 1.................................. 93

Figure 9-2: Work-Window PM Emission Distribution for TV 1 .......................................... 93

Figure 9-3: Work-Window Emission Distribution for TV 2 _............................................. 94

Figure 9-4: Work-Window Emission Distribution for TV 3 .............................................. 94 
Figure 9-5: Work-Window Emission Distribution of TV 4 ............................................. 95

Figure 9-6: Work-Window Emission Distribution of TV 5 ............................................... 95

Figure 9-7: Work-Window Gaseous Emission Distribution TV 6 ..................................... 96

Figure 9-8: Work-Window PM Emission Distribution TV 6 ............................................. 96

Figure 9-9: Work-Window Gaseous Emission Distribution TV 7 ....................................... 97

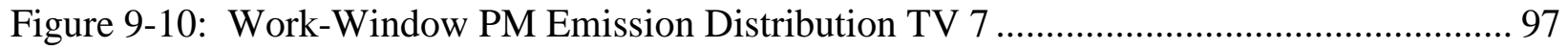

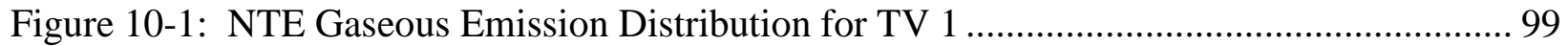

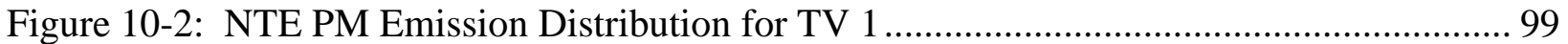

Figure 10-3: NTE Emission Distribution for TV 2 ....................................................... 100

Figure 10-4: NTE Emission Distribution for TV 3 ....................................................... 100

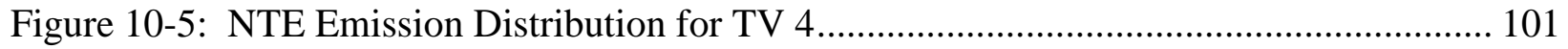

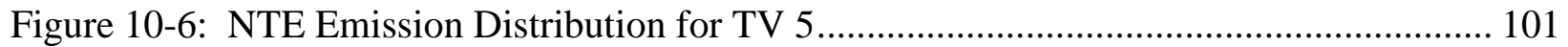

Figure 10-7: NTE Gaseous Emission Distribution for TV 6 ........................................... 102

Figure 10-8: NTE PM Emission Distribution for TV 6................................................... 102

Figure 10-9: NTE Gaseous Emission Distribution for TV 7 .......................................... 103

Figure 10-10: NTE PM Emission Distribution for TV 7 ................................................ 103 


\section{List of Tables}

Table 2-1: EPA Emission Standards for Diesel Heavy-Duty Trucks and Urban Buses [12] ........ 8

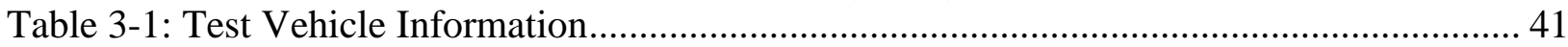

Table 3-2: Test Vehicles Engine's Families Allowable Emission Certification Levels............. 41

Table 3-3: Test Vehicles Engines' Families Reported FTP Certification Emission Levels........ 42

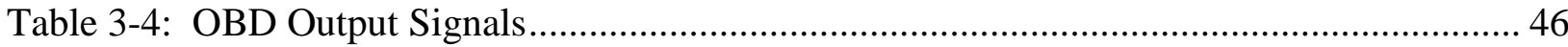

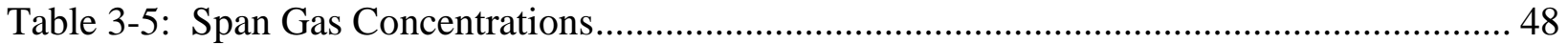

Table 3-6: Horiba Recommended OBS Maintenance Schedule .............................................. 53

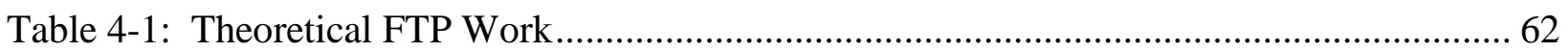

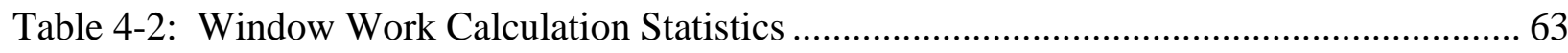

Table 4-3: Brake Specific Work-Window Results ..................................................................... 72

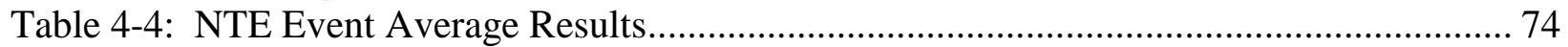

Table 4-5: Percent Difference (\%) Between Work-Window and NTE Results ....................... 80

Table 4-6: Work-Window Percent Change from the FTP Certification Reported Levels .......... 80

Table 4-7: NTE Percent Change from the FTP Certification Reported Levels ......................... 81 


\begin{tabular}{|c|c|}
\hline \multicolumn{2}{|c|}{ Nomenclature } \\
\hline $\mathrm{AC}$ & Alternating Current \\
\hline BHP & Brake Horsepower \\
\hline $\mathrm{bsCO}$ & Brake Specific Carbon Monoxide \\
\hline bsCO2 & Brake Specific Carbon Dioxide \\
\hline BSFC & Brake Specific Fuel Consumption \\
\hline bsNOx & Brake Specific Oxides of Nitrogen \\
\hline bsPM & Brake Specific Particulate Matter \\
\hline bsTHC & Brake Specific Total Hydrocarbons \\
\hline${ }^{\circ} \mathrm{C}$ & Degree Celsius \\
\hline CAFEE & Center for Alternative Fuels, Engines, and Emissions \\
\hline CARB & California Air Resources Board \\
\hline CFR & Code of Federal Regulations \\
\hline $\mathrm{CI}$ & Compression Ignition \\
\hline CLD & Chemiluminescence Detector \\
\hline $\mathrm{CO}$ & Carbon Monoxide \\
\hline $\mathrm{CO}_{2}$ & Carbon Dioxide \\
\hline CVS & Constant Volume Sampling \\
\hline DC & Direct Current \\
\hline DCS & Diffusion Charge Sensor \\
\hline DOC & Diesel Oxidation Catalyst \\
\hline DPF & Diesel Particulate Filter \\
\hline ECM & Engine Control Module \\
\hline EERL & Engine and Emissions Research Laboratory \\
\hline EFM & Exhaust Flow Meter \\
\hline EGR & Exhaust Gas Recirculation \\
\hline EIU & External Input Unit \\
\hline EPA & Environmental Protection Agency \\
\hline $\mathrm{ESC}$ & European Stationary Cycle \\
\hline${ }^{\circ} \mathrm{F}$ & Degree Fahrenheit \\
\hline FID & Flame Ionization Detector \\
\hline FTP & Federal Test Procedure \\
\hline $\mathrm{g}$ & Gram \\
\hline g/bhp-hr & Grams per Brake Horsepower Hour \\
\hline $\mathrm{g} / \mathrm{kW}-\mathrm{hr}$ & Grams per Kilowatt Hour \\
\hline $\mathrm{g} / \mathrm{mi}$ & Grams per Mile \\
\hline GPS & Global Positioning System \\
\hline $\mathrm{HC}$ & Hydrocarbon \\
\hline HDDE & Heavy Duty Diesel Engine \\
\hline HEPA & High Efficiency Particulate Air \\
\hline $\mathrm{hr}$ & Hour \\
\hline JRC & Joint Research Centre \\
\hline lpm & Liters Per Minute \\
\hline MEMS & Mobile Emissions Measurement System \\
\hline MPS & Micro-Proportional Sampling \\
\hline$\mu \mathrm{g}$ & Microgram \\
\hline NDIR & Non-Dispersive Infrared \\
\hline NDUV & Non-Dispersive Ultraviolet \\
\hline NEDC & New European Driving Cycle \\
\hline
\end{tabular}


NMHC

$\mathrm{NO}$

$\mathrm{NO}_{2}$

NOx

NTE

OBD

OBS

PEMS

PM

ppm

PSU

PTO

QCM

RTD

SET

THC

TV

WVU

$\mathrm{ZrO}_{2}$
Non-Methane Hydrocarbons

Nitric Oxide

Nigrogen Dioxide

Oxides of Nitrogen

Not-To-Exceed

On-Board Diagnostics

On-Board Emissions Measurement System

Portable Emissions Measurement System

Particulate Matter

Parts per Million

Power Supply Unit

Power Take-Off

Quartz Crystal Microbalance

Resistance Temperature Detector

Supplemental Emissions Test

Total Hydrocarbons

Test Vehicle

West Virginia University

Zirconium Oxide 


\section{Introduction and Objectives}

\subsection{Introduction}

In 1998 the United States Environmental Protection Agency (EPA) and six heavy-duty diesel engine (HDDE) manufacturing companies agreed upon a set of Consent Decrees involving emission certification testing for diesel engines. These Consent Decrees were a result of a lawsuit brought by the United States government against the six HDDE manufacturers. This lawsuit accused the manufacturers of implementing defeat devices into the engine control strategies of production engines in an effort to meet emissions regulations while providing the consumer maximum performance and fuel efficiency. This led to production engines in the field of the same model and family producing higher levels of regulated emissions than test engines used in dynamometer certification. To resolve this issue, as a part of the Consent Decrees, the engine manufacturers agreed to conduct in-use emissions testing on select production engines in addition to the engine testing procedures already conducted to help assure that production engines meet EPA regulations while admitting no wrong doing [1-6].

Traditionally, HDDE emissions are tested in specialized laboratory test cells to demonstrate that HDDEs met prescribed emissions standards. These test cells require the use of large electric dynamometers to measure engine speed and engine torque. Test cells used for emission certification work often use constant volume sampling (CVS) systems with dilution tunnels to dilute engine exhaust to levels readable by the various gaseous and particulate matter analyzers. Engines tested in these cells operate on standardized test cycles, such as the Federal Test Procedure (FTP), that are designed to simulate real-world driving scenarios. These test cycles 
consist of various engine speed and torque set points that the engine is exercised over and the measured speed and torque values recorded by the dynamometer [7].

In-use testing of engine emissions differs from that of test cell emissions testing in that the engine is tested while installed in a vehicle and being driven over the road. While in theory inuse testing will result in the exact emissions produced from the engine in the real world, the very nature of conducting this type of testing presents inherent difficulties not found in traditional engine emissions testing. During in-use testing the engine is subjected to various changes in environmental conditions; these changes can often occur rapidly and quite substantially. For instance, if the test vehicle ascends a mountain during the test, outside temperature and barometric pressure can change and these ambient changes can affect the combustion processes and resulting emissions. These ambient conditions also have an effect on emission calculations and if their changes are not accounted for can lead to inaccuracies in the emissions data being reported. One of the largest obstacles to overcome during in-use testing is accounting for these changes in environmental conditions when calculating emission levels. In a test cell, however, engines operate under strictly controlled conditions. Intake air is conditioned to be a certain temperature and humidity and does not vary significantly during the test. Coolant temperature and fuel temperature are also controlled to some extent. It should be noted that barometric pressure is generally an exception and not controlled within an engine dynamometer test cell and can vary due to local weather events. However, barometric pressure does not generally change to any significant amount during a certification test. 
In-use testing also requires specialized equipment that must be tailored to the environment it will be used in. Since the test vehicle is operating over the road the test equipment must be capable of handling the vibration seen in over the road travel. Additionally, all equipment and support systems must be compact enough to fit onto the test vehicle. This includes all analyzers, calibration gases, and power sources. Traditional test cell equipment is often large in size and intended to be housed in a stationary, interior location where additional support systems like electrical power and heating, ventilation, air conditioning systems are located.

The goal of in-use testing is to measure an engine's emissions as the vehicle is being driven over the road in a real world environment. However, the test route the vehicle is driven over is subject to varying traffic as opposed to engine dynamometer testing in traditional engine test cells where the test cycle is prearranged and does not change for a given engine (or engine lug curve). This means that the engine dynamometer test run on these engines are repeatable and, from experience, produce little variance in total work done by the engine. During in-use emissions testing it is not expected to exactly recreate the results of a previous test. Even if the vehicle is operated over the same test route, varying traffic patterns and other uncontrollable circumstances affect the driving pattern and the resulting data. To alleviate some of the real-world influences on in-use testing, it was necessary to consider real world operation that may be experienced but not significantly impact overall emissions generation and to limit the evaluation of the engine's emissions in real-world operation. These operating conditions led to the implementation of the Not-To-Exceed (NTE) zone. The NTE zone consists of a specified region in each engine's speed and torque curve, also known as an engine map. A generic representation of the NTE zone as it falls over an engine map is shown below in Figure 1-1. 


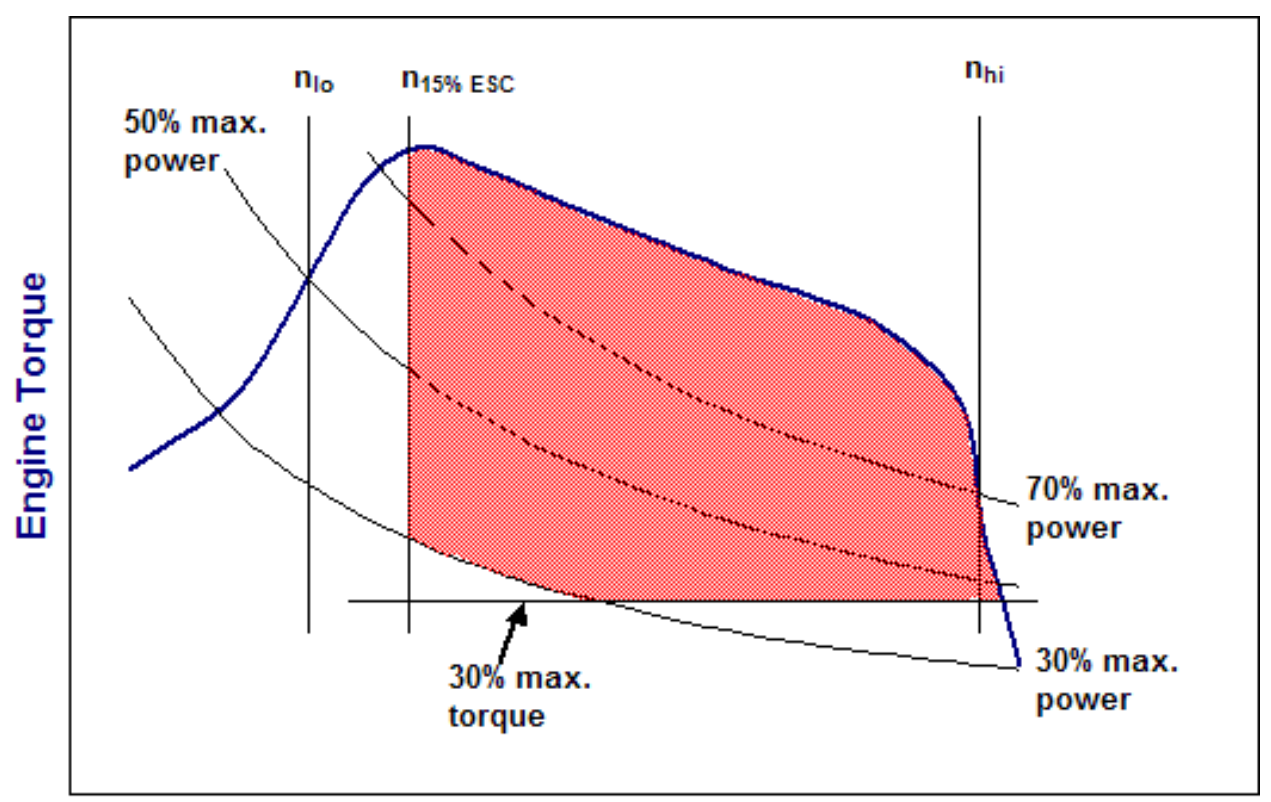

Engine Speed

Figure 1-1: Not-to-Exceed Zone [8]

The NTE zone is defined as being points of engine speed above 15\% engine speed relative to the European Stationary Cycle (ESC) speeds. The high and low ESC speeds are defined by the intersection of the torque curve and the $70 \%$ maximum power curve and the intersection of the torque curve and the 50\% maximum power curve, respectively. Points must also be greater than or equal to $30 \%$ maximum power and torque to be considered inside of the NTE zone. Each string of points lasting a minimum of 30 seconds or longer within the NTE zone is considered a NTE event. The individual NTE events are then analyzed for emissions while points not contained within a NTE event are neglected [8].

One of the major difficulties of measuring in-use emissions within 30 second, or even longer, windows is time delays between the emissions formation and the recording of the emissions values with the analytical equipment. Axial dispersion diffusion in the vehicle's exhaust and 
sampling equipment make it difficult to relate the measured emissions to the recorded engine events (engine speed and torque) in order to determine brake-specific mass emissions within 30 (or more) seconds. Experience has shown that most engine operation does not occur at steady state conditions, especially for any roads where there are changing terrain and or traffic conditions. Constant engine operation may be expected where there is relatively flat road (level terrain) and steady engine operation where the cruise control may be employed such as found in the midwest portion of the United States.

In 2006 a West Virginia University (WVU) student, Benjamin Shade, proposed to examine inuse emissions on a work-based window in place of the 30 second NTE window, arguing a more equal comparison between laboratory certification and in-use compliance [9]. In Shade’s approach, a window is defined based on the work the engine was required to perform during the applicable certification test. The engine would be operated in-use and the resulting engine power would be continuously integrated until the target work was reached. The emissions would then be integrated over this same time period and the brake-specific mass emissions determined. A moving window would then be defined and the window of integration adjusted based on the engine operation. For instance, low power operation would result in longer time periods while higher power operation would result in shorted time periods for the reference work integration period. A potential limitation of this method includes measuring emissions from vehicles undergoing activity at low power or under long idle durations where the emissions would not have been reported using 30 second windows due to these engine operating conditions being outside the NTE zone. Extended idle emissions could skew "normal" engine operation emissions due to zero work at idle. However, most HDDE are not operated under these 
conditions and allowances would need to be made for those vehicles that have vocational activity that may skew brake-specific emissions results. Although this method has limitation, it provided a rationale for an integration window and should result in a window that was longer than 30 seconds in duration, thus reducing the dispersion and diffusion issue with 30 second windows.

Shade examined the WVU data collected as part of the Phase III and Phase IV Consent Decree work [9] performed for the settling manufacturers. The primary focus of Shade's research was the study of in-use NOx emissions since these emissions were the only regulated emissions constituent measured at the time of that work [9]. Significant changes have been made to engines to comply with 2007 and 2010 emissions standards and these changes include combustion and aftertreatment systems. Additionally, emissions of $\mathrm{THC}, \mathrm{CO}, \mathrm{CO}_{2}$ and $\mathrm{PM}$ are required in addition to NOx as part of the in-use regulations. There is need to extend Shade's work-based windows for these newer engines and to examine the impact the work window has on THC, CO, $\mathrm{CO}_{2}$ and $\mathrm{PM}$ emissions.

\subsection{Objectives}

The focus and main objective of this thesis is to analyze the effectiveness of a work-based window method for measuring in-use gaseous and particulate emissions for on-road, heavy duty diesel engines with respect to the Not-To-Exceed method of measurement which is currently practiced. This research will look at in-use emissions data from two separate engine families and analyze the data using each method. This analysis will compare brake specific emissions from each method and from this comparison a conclusion of the effectiveness of the work-based window method will be made. 


\section{Literature Review}

\subsection{Introduction}

For many years, diesel fuel powered vehicles have dominated the heavy duty vehicle industry. Vehicles equipped with heavy duty diesel engines range from long-haul Class 8 tractors to vocational vehicles such as bucket trucks and cement mixers. According to the Research and Innovative Technology Administration Bureau of Transportation Statistics, in 2003 there were almost 6.5 million fleet operated trucks in the United States [10]. In that same year there were 1.3 trillion ton-miles of freight moved by intercity trucks [11]. The large number of these vehicles in service and extent of the miles that they travel has prompted the U.S. Government to enforce regulations limiting the amount of pollutants produced by these vehicles. The EPA first put limits on the levels of emissions constituents contained in heavy duty engine exhaust in the late 1960's when Congress passed the Air Quality Act [12] and has since periodically lowered these levels requiring advancements to be made in diesel engine and aftertreatment technology. Since the introduction of these regulations, diesel emissions of NOx and PM have been reduced by approximately 99\%. Table 2-1 displays the reduction in emissions levels since 1974 . The table shows a significant reduction in allowable levels in NOx, CO, and PM from between 1974 and 2007 especially with the implementation of the 2004 and 2007 standards. 
Table 2-1: EPA Emission Standards for Diesel Heavy-Duty Trucks and Urban Buses [12]

\begin{tabular}{|c|c|c|c|c|c|c|c|c|c|c|c|}
\hline & Year & $\mid \begin{array}{c}\text { HC } \\
(\mathbf{g} / \mathbf{b h p}- \\
\mathbf{h r})\end{array}$ & $\begin{array}{c}\text { NMH C } \\
\text { (g/bhp- } \\
\text { hr) }\end{array}$ & NMHC + NOx (g/bhp-hr) & $\begin{array}{c}\text { NOx } \\
\text { (g/bhp- } \\
\text { hr })\end{array}$ & $\begin{array}{c}\text { PM } \\
\text { (g/bhp- } \\
\text { hr })\end{array}$ & $-\begin{array}{c}\text { CO } \\
(\mathbf{g} / \mathbf{b h p}- \\
\mathrm{hr})\end{array}$ & $\begin{array}{l}\text { Idle CO (percent } \\
\text { exhaust gas flow) }\end{array}$ & $\begin{array}{c}\text { Smoke }^{a} \\
(\text { Percentage })\end{array}$ & $\begin{array}{c}\text { Useful Life } \\
\text { (hours/years/miles) }\end{array}$ & $\begin{array}{c}\text { Warranty Period } \\
\text { (years/miles) }\end{array}$ \\
\hline \multirow{10}{*}{ Federal ${ }^{b}$} & $1974-78$ & - & - & 16 & - & - & 40 & - & $20 / 15 / 50$ & - & - \\
\hline & $1979-84$ & 1.5 & - & 10 & - & - & 25 & - & $20 / 15 / 50$ & - & - \\
\hline & $1985-87$ & 1.3 & - & - & 10.7 & - & 15.5 & - & $20 / 15 / 50$ & $\begin{array}{l}\text { LHDDE: }-/ 8 / 110,000 \\
\text { MHDDE: }-/ 8 / 185,000 \\
\text { HHDDE: - / } 8 / 290,000\end{array}$ & - \\
\hline & $1988-89$ & $1.3^{\mathrm{d}}$ & - & - & 10.7 & 0.6 & 15.5 & $0.5^{c}$ & $20 / 15 / 50$ & \multirow{5}{*}{$\begin{array}{c}1990-97 \text { and } 1998+ \\
\text { for HC, CO, and PM: } \\
\text { LHDDE: }-/ 8 / 110,000 \\
\text { MHDDE: }-/ 8 / 185,000 \\
\text { HHDDE: }-/ 8 / 290,000 \\
1994+\text { urban buses for } \\
\text { PM only: } \\
-/ 10 / 290,000 \\
1998+\text { for NOx: } \\
\text { LHDDE: }-/ 10 / \\
110,000 \\
\text { MHDDE: }-/ 10 / \\
185,000 \\
\text { HHDDE: }-/ 10 / \\
290,000\end{array}$} & \multirow{5}{*}{$5 / 100,000^{9}$} \\
\hline & 1990 & $1.3^{\mathrm{d}}$ & - & - & 6.0 & 0.6 & 15.5 & $0.5^{c}$ & $20 / 15 / 50$ & & \\
\hline & 1991-93 & 1.3 & - & - & $5.0[\mathrm{ABT}]$ & $\begin{array}{c}0.25 \\
{[\mathrm{ABT}]} \\
0.10^{\mathrm{e}}\end{array}$ & 15.5 & $0.5^{c}$ & $20 / 15 / 50$ & & \\
\hline & $1994-97$ & 1.3 & - & - & $5.0[\mathrm{ABT}]$ & $\begin{array}{c}0.1 \\
{[\mathrm{ABT}]} \\
0.07^{\mathrm{f}} \\
0.05^{\mathrm{g}}\end{array}$ & 15.5 & $0.5^{c}$ & $20 / 15 / 50$ & & \\
\hline & $1998-2003$ & 1.3 & - & - & $4.0[\mathrm{ABT}]$ & $\begin{array}{c}0.1 \\
{[\mathrm{ABT}]} \\
0.05^{9}\end{array}$ & 15.5 & $0.5^{c}$ & $20 / 15 / 50$ & & \\
\hline & $2004-2006^{h}$ & - & - & $\begin{array}{c}2.4 \text { (or } 2.5 \text { with a limit of } \\
0.5 \text { on } \mathrm{NMHC})^{\circ}\left[\mathrm{ABT}^{\mathrm{i}, j}\right]\end{array}$ & - & $\begin{array}{c}0.1 \\
0.05^{9}\end{array}$ & 15.5 & 0.5 & $20 / 15 / 50$ & \multirow{2}{*}{\begin{tabular}{|c|} 
For all pollutants: \\
LHDDE: $^{\mathrm{P}}-/ 10 /$ \\
110,000 \\
MHDDE: $-/ 10 /$ \\
185,000 \\
HHDDE: $22,000 / 10 /$ \\
435,000
\end{tabular}} & \multirow[b]{2}{*}{$\begin{array}{l}\text { LHDDE: } 5 / 50,000 \\
\text { All other HDDE: } 5 / \\
100,000^{9}\end{array}$} \\
\hline & $2007+h, k, l, m, n$ & - & $0.14^{\circ}$ & $\begin{array}{l}2.4 \text { (or } 2.5 \text { with a limit of } \\
0.5 \text { on NMHC) [ABT] }\end{array}$ & $0.2^{\circ}$ & 0.01 & 15.5 & 0.5 & $20 / 15 / 50$ & & \\
\hline
\end{tabular}

To ensure that heavy duty diesel engines sold in the United States comply with EPA regulations, engines models from each engine family are tested for and must comply with the emissions standards for the corresponding model year of the engine being tested. This testing includes engine dynamometer testing conducted in a laboratory test cell and in-use emissions testing of the engine installed in a vehicle and operated in the vehicle's normal daily routine.

\subsection{Air Quality and Emissions Regulatory History}

One of the first steps the United States Government took to begin improving air quality came in the form of the Air Pollution Control Act of 1955; this was the first federal legislation involving air pollution. This act allocated federal funds to be used to research the scale and sources of air pollution. The first federal legislation involving air pollution control came in the early 1960s as the Clean Air Act of 1963. This act established a specialized federal program within the U.S. Public Health Service that conducted research to determine the best methods for monitoring and 
minimizing air pollution [12]. In 1967, Congress passed the Air Quality Act. This gave the Secretary of Health, Education, and Welfare the authorization to establish individual air quality regions in the country and authorized additional research studies focusing on emission inventories, air quality monitoring and control techniques. The Air Quality Act also initiated the first enforcement procedures involving areas subject to interstate air pollution $[12,13]$.

A milestone event in the federal government's role in air pollution control came in 1970 with the enactment of the Clean Air Act. This federal legislation authorized the establishment of federal and state emissions regulations. These regulations applied to both stationary industrial engines and vehicles, including on- and off-highway vehicles. In order to enforce these regulations, the National Environmental Policy Act was also passed. This act established the U.S. Environmental Protection Agency on May 2, 1971 which was tasked with enforcing the emissions requirements put forth by the Clean Air Act of 1970. The Clean Air Act also established four other regulatory programs affecting stationary engines. These programs were the National Ambient Air Quality Standards (NAAQS), State Implementation Plans (SIPs), New Source Performance Standards (NSPS), and National Emission Standards for Hazardous Air Pollutants (NESHAPs) [12].

Since the Clean Air Act of 1970 has been established two amendments to the act have been implemented. The first amendment came in 1977 which focused on setting new dates for attaining goal of the NAAQS in areas of the country which did not meet these standards for air quality. The second amendment came in 1990 which significantly increased the responsibility and authority of the federal government regarding air quality management. 
The Clean Air Act still serves as the basis behind air quality and pollution control in the United States. Since its enactment, it has served to greatly reduce emissions and improve air quality. It has addressed all areas of air pollution including acid rain, ozone depletion, toxic air pollution, and evaporative emissions from fuels [12].

\subsection{Consent Decrees}

\subsubsection{History}

In October 1998, six of the leading HDDE manufacturing companies established a set of individual Consent Decrees with the EPA as a result of lawsuits against the companies by the EPA. The companies involved included Cummins Engine Company, Detroit Diesel, Caterpillar, Mack Trucks Inc., Navistar International Truck and Engine Company, and Volvo Trucks Inc. The agreed upon Consent Decree between the EPA and each HDDE manufacturer was different; however, each Consent Decree established the requirement for the manufacturer's different engine families to be tested through an additional method of emissions measurement. This additional method was identified as being in-use emissions measurement [1-6].

The need for in-use testing arises from the discovery that engines that were used on an engine dynamometer for certification were producing different levels of emissions than production engines of the same model and family found in normal day-to-day operation. Several conditions contribute to these variances in engine performance. Most commonly, engines in a test cell operate under controlled conditions. Intake air temperature and humidity are set to a given value and do not vary significantly during the test. Coolant temperature and fuel temperature are also somewhat controlled. In a real world environment ambient conditions can vary substantially and 
rapidly. Also, engine cooling may not be as effective as it is in a laboratory. The standard test cycles currently used in engine test laboratories only estimate the duty cycle of the engine and do not accurately represent actual engine operation in real world environments. While these elements may contribute to the production of varying emissions between test cell and in-use measurements, the key element that led to the establishment of the Consent Decrees was the claim that the engine manufacturers had been implementing specialized control strategies in the engine control modules (ECM) to produce lower NOx emissions only while the engine was being tested on the Federal Test Procedure while in an engine dynamometer facility [15].

Since the late 1980s on-board computers have been used on on-road HDDEs to control fueling and combustion strategies. This enabled engine manufacturers to program their ECMs with multiple engine maps, one for urban operation and one for highway operation, and to modify fueling accordingly. This resulted in an improved real-world fuel economy compared to laboratory ECM setting and this setting was attractive to consumers. However, this improved fuel economy setting resulted in higher NOx emissions [15].

It was discovered that certain HDDE manufacturers had been implementing these programs in their ECMs since the early 1990s. The EPA conducted tests which showed that the manufacturers had been allegedly using computer programs in the ECM to meet emissions regulations on the FTP cycle but changed fueling strategy in actual vehicle operation in an attempt to reduce fuel consumption. In regulations stated in the Clean Air Act and by the EPA prohibit the use of "defeat devices" to reduce emissions production to meet current standards. Therefore, the EPA deemed what the manufacturers were doing as illegal and filed lawsuits 
against six HDDE manufacturers. After extensive negotiations, the EPA and the manufacturers agreed upon the Consent Decrees in the U.S. District Court for the District of Columbia in October 1998 and the Court enacted the Consent Decrees in July 1999. As an outcome of these legal pursuits, the manufacturers were also required to pay $\$ 83.4$ million in civil penalties for violating the Clean Air Act and EPA regulations. At the time, this was the largest fine in the history of environmental enforcement. Also, in accordance with the Consent Decrees, the manufacturers were required to modify their engine control strategies in order to eliminate the use of defeat devices and must perform in-use emissions testing of various engine families selected by the EPA, among other requirements [15].

\subsubsection{Phases}

The in-use test pilot program outlined in the Consent Decrees was broken down into four phases. Since the technology and methodology for conducting this new kind of emissions testing was yet to be developed, each phase was designed to research and develop different aspects of this type of testing to be used during the next phase. The EPA mandated that each of the settling HDDE manufacturers must allocate a set amount of money to be spent on completing the in-use testing pilot program outlined in the Consent Decrees [1-6].

Phase I of the pilot program involved the settling HDDE manufacturers conducting engineering studies to determine the correlation, accuracy, precision, and repeatability of mobile monitoring technologies in circa 1999. These studies focused on determining the highest levels of accuracy and precision the existing technology was capable of providing in regards to mass of regulated gaseous emissions and reported engine speed and output torque. This phase served to establish 
preliminary groundwork for the rest to the program to be developed from, specifically Phases III and IV, which are discussed below. By January 1, 1999, the engine manufacturers were to have submitted a Scope of Work for Phase I to the EPA and CARB for approval. This Scope of Work included the mobile monitoring technology that was to be evaluated, the facility that would conduct the evaluation, the companies that would participate in the program, and the schedules involved with implementing those tasks. Once approved, the engine manufacturers then had until September 1, 1999 to complete the tasks outlined in the Scope of Work for Phase I [1-6].

Phase II of the in-use testing program developed in-use testing procedures to be used during Phase III and Phase IV. These testing procedures were developed using HDDEs performing a variety of typical on-road operations. These operations were performed in various seasonal conditions and at various stages over the engine's useful life. Phase II also developed candidate driving routes to represent typical urban, suburban, and highway driving. These routes were to include at least 45 minutes of driving at posted speeds limits and one candidate route was to include at least 15 minutes of operation at $65 \mathrm{mph}$ or more. Another Scope of Work was due to the EPA and CARB by March 1, 1999 for approval. This Scope of Work identified the testing procedures for the in-use testing equipment and proposed driving routes to be evaluated during Phase II. The HDDE manufacturers were then given until November 1, 1999 to complete the work outlined in the Phase II Scope of Work [1-6].

Phase III of the in-use testing program was the first phase of the program that involved testing of diesel engine exhaust emissions. During this phase the HDDE manufacturers conducted emissions testing on a variety of their in-service diesel engines in order to characterize real world 
emissions that were produced. This phase was intended to establish a baseline set of emissions data on a wide range of in-use engines that varied in age and service characteristics. This data would provide a demonstration of the effect that the changes enforced on engine production had in comparison to older model year engines. Phase III focused on testing engine models manufactured between 1988 and 1998 and included a combination of on-road and laboratory testing. The deadline for the Scope of Work for Phase III was set to be no later than November 1, 1999. It was to identify the proposed test engines, schedule, and any test routes and facilities that would be used during the phase. Once the Scope of Work for Phase III was approved, manufacturers were given eight months to complete testing [1-6].

During Phase IV, manufacturers conducted on-road compliance testing which monitored their engines using the procedures, equipment, and routes established in Phases I and II for engine model years included 2001 through 2003. This testing was to continue until the monies allotted for this in-use testing pilot program had been expended [1-6].

\subsection{Differences between In-Use Testing and Laboratory Emissions Measurement}

The major development established by the Consent Decrees between the EPA and the six settling HDDE manufacturers was the implementation of in-use testing. In-use testing provides a method for determining actual engine-out emissions in a real world environment while the vehicle is performing its intended vocation. 
In order for any engine mass produced and sold in the United States, representative engines in a given engine family must pass EPA emissions standards for the model year of that engine. Historically, before the Consent Decrees of 1998, HDDE emissions were certified to meet current standards solely in engine dynamometer test cells. In these test cells, the engine is operated as a standalone unit outside of any vehicle and installed on an engine dynamometer. An engine dynamometer is a device that measures power, torque, or force applied to a system [16], in this case a heavy duty diesel engine. The engine is supplied with fuel, intake air, and coolant, the engine's output shaft is connected to the dynamometer, the exhaust is directed to dilution tunnel, and the engine operated over a given test cycle. This test cycle is comprised of various engine speed and engine torque set points. During the test, engine speed is maintained by the dynamometer while the torque is controlled by the fueling to the engine. It is noted that torque could be maintained by the dynamometer while the engine speed was controlled by the fueling to the engine. Typically, exhaust constituents produced by the engine enter a constant volume sampling (CVS) system where the raw exhaust is diluted with ambient air in a dilution tunnel. The raw exhaust and dilution air are allowed to mix. Samples of this diluted exhaust are then pulled by various analyzers used to measure each specific constituent. The analyzers give a continuous concentration in engineering units such as parts per million or as a volume percentage. These measurements are then combined with the tunnel mass flow rate and integrated along with total work done by the engine to provide brake specific mass emissions. PM emissions are measured similarly in engine test cells as gaseous emissions. For PM measurement, a sample of diluted exhaust is taken from the dilution tunnel and is passed through a filter. By knowing the percent of the total flow in the dilution tunnel taken for the PM sample and by knowing the pre- and post-test weights of the filter, it is possible to determine PM 
emissions over the test. An example of a typical emissions measurement test cell is displayed below in Figure 2-1.

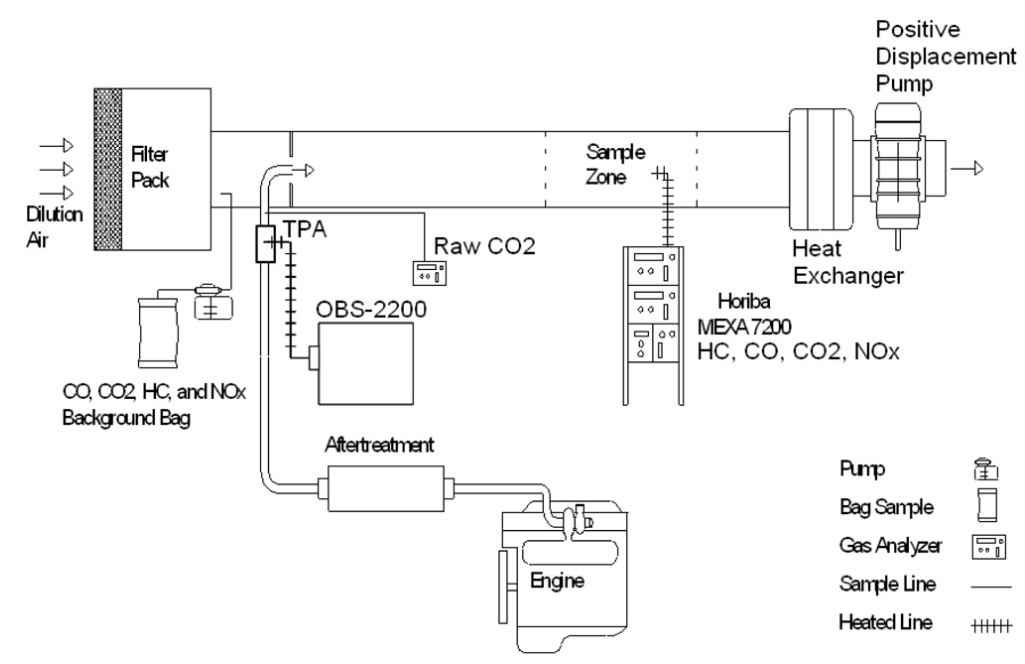

Figure 2-1: Example of Engine Test Cell Configuration [17]

As stated above, engine emission testing is performed using a specified test cycle. The specified test cycle used for EPA emissions verification of HDDEs is what is known as the Federal Test Procedure (FTP). It was developed in the 1970s after monitoring the typical routes of multiple vehicles in the cities of Los Angeles and New York City. The FTP was developed to simulate the duty cycles of the various heavy duty trucks and buses in American cities [18]. It is made up of four different sections: the New York Non-Freeway (NYNF), the Los Angeles Non-Freeway (LANF), the Los Angeles Freeway (LAFY), and the fourth section is a repeat of the NYNF section. The NYNF section simulates light urban traffic with multiple starting and stopping events. The LANF section was designed to simulate typical heavy urban traffic with few stops. The LAFY section models a crowded expressway typical to the Los Angeles area. The cycle contains both motoring and engine driven operation and therefore it is necessary to use a dynamometer that is capable of supplying and absorbing power such as an electric alternating 
current (AC) or direct current (DC) dynamometer [18]. Figure 2-2 below shows the percent torque and percent speed plot for the FTP cycle.

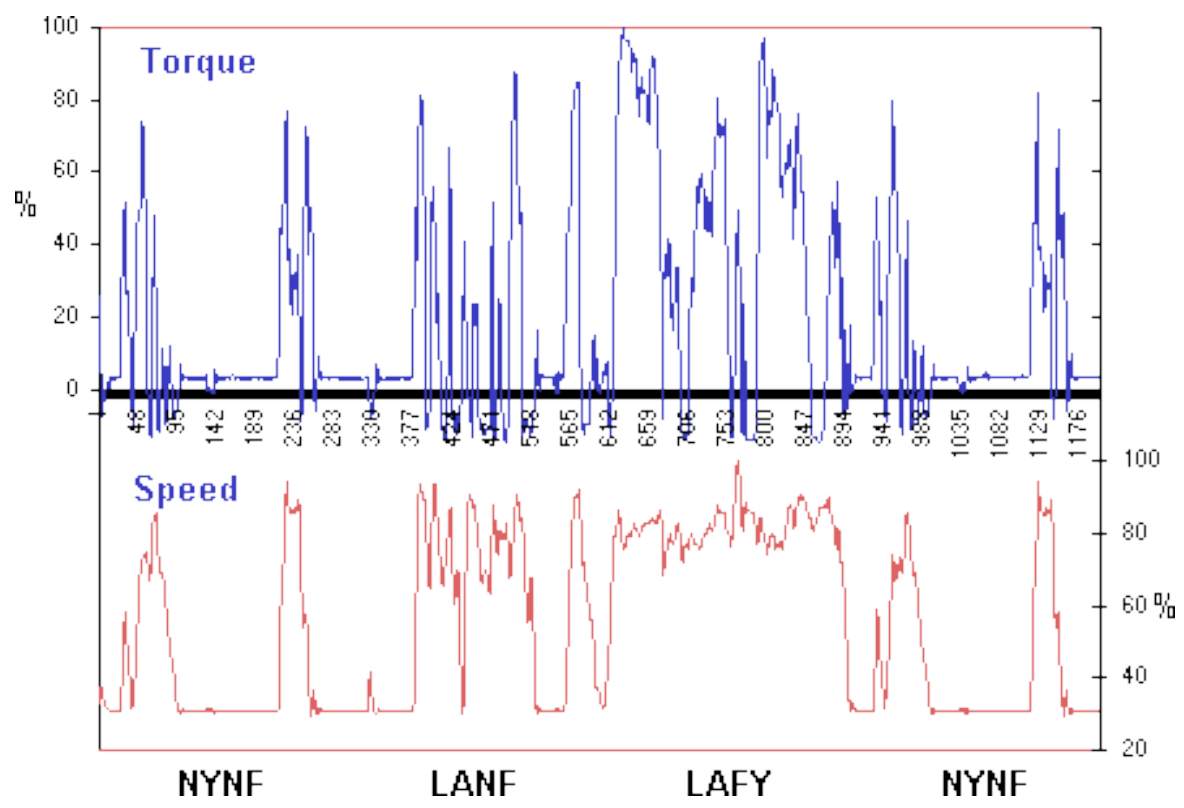

Figure 2-2: Federal Test Procedure for Heavy Duty Engines [18]

While the FTP was intended to closely simulate the duty cycle of typical heavy duty vehicle operation in urban environments; the FTP cycle may not give an accurate representation of the operation of today's on-road heavy duty vehicles that are now being manufactured and operated. The average load factor for the FTP cycle is between 20 to $25 \%$ of the engines maximum power at a given speed. This value is much lower than the typical duty cycle experienced by heavy duty vehicles currently in service.

In addition to in-use testing, the Consent Decrees outlined an additional laboratory test cycle that engines must be certified on as well as the FTP cycle. This test cycle is known as the Supplemental Emissions Test (SET). Engines that are subject to the 2004 EPA emission 
standard and model year 2007 and later engines must demonstrate compliance to regulations over this test cycle. The SET is a 13-mode test that can be found in several versions. The first version of the SET is a discrete mode cycle which is equivalent to the European Stationary Cycle. The second version is two ramped mode cycles. For 2007-2009 model year engines the engine manufacturers could use either the ramped mode SET or the discrete mode SET. For 2010 and later model year engines, manufacturers are required to use the ramped mode SET [19].

An elemental difference between laboratory emissions testing and in-use emissions testing is the fact that in-use testing, as the description implies, is conducted outside of the laboratory in a realworld environment. In this case the test engine is subjected to real-world conditions that it may not experience in a laboratory setting. During laboratory testing ambient conditions in the test cell are strictly controlled and vary little throughout the course of the test. In an engine test cell the intake air used for combustion in the engine is conditioned and controlled to a certain temperature and humidity. During in-use testing, changes in barometric pressure, relative humidity, and air temperature can fluctuate as the test continues. These ambient conditions all affect the performance of the engine and during in-use testing it is not possible to control these conditions. To help negate the effects of these changes certain correction factors are implemented during data reduction. These correction factors are outlined in CFR $40 \$ 86.1370$ 2007. The CFR states that NOx emissions shall be corrected to a standard humidity level of 50 grains if ambient humidity was less than 50 grains and is to be corrected to 75 grains if ambient humidity is above 75 grains. It also states that NOx and PM emissions are to be corrected for ambient air temperatures that are not between 55 and 95 degrees Fahrenheit $\left({ }^{\circ} \mathrm{F}\right)$. If ambient air 
temperatures are outside this range then they are to be corrected to $55^{\circ} \mathrm{F}$ if ambient air temperature is below $55^{\circ} \mathrm{F}$ and to $95^{\circ} \mathrm{F}$ if ambient air temperature is above $95^{\circ} \mathrm{F}$. No corrections for ambient air temperature or humidity are implemented for conditions between 50-75 grains humidity and $55-95^{\circ} \mathrm{F}[20]$.

Another fundamental difference between in-use testing and laboratory testing is the equipment used for in-use testing. The equipment needed to operate an engine dynamometer and CVS system is very large and not easily transportable. Since in-use testing requires that the vehicle be driven over the road in real world environments, it is necessary that the equipment be small and portable enough to be outfitted on a vehicle and must be powered such that it does not inhibit the vehicles ability to travel over the road. To do this, in-use test equipment samples raw exhaust from the vehicles exhaust stack instead of a diluted sample like in a CVS system. This

eliminates the need for the large dilution tunnel. Specialized emissions measurement equipment had to be developed with the implementation of in-use testing for EPA certification; this equipment is known as portable emissions measurement systems (PEMS).

\subsection{Portable Emissions Measurement Systems}

Since the introduction of in-use testing for HDDE certification several companies have introduced portable emissions measurement systems to be used to measure emissions in-use. Companies that manufacture laboratory grade emissions measurement equipment also offer PEMS systems. Both Horiba and Sensors Inc. offer commercially available PEMS for gaseous emissions measurement and AVL has a system in the final stages of development $[20,22,23]$. Particulate matter measurement systems are also available from these companies. AVL and 
Sensors Inc. have commercially available systems and Horiba offers a prototype system that is available to rent.

\subsubsection{MEMS}

A predecessor to today's commercially available PEMS was known as the Mobile Emissions Measurement System (MEMS) and was developed by West Virginia University (WVU). WVU was contracted by the six settling HDDE manufacturers to construct and test a system to complete Phases III and IV set forth by the Consent Decrees. MEMS was designed as a selfcontained unit capable of measuring in-use brake-specific mass emissions of $\mathrm{CO}_{2}$ and $\mathrm{NOx}$. It was the first system that was capable of reporting brake specific mass emissions over 30 second windows in accordance with the Consent Decrees [24]. It was found during development of MEMS that current analyzers that were available at the time were not capable of accurately measuring the low concentrations found in diesel exhaust and the available units portable enough to be used on-board worked on the principle of non-dispersive infrared (NDIR) which has a poor response to hydrocarbons. Because of these difficulties and since $\mathrm{NOx}$ and $\mathrm{CO}_{2}$ are considered the main constituents of interest of diesel exhaust, it was determined to only incorporate means of measurement for these two components. To measure $\mathrm{CO}_{2}, \mathrm{MEMS}$ used a NDIR detector while NOx was measured by a zirconium oxide $\left(\mathrm{ZrO}_{2}\right)$ sensor. Vehicle speed was measured from both the ECM and through the use of a global positioning system (GPS). GPS was used primarily as a quality assurance device for vehicle speed and also because it provided a means of recording vehicle position. For exhaust flow measurement, MEMS used a multiport averaging pitot tube sensor called an Annubar. The Annubar was installed in a piece of exhaust pipe which was attached to the end of the vehicles exhaust stack. It measured the differential pressure across the pitot tubes which could be correlated to a velocity of exhaust. Exhaust temperature was also 
measured next to the pitot tubes via thermocouples. MEMS obtained engine speed and output torque data by interfacing with the vehicles ECM [24]. Figure 2-3 below shows a MEMS data acquisition unit installed on a test vehicle.

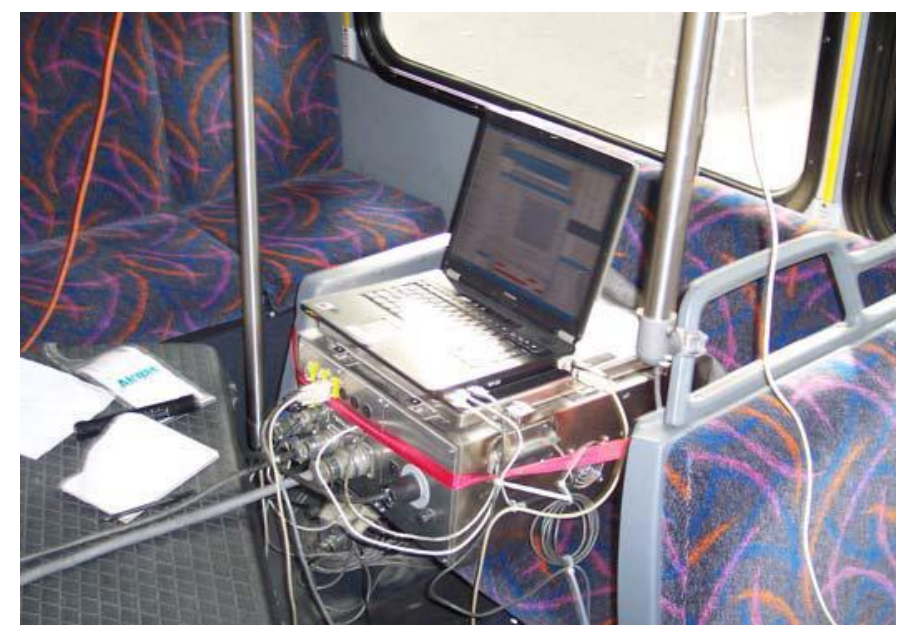

Figure 2-3: MEMS Data Acquisition Unit Installed on a Test Vehicle [9]

When compared to laboratory instruments, MEMS reported NOx within 5\% and $\mathrm{CO}_{2}$ measurements within 2\% [24]. For this comparison MEMS was installed in the test cell at West Virginia University's Engine and Emissions Research Laboratory (EERL). An FTP test was conducted using a Cummins ISM 370 ESP diesel engine. The tests were conducted in accordance to 40 CFR, Part 86 , Subpart N. The results from this comparison can be seen below in Figure 2-4 and Figure 2-5. 


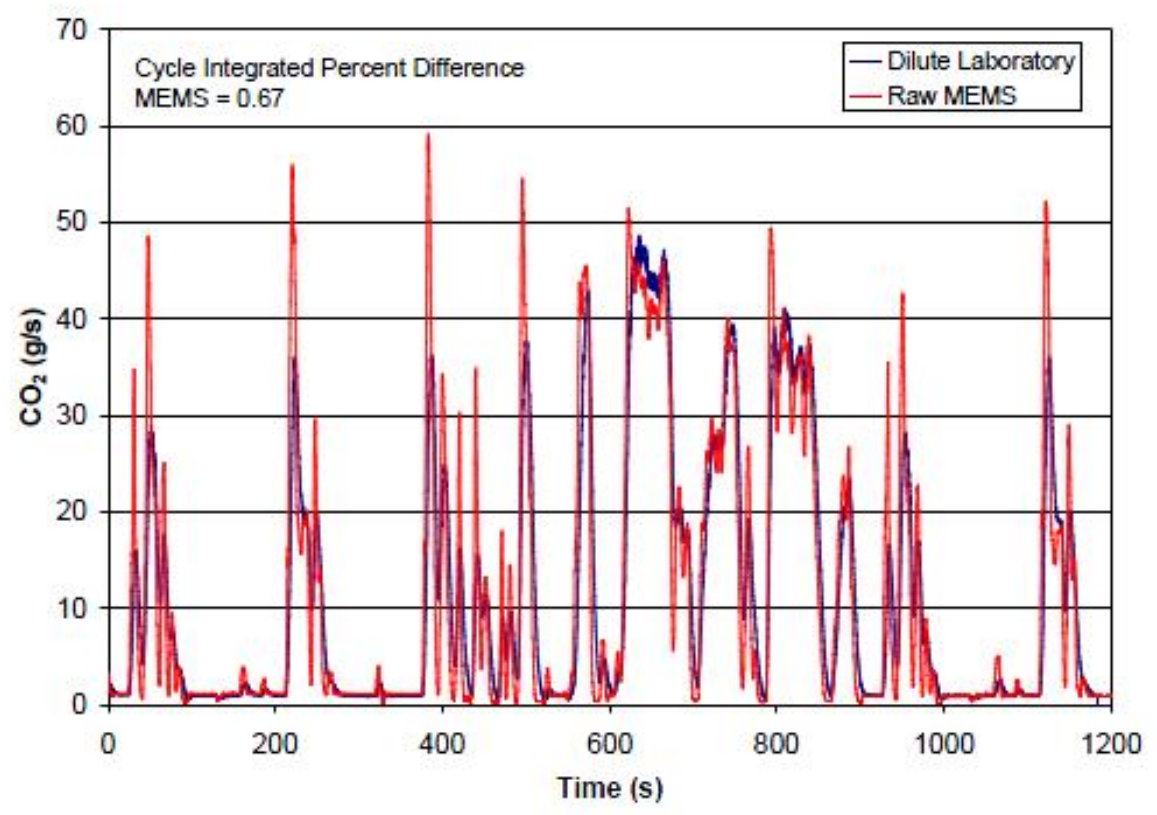

Figure 2-4: $\mathrm{MEMS} \mathrm{CO}_{2}$ Comparison [24]

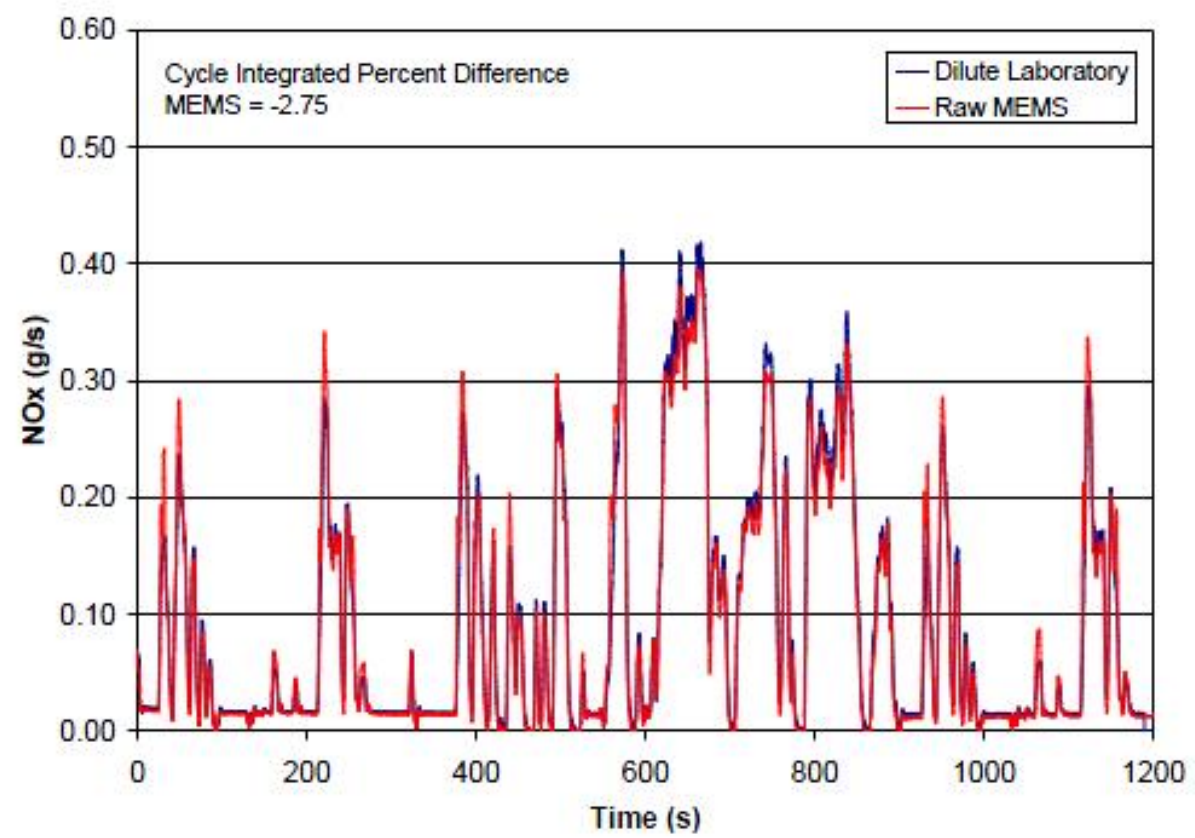

Figure 2-5: MEMS NOx Comparison [24] 


\subsubsection{Sensors' SEMTECH-DS}

The SEMTECH-D was the first generation in the Sensors' SEMTECH line of PEMS units. The SEMTECH-D is a portable emission measurement system manufactured by Sensors Inc that operates on the guidelines described in 40 CFR Part 86 . It was one of the first commercially available PEMS units and has been used in many in-use test programs. It is capable of simultaneously measuring and recording levels of $\mathrm{NO}, \mathrm{NO}_{2}, \mathrm{CO}, \mathrm{CO}_{2}$, and $\mathrm{THC}$ contained in diesel engine exhaust within a claimed accuracy of $\pm 3-4 \%$. The unit was designed as a portable standalone unit with dimensions of 22 ” $\mathrm{D} \times 17$ ” $\mathrm{W} \times 14$ ”' $\mathrm{H}$ with a weight of 70 pounds [25].

The SEMTECH-D utilizes many of the same analysis techniques used in traditional engine test laboratories. It uses a NDIR cell to measure $\mathrm{CO}$ and $\mathrm{CO}_{2}$, a FID for hydrocarbon analysis, and a NDUV for detecting $\mathrm{NO}$ and $\mathrm{NO}_{2}$ [25]. This system uses an electronic exhaust flow meter to measure exhaust flow, an OBD interface for recording engine speed and load, a GPS provided the vehicle's speed, altitude, and location, and various external sensors record ambient conditions such as temperature and relative humidity. A newer version of the SEMTECH-D is also available. The SEMTECH-DS is the successor to the SEMTECH-D and is compliant with 40 CFR Part 1065 regulations. The same analyzers and techniques used by the SEMTECH-D for measuring engine exhaust emissions are also used in the SEMTECH-DS except the guidelines for measurement laid out in Part 1065 are applied as opposed to Part 86 [26]. A photograph of the recent SEMTECH unit is displayed below in Figure 2-6. 


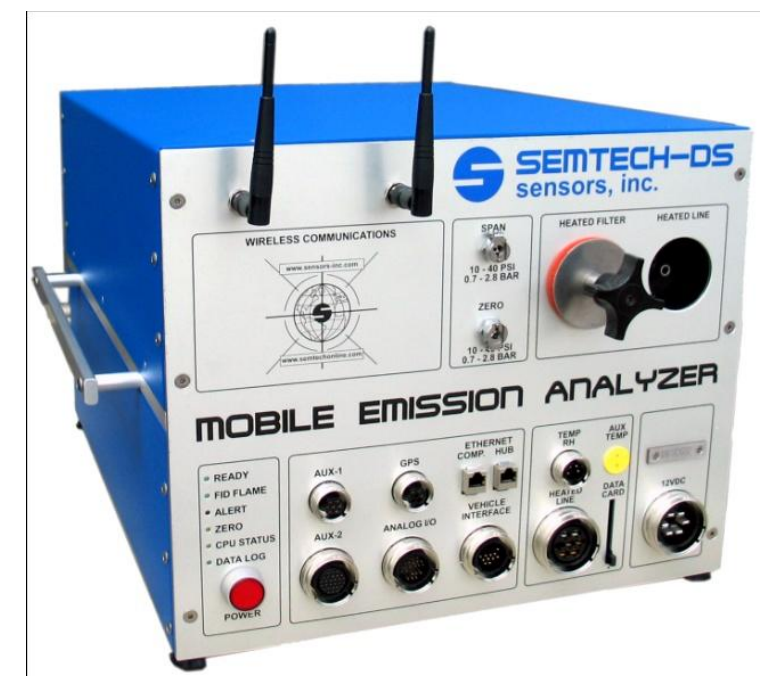

Figure 2-6: SEMTECH-DS Main Unit [22]

\subsubsection{Horiba OBS-2200}

The OBS-2200 is a gaseous PEMS unit designed for in-use testing as well as being able to be used as a standalone unit in a laboratory setting. The OBS is a 40 CFR Part 1065 system manufactured by Horiba Instruments of Japan. It is able to measure and record the levels of diesel exhaust constituents including NOx, $\mathrm{CO}, \mathrm{CO}_{2}$, and THC. Unlike the SEMTECH-D and DS, the OBS measures levels of NOx as opposed to measuring $\mathrm{NO}_{2}$ and $\mathrm{NO}$ separately. However, it uses the same principles of measurement for each of these constituents. $\mathrm{CO}$ and $\mathrm{CO}_{2}$ are measured using NDIR technology, a FID is used for THC detection and a CLD analyzer measures NOx. The OBS main unit itself measures 13.75"W×13”H×19.7'D and weighs 64 pounds. The OBS main unit does require auxiliary components for operation. Included with the OBS main unit is an External Input Unit (EIU), and a Power Supply Unit (PSU). The EIU is used to interface with other devices that could be used during testing such as a particulate matter measurement system. The PSU is used to supply the OBS system with electrical power. There are two options for powering the OBS; the first is to run the system on $110 \mathrm{VAC}$ or by using two 
12 VDC truck batteries charged through the vehicle's alternator. When using the OBS, exhaust flow is measured using two opposing pitot tubes that measure differential pressure in the exhaust stack. Vehicle data such as engine speed and torque which are used for NTE calculations are obtained via the vehicle's ECM through the on-board diagnostic port. A GPS receiver mounted on top of the vehicle provides vehicle speed, altitude, and location. An ambient temperature and humidity sensor is also included with the system to measure temperature and humidity of the ambient air [27]. A Horiba OBS main unit, PSU, and EIU are displayed in Figure 2-7 as they were installed on a test vehicle.

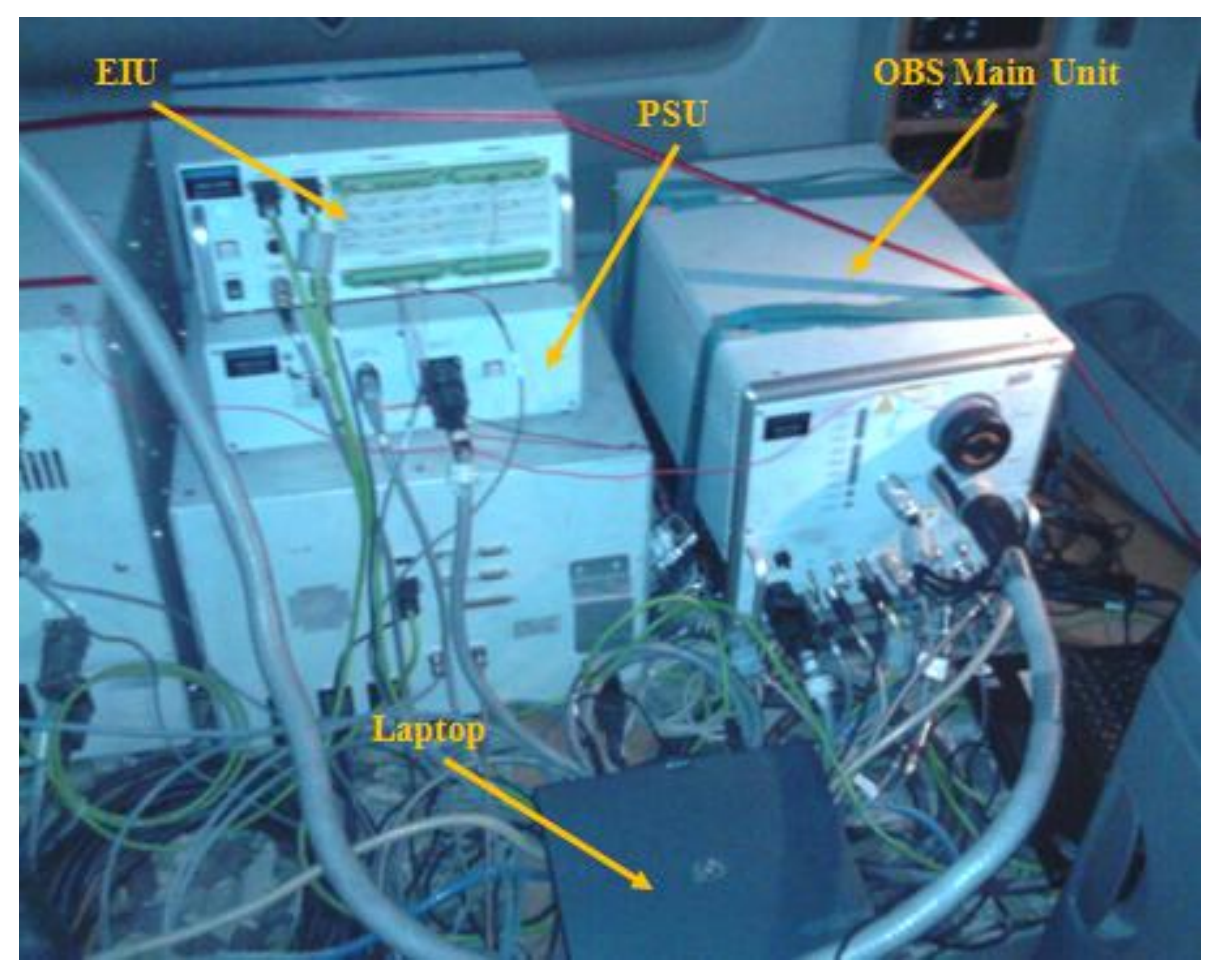

Figure 2-7: Horiba OBS System as Installed on a Test Vehicle

\subsubsection{Horiba TRPM}

Horiba Instruments developed the on-board transient response diesel particulate measurement (OBS-TRPM) system to measure particulate matter emissions from diesel engines in conjunction with their on-board gaseous OBS analyzer. The OBS-TRPM or TRPM measures total PM 
emissions gravimetrically on a pre-weighed $47 \mathrm{~mm}$ Teflon filter. This partial flow system operates using a proportional dilution ratio control strategy which is dependent on exhaust flow. The TRPM requires certain input signals from the OBS in order for in-use operation. It must receive exhaust flow signal from the OBS to calculate the proportional dilution ratio and must also receive an NTE signal which triggers PM measurement in the TRPM. The TRPM also incorporates the use of a real-time diffusion charge sensor (DCS) that samples upstream of the filter. The DCS is used to measure PM in terms of particle length per volume $\left(\mathrm{mm} / \mathrm{cm}^{3}\right)$ [28]. The two methods of PM measurement are used together to determine particulate emissions in the NTE zones as defined by the EPA. The real-time particle size recorded by the DCS while the system is sampling across the filter is integrated to provide the cumulative fraction of PM. Once the filter is weighed and a mass emission is determined, the fraction of the real-time PM signal is used to calculate the PM mass emission during NTE operation. The prototype TRPM system consisted of four separate units. One of the units contained the heated filter holder for the gravimetric sampling and another contained the DCS unit for real-time particle sizing. The other two units in the system contained all of the mechanical and electrical components necessary for operation [29]. A newer model of the TRPM is now available which combines the mechanical and electrical components into one unit. Figure 2-8 shows the prototype TRPM unit that was used for this research as it was installed on a test vehicle. Since the OBS-2200 and OBS-TRPM were the PEMS systems used for this research they are explained in more detail in the following chapter. 


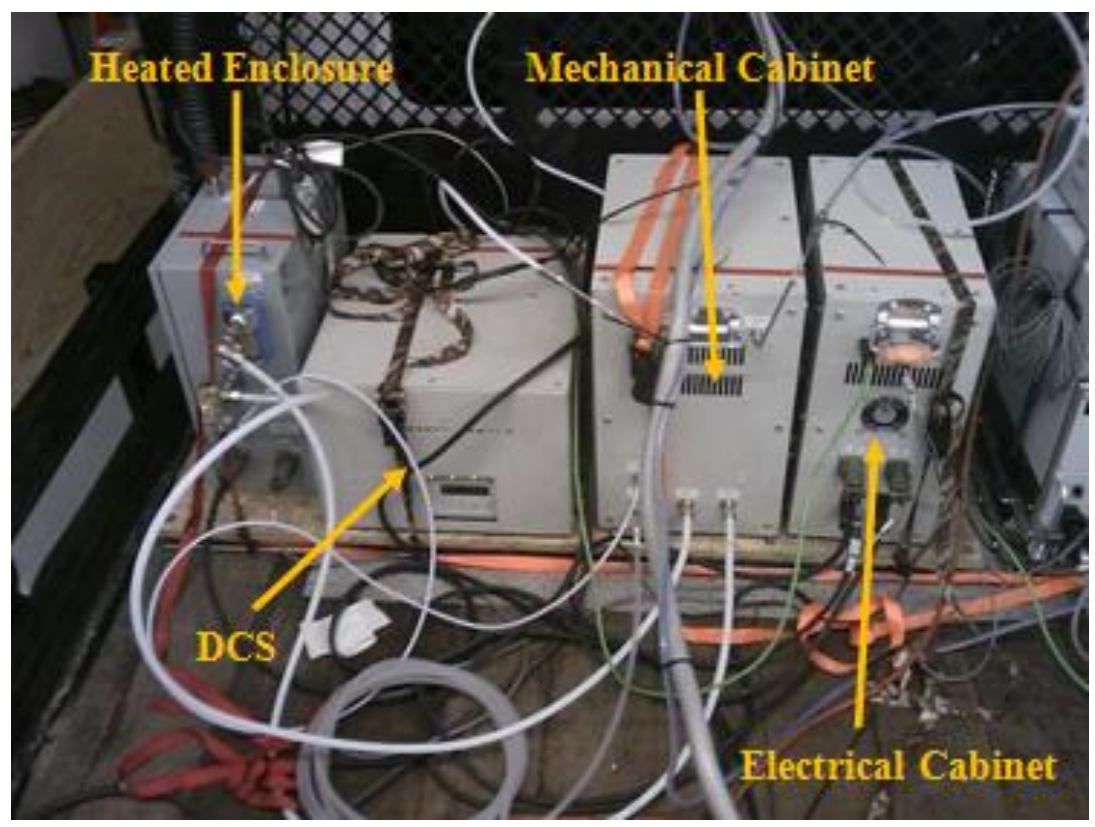

Figure 2-8: Prototype Horiba TRPM Installed on a Test Vehicle

\subsubsection{Sensors' SEMTECH PPMD}

In June 2005 the EPA mandated in-use testing be conducted on heavy duty diesel engines for gaseous and particulate emissions using PEMS. A cooperative effort between the EPA and Sensors Inc. developed the Proportional Particulate Mass Device (PPMD). This device is now a commercially available system from Sensors Inc. The PPMD was designed to complement the SEMTECH-DS during in-use emissions tests where the DS would measure gaseous emissions and the PPMD would measure particulate emissions. The PPMD is comprised of three main components. The first component of the PPMD is a micro-proportional sampling system (MPS) that extracts a proportional sample from the engine's exhaust stack and dilutes it for succeeding PM measurement. The MPS uses the second component, an exhaust flow meter (EFM), to accurately measure exhaust flow used for the proportional flow calculations. The third component is an eight element quartz-crystal microbalance (QCM) which measures particulate mass. The QCM method of measurement varies from the gravimetric method utilized by the 
TRPM in that the QCM does not use filters to collect PM to be weighed after the test. The QCM used by the PPMD uses eight quartz crystal micro-balances which oscillate in the diluted exhaust flow at a given frequency. As PM is deposited onto the surface of the quartz crystal its frequency changes proportionally to the deposition. By knowing the relationship between frequency and PM deposit, the change in frequency can then be integrated to determine the change in PM mass [30]. The SEMTECH PPMD is displayed in the following picture, Figure $2-9$.

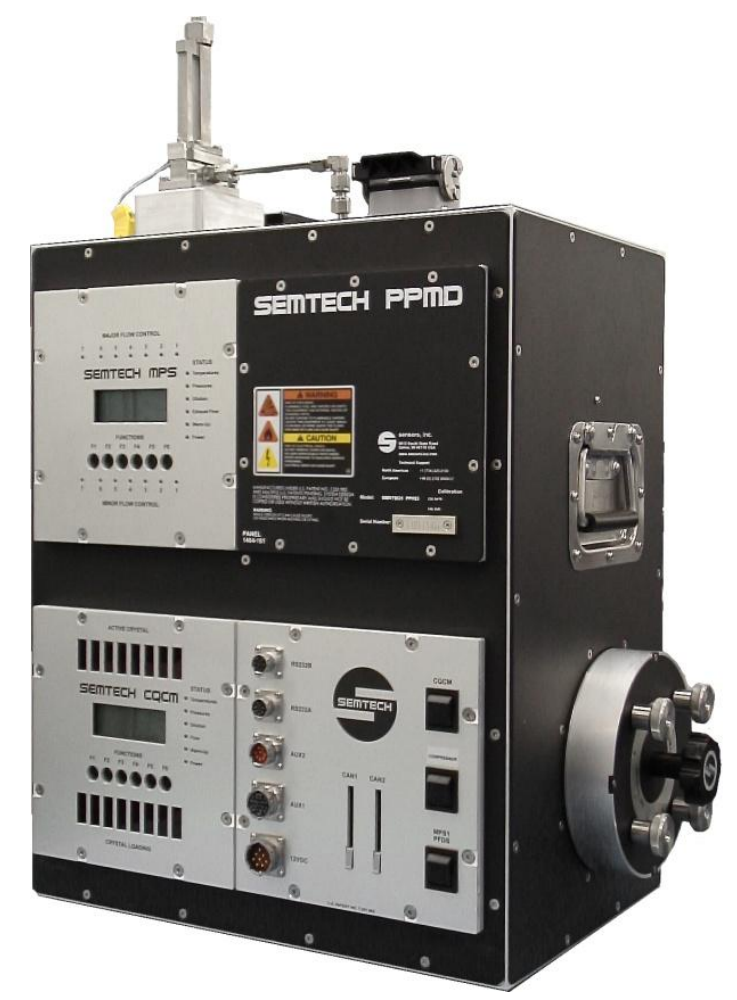

Figure 2-9: SEMTECH PPMD [31]

\subsection{Not-To-Exceed Zone}

Included in the Consent Decrees between the six settling HDDE manufacturers and the US EPA, the EPA introduced new limits and protocols to which in-use testing is to be conducted. These limits defined an exact region on an engine's map within which in-use emissions would be 
measured; this region was called the not-to-exceed region. By defining a broad region of the engine's map it was assured that the emissions would be measured over a broad range of engine speed and load combinations regardless of the type of driving operation performed during the test. This allows NTE testing to disregard the use of reproducible driving routes of specific length and time and rather standardize emissions produced by the engine operated on any test route.

The NTE region is defined in CFR 40 Part 86 Subpart N Section 1370 [20]. The boundaries of this region are based on percents of engine speed, torque, and power. Engine speed contained within the boundaries of the NTE region is governed by the ESC. The ESC is a test cycle in which the engine operates over 13 steady state modes of varying engine speeds and loads. In order to be contained in the NTE region, the engine must be operating at speeds relative to $15 \%$ of the ESC speeds. This speed boundary is calculated using the following equation.

$$
N_{N T E} \geq n_{l o}+0.15 \times\left(n_{h i}-n_{l o}\right)
$$

Where $\mathrm{n}_{\mathrm{hi}}$ is the highest engine speed on the power curve where $70 \%$ of the maximum engine power occurs. The parameter $\mathrm{n}_{\mathrm{lo}}$ is the lowest engine speed where $50 \%$ of the maximum power of the engine occurs [8]. The CFR also states that all load points greater than or equal to $30 \%$ of the maximum torque produced by the engine are also contained within the NTE region. There are also engine specific exclusion zones, called carve outs for gaseous and PM emissions. These carve-outs are agreed upon between the engine manufacturer and the EPA and are designed to 
exclude certain areas of engine operation that would otherwise be in the NTE region. A PM specific carve-out is usually applied to areas of high speed and low torque where at these points of operation it is usually difficult to control PM formation. It should be noted that vehicles equipped with a DPF are not allowed to use a PM carve out region as an exclusion during NTE testing. A diagram of the Not-To-Exceed region with representative carve-out zones is displayed below in Figure 2-10. [8]

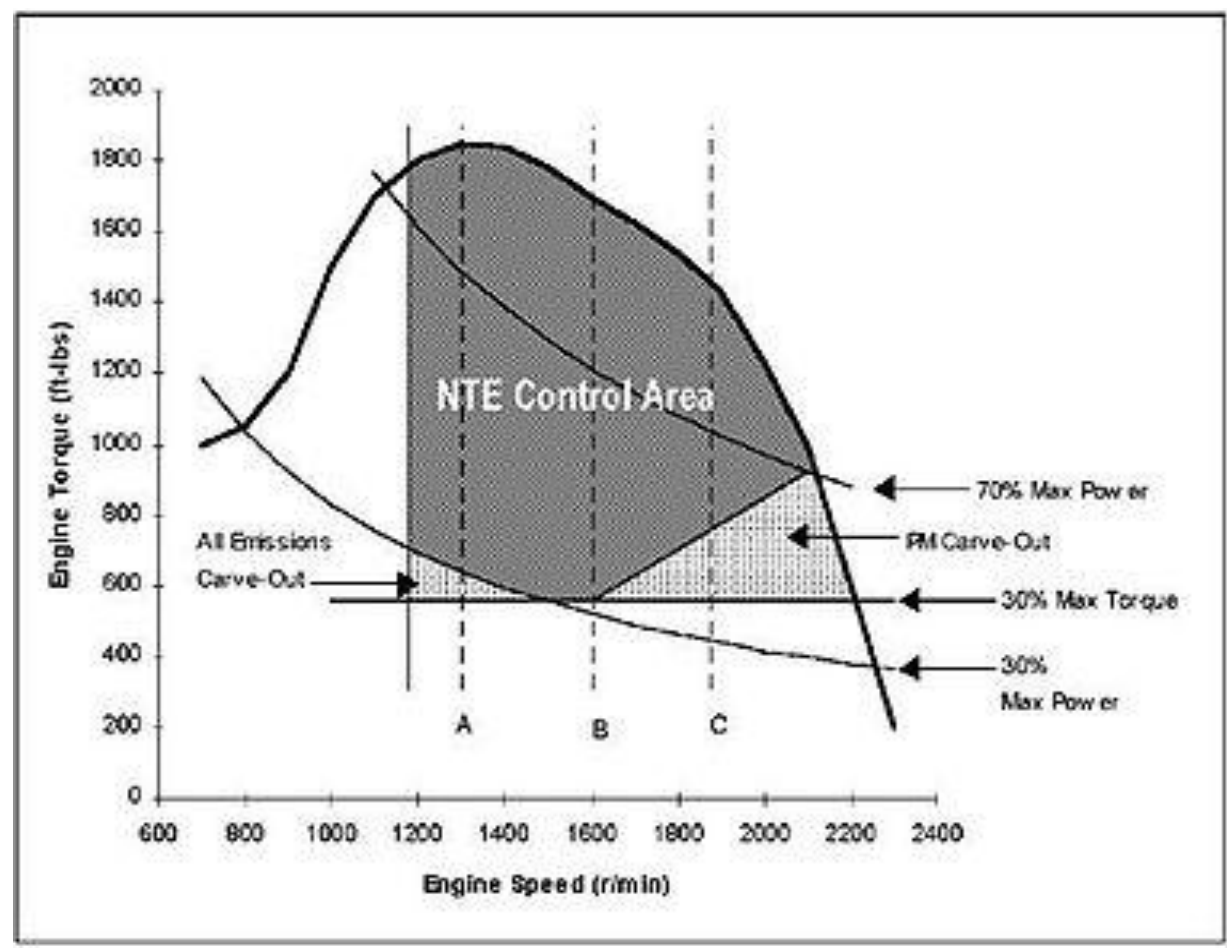

Figure 2-10: Diagram of the Not-To-Exceed Region [8]

\subsection{Previous Work-Based Window Research}

\subsubsection{European PEMS Program}

The European Commission's Joint Research Centre (JRC) has conducted extensive research into the use of work-based windows for in-use emissions measurement in comparison to the EPA's NTE method of testing. One of the major concerns the JRC had when considering the NTE 
method was the limited amount of engine operation included in the NTE zone. Because of this they have chosen an averaging window method as the official emissions testing method for characterizing Euro VI heavy-duty vehicle in-use emissions. In this method, measured emissions are averaged over a predefined quantity. For heavy-duty vehicles emissions are based on a work specific value, therefore, emissions are averaged over a predefined quantity of work done by the engine. For light-duty vehicles which are regulated on a distance specific basis the predefined quantity is based on $\mathrm{CO}_{2}$ mass emitted. For in-use testing of light duty vehicles the window is determined as the distance travelled by the vehicle until the equivalent mass of $\mathrm{CO}_{2}$ is produced as emitted during the New European Driving Cycle (NEDC) [32].

\subsubsection{West Virginia University}

In 2006 a study similar to the research outlined in this research was conducted at West Virginia University [9]. This study took data from in-use testing conducted during Phase III and Phase IV of the in-use program described in the Consent Decrees. The data came from over 180 in-use tests using 31 different test vehicles ranging in model years from 1996 to 2003 . The engines in these vehicles ranged in displacement from 6 to 12 liters with power ratings from 300 hp to 500 hp. The in-use test equipment used for this testing was the MEMS portable emissions system developed by WVU. The study focused on developing a work window based method for calculating in-use brake specific NOx emissions for all engine speeds and engine loads. The work based window method consisted of reading instantaneous engine speed and torque from the ECM of the vehicle. These parameters were then used to determine instantaneous power produced by the engine which was then used along with the time differential to determine instantaneous work done by the engine. The instantaneous work was summed for each time interval until a target value of total work done by the engine was reached. The total work done 
during an FTP or SET test cycle may be used for this target value. This method allows the calculation of in-use emissions that are produced over similar work intervals such as the FTP or the SET engine test cycles that are used for certification testing; it was argued this approach provides a closer comparison between in-use testing and laboratory testing. The equation used for this study for determining the accumulated work contained in the work window is displayed below in Equation 2.

WorkWindow $(\mathrm{bhp} \cdot \mathrm{hr})=\sum_{i=0}^{i^{*}}\left(\frac{N_{i}\left(\frac{r e v}{\min }\right) \times T_{i}\left(\mathrm{ft} \cdot \mathrm{lb} b_{f}\right)}{\left(\frac{1 r e v}{2 \pi r a d}\right)\left(\frac{60 \mathrm{sec}}{1 \min }\right)\left(\frac{550 \mathrm{ft} \cdot \mathrm{lb} f}{1 \mathrm{sec} \cdot \mathrm{bhp}}\right)} \times \Delta t_{i}(\mathrm{sec}) \times\left(\frac{1 \mathrm{hr}}{3600 \mathrm{sec}}\right)\right)$

Eqn. 2

Where engine speed is designated by $N$, engine torque is $T$, and time is $t$. For this study engine speed and torque was collected at $5 \mathrm{~Hz}$. Instantaneous work was calculated for each data point. From there, beginning at each data point, the instantaneous work was summed until the target value for total work had been reached. The point in time that this value is reached is noted as $i^{*}$ and the amount of accumulated work is denoted as the work window.

Brake specific mass emissions were calculated for this study using Equation 3 below.

$$
b s X\left(\frac{g}{b h p \cdot h r}\right)=\frac{\sum_{i=0}^{i^{*}}\left\{\frac{[X]_{i}(p p m)}{10^{6}} \times \rho_{x}\left(\frac{g}{f t^{3}}\right) \times \dot{Q}_{i}\left(\frac{f t^{3}}{s e c}\right) \times \Delta t_{i}(s e c)\right\}}{\text { WorkWindow }(b h p \cdot h r)}
$$

Eqn. 3 
For this equation, $X$ is the concentration of the desired exhaust constituent, $Q$ is the exhaust flow rate, $\rho$ is the density of the exhaust constituent, and $\Delta t$ is the time interval.

The time duration of the work window for this method was determined using the following equation, Equation 4.

$$
\text { WorkWindow }(\min )=\sum_{i=0}^{i^{*}} \Delta t_{i}(\mathrm{sec}) \times\left(\frac{1 \mathrm{~min}}{60 \mathrm{sec}}\right)
$$

Eqn. 4

When these calculations for work window, brake-specific mass concentration of an exhaust constituent, and work window duration have been completed for a point in the data set, the process is repeated for the following data point.

A similar method for measuring in-use brake specific emissions is used for non-road diesel NTE operation. This method evaluates the non-road engine for the entire day and then normalizes the data to a six hour day. A work window equal to $10 \%$ of the total work produced during the normalized six hour test period is moved throughout the data in $1 \%$ increments of total work in order to determine brake specific mass emissions [9].

The results from this study compared brake-specific NOx (bsNOx) emissions from the workwindow based method to two NTE methods for a range of work windows from $1 \mathrm{bhp}-\mathrm{hr}$ to 75 bhp-hr. The first NTE method was the current 30 second NTE window and the second was a 
continuous NTE window. It was found that for smaller work windows, periods of engine operation consisting of high engine speed and torque may produce periods of lower bsNOx. A larger work window results in bsNOx emissions that approach a constant level. Ideally this level is less than or equal to the FTP NOx certification level of the engine. This trend is displayed below in Figure 2-11 using data from a 12 liter diesel engine rated at 400hp [9]. It can be seen that with increasing work window duration the variance in the bsNOx measurement decreases as indicated in the length of the error bars (representing $\pm 1 \sigma$ ).

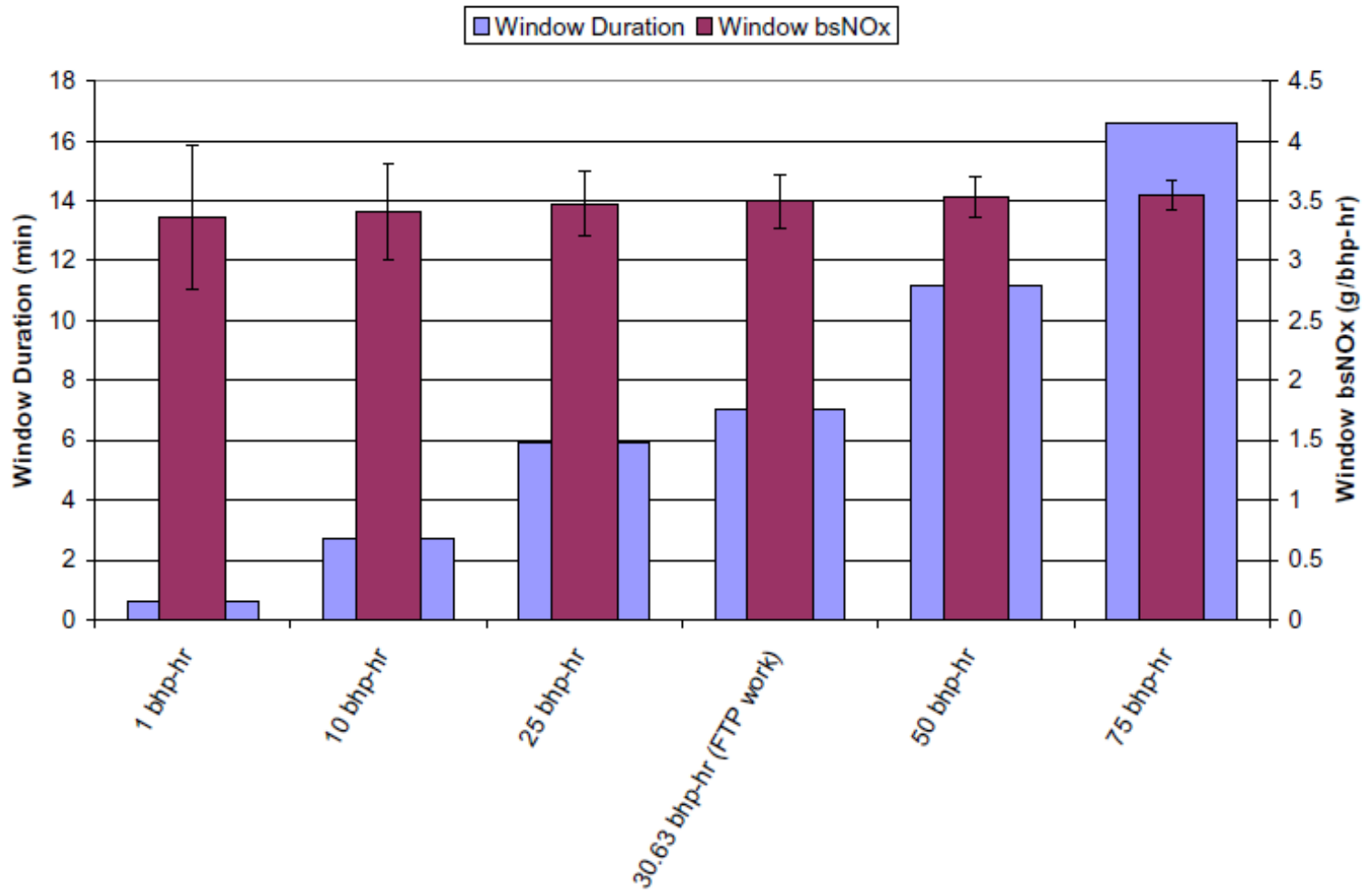

Figure 2-11: Effect of Window Duration on bsNOx Emissions [9] 
The study compared four 2003 model year engines from the same certification family over four different test routes. All of the engines had approximately 6 liters in displacement and were all rated at approximately $300 \mathrm{hp}$ and certified to $2.5 \mathrm{~g} / \mathrm{bhp}-\mathrm{hr}$ of NOx $+\mathrm{NMHC}$. The study compared the work window method to two variants of the NTE method; one using a 30 second window and the other using a continuous window. The results from this comparison are shown below in Figure 2-12 to Figure 2-14.

Figure 2-12 shows the results from the work window based comparison for bsNOx using a FTP work window equivalent. For these engines it was found that the FTP work window was equal to 17.84 bhp-hr. It can be seen from the plot that the overall average bsNOx value for the four engines using the work window method was close to the FTP certification level of $2.5 \mathrm{~g} / \mathrm{bhp}-\mathrm{hr}$. The actual average bsNOx value was found to be $2.576 \pm 0.323 \mathrm{~g} / \mathrm{bhp}-\mathrm{hr}$ with a coefficient of variation of $12.52 \%$. 


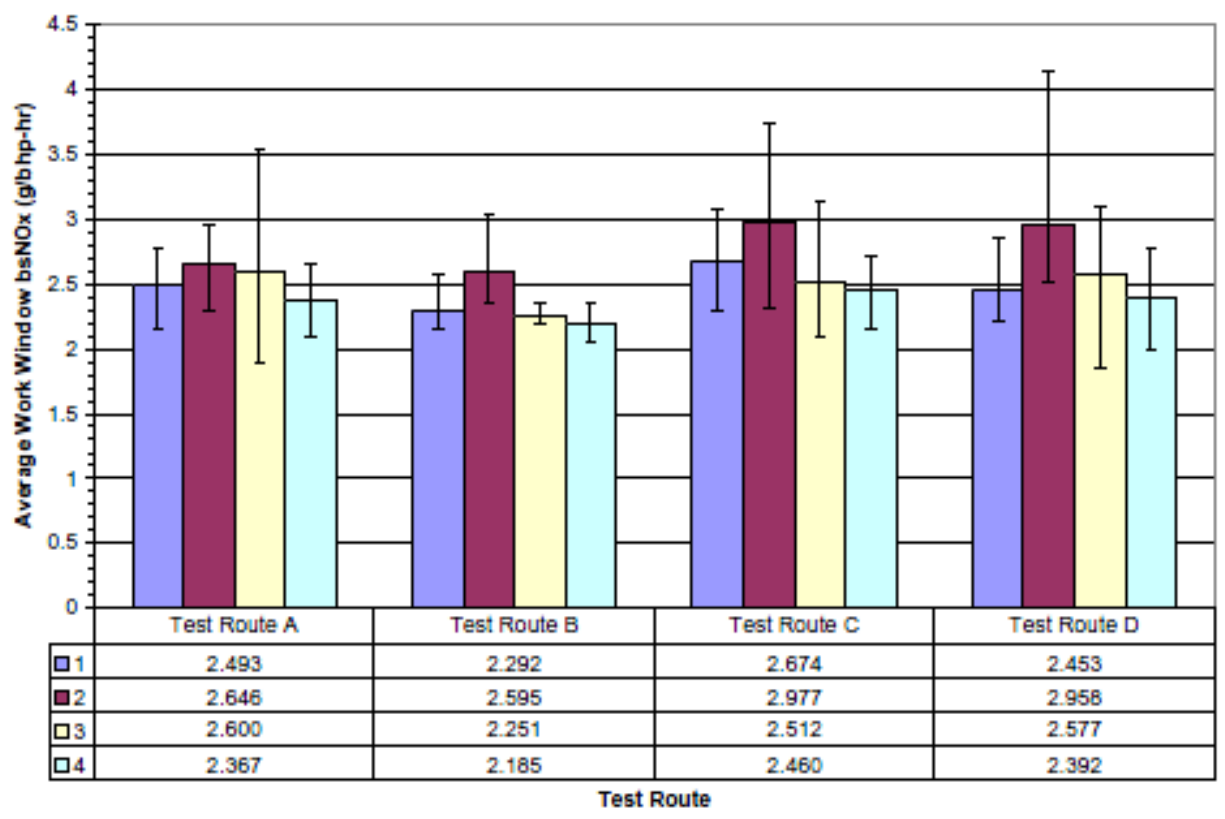

Figure 2-12: Work Window bsNOx Results [9]

Figure 2-13 represents the bsNOx emissions using the 30 second NTE window method. It can be seen from this plot that the 30 second NTE method yielded consistently lower bsNOx emissions when compared to the FTP work window method. The overall average bsNOx level using this method was $2.302 \pm 0.388 \mathrm{~g} / \mathrm{bhp}-\mathrm{hr}$. 


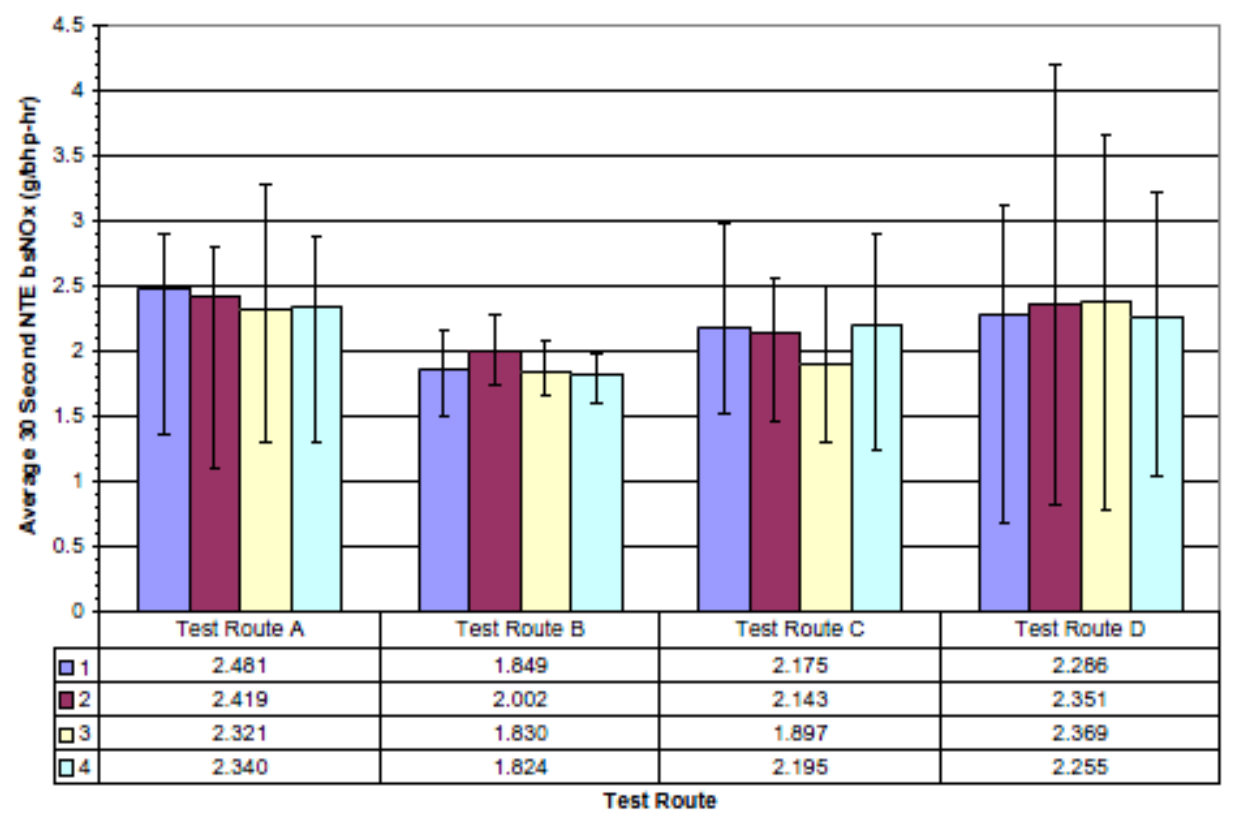

Figure 2-13: 30 Second NTE Window bsNOx Results [9]

The bsNOx results from the continuous NTE window method are shown in Figure 2-14. The figure shows the lowest levels of bsNOx emissions of the three methods in this comparison. Much like the 30 second NTE method, the continuous NTE method yielded bsNOx levels at or below the engine's certification levels. The overall average bsNOx value using this method was found to be $2.144 \pm 0.366 \mathrm{~g} / \mathrm{bhp}-\mathrm{hr}$. 


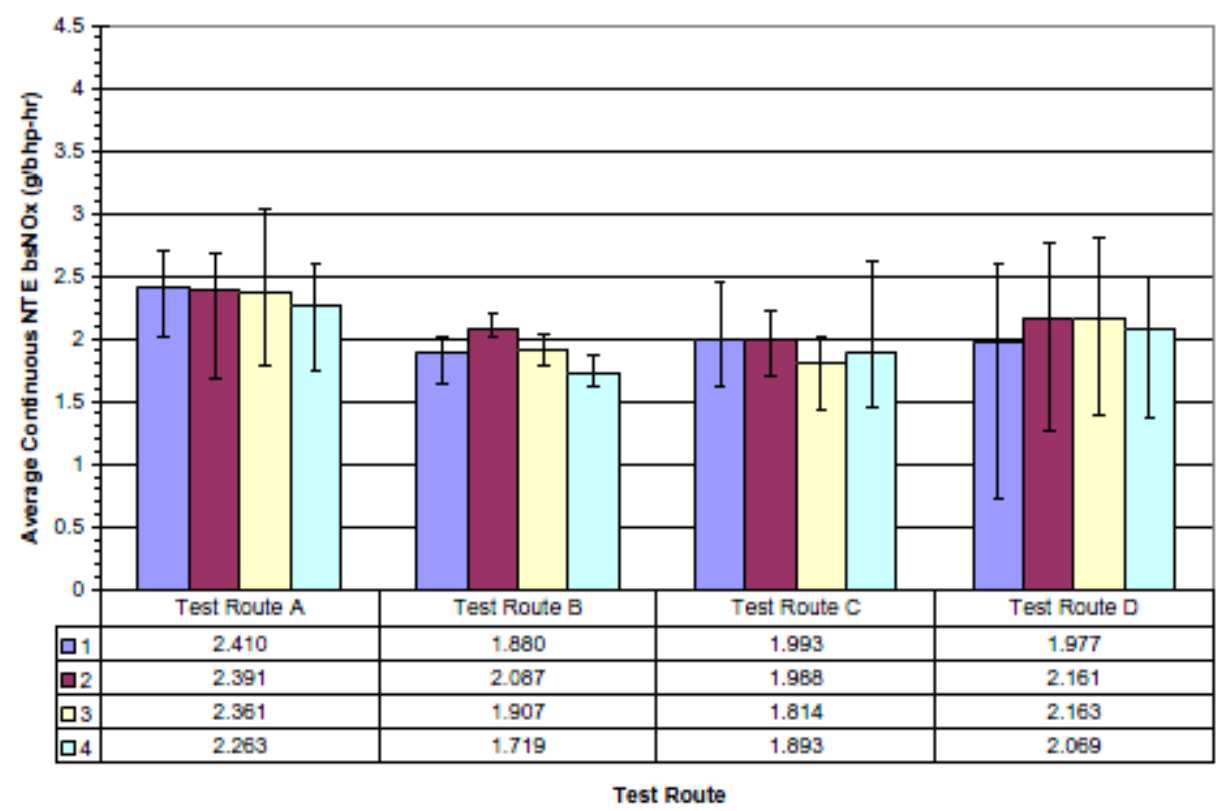

Figure 2-14: Continuous NTE Window bsNOx Results [9]

It was concluded that using the work window method provided a viable alternative to using either the 30 second or continuous NTE methods for determining in-use emissions. It was also found that each method of determining in-use brake specific emissions has advantages and disadvantages associated with it. For instance, the work window method provided emissions data for all engine operation ranges as opposed to the NTE method in which only a specific region is represented. However, the work window method is not without its faults; it was determined that this method is sensitive to inaccuracies in the torque value broadcast by the ECU at low engine loads where the NTE method is unaffected due to the $30 \%$ of maximum torque lower limit imposed by the NTE zone. It was recommended by the study that a minimum power requirement be imposed to reduce this variation and to eliminate the effects of prolonged idle operation or periods of highly transient engine operation such as in stop and go traffic. The work 
window method also consistently resulted in higher levels of bsNOx as compared to the NTE method. It is estimated that increasing the minimum power requirements to be included in the work window would yield lower average and maximum emission values. Less variation in the results was found when using the work window method than either of the NTE methods. The coefficient of variation was typically significantly less when compared to the 30 second NTE method while the continuous NTE method showed only a slightly higher variation when compared to the work window method [9]. 


\section{Experimental Setup}

\subsection{Introduction}

This chapter contains information describing the equipment, test procedures, and methods used for this research. This research focused on in-use emissions measurement of on-highway, heavy duty, commercial diesel trucks. These trucks were tested in real world environments while they performed their normal daily operations. Each of the individual trucks was outfitted with an identical CFR 1065 compliant gaseous and particulate matter measuring PEMS device.

\subsection{Test Vehicles}

The vehicles used for this research were heavy-duty, diesel fueled vehicles designed for onhighway operation. Seven individual vehicles were tested as a part of this research; these vehicles came from four different vocations and included two service trucks, one flatbed delivery truck, two aerial bucket trucks, and two long-haul trucks. The engines installed in these trucks were of two different engine families. It should be noted that Test Vehicles 4 and 5 were of the same engine family as Test Vehicles 1-3 only with a different power rating. An overview of the trucks and engines is outlined below in Table 3-1. 
Table 3-1: Test Vehicle Information

\begin{tabular}{|l|c|c|c|c|c|}
\hline Test Vehicle \# & Vocation & Engine & $\begin{array}{c}\text { Approximate } \\
\text { Displacement } \\
(\mathrm{L})\end{array}$ & $\begin{array}{c}\text { Approximate } \\
\text { Rated Power } \\
(\mathrm{hp})\end{array}$ & $\begin{array}{c}\text { Aftertreatment } \\
\text { Devices }\end{array}$ \\
\hline 1 & Lubrication Service & $\mathrm{A}$ & 7 & 250 & DPF/EGR \\
\hline 2 & Welding Service & $\mathrm{A}$ & 7 & 250 & DPF/EGR \\
\hline 3 & Flatbed & $\mathrm{A}$ & 7 & 250 & DPF/EGR \\
\hline 4 & Aerial Bucket & $\mathrm{B}$ & 7 & 300 & DPF/EGR \\
\hline 6 & Aerial Bucket & $\mathrm{B}$ & 7 & 300 & DPF/EGR \\
\hline 7 & Long-Haul & $\mathrm{C}$ & 13 & 430 & DPF/EGR \\
\hline
\end{tabular}

The permissible emissions certification levels for the two engine families are shown below in Table 3-2 below. These values represent the maximum allowable emissions levels that the engine can produce over the FTP cycle and the allowable NTE limits. Note that the only CO and PM have individual certification levels and that the certification level for NOx is grouped with non-methane hydrocarbons (NMHC). Table 3-3 shows the actual emission levels that were reported over the FTP cycle for these engine families. Both tables also show the allowable levels for in-use testing which is equal to 1.25 times for $\mathrm{CO}$ and 1.5 times for NOx, THC, and PM. Since the emission levels of $\mathrm{CO}_{2}$ are unregulated, the allowable in-use level for this constituent was not included in Table 3-3. Note that in the research presented herein, the emissions values for NOx and THC are reported separately so that a baseline could be formed to compare the two measurement methods.

Table 3-2: Test Vehicles Engine's Families Allowable Emission Certification Levels

\begin{tabular}{|c|c|c|c|c|c|c|}
\hline & \multicolumn{3}{|c|}{ Certification Levels (g/bhp-hr) } & \multicolumn{3}{c|}{ NTE Levels (g/bhp-hr) } \\
\hline Test Vehicles & CO & NOx+NMHC & PM & CO & NOx+NMHC & PM \\
\hline $1-7$ & 15.5 & 1.3 & 0.01 & 19.4 & 2.0 & 0.02 \\
\hline
\end{tabular}


Table 3-3: Test Vehicles Engines' Families Reported FTP Certification Emission Levels

\begin{tabular}{|l|c|c|c|c|c|c|c|c|c|}
\hline & \multicolumn{4}{|c|}{ FTP Reported Levels (g/bhp-hr) } & \multicolumn{4}{c|}{ Allowable In-Use Levels (g/bhp-hr) } \\
\hline Test Vehicles & $\mathrm{CO}$ & $\mathrm{CO}_{2}$ & NOx & THC & PM & CO & NOx & \multicolumn{1}{c|}{ THC } & PM \\
\hline $1-5$ & 0.80 & 630 & 0.90 & 0.10 & 0.01 & 1.00 & 1.35 & 0.15 & 0.015 \\
\hline $6-7$ & 1.70 & 562 & 1.16 & 0.14 & 0.01 & 2.125 & 1.74 & 0.21 & 0.015 \\
\hline
\end{tabular}

\subsection{Horiba OBS-2200}

The on-board system used for in-use testing during this research was a Horiba OBS-2200. The figure below, Figure 3-1, shows a schematic of the OBS main unit and all the above listed subsystems and optional equipment. The figure also shows plumbing and wiring connections between the various components of the system.

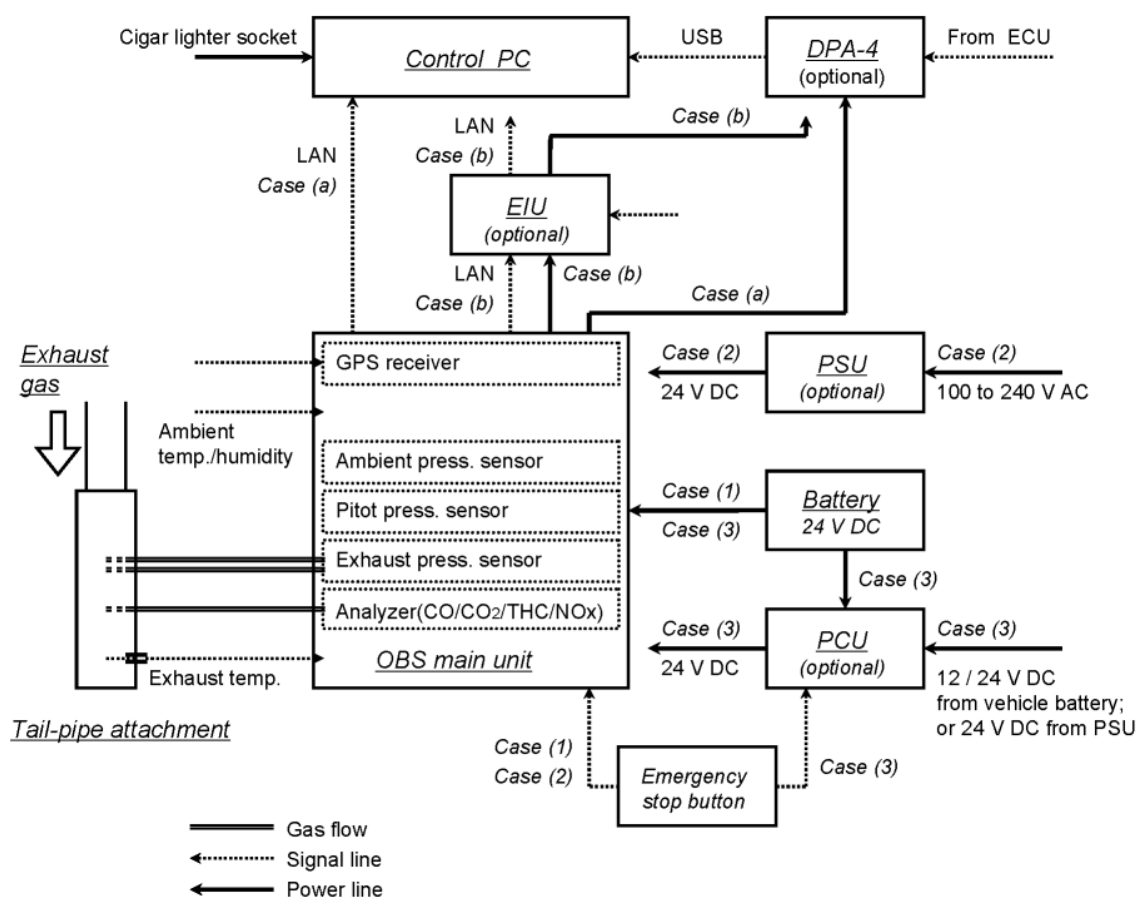

Figure 3-1: Schematic of the OBS-2200 System [27] 
For the testing that was the focus of this research, the system configuration was similar to the figure above. At the heart of the OBS-2200 system is the main unit. The main unit contains all of the analyzers, pumps, valves, and pressure transducers that are necessities for gaseous emissions measurement. It uses three separate types of gaseous analyzers to accurately measure each regulated constituent of exhaust gas.

\subsubsection{Carbon Monoxide/ Carbon Dioxide Analyzer}

The OBS-2200 uses heated NDIR technology to measure $\mathrm{CO}$ and $\mathrm{CO}_{2}$. The detector unit of the analyzer consists of a light source, a heated sample cell and a light chopper. Figure 3-2 shows how the analyzer is configured.

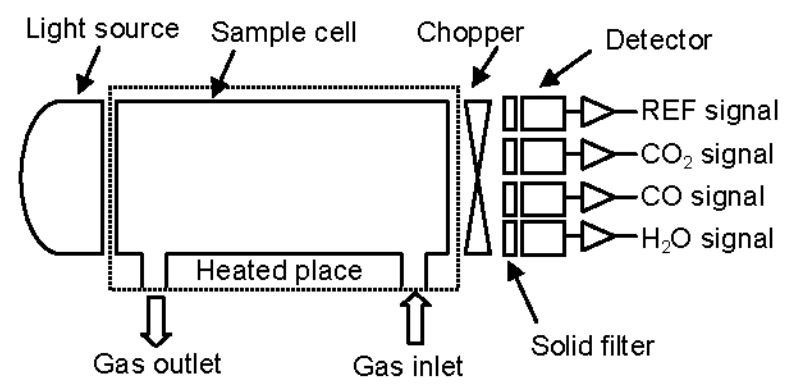

Figure 3-2: Heated NDIR Analyzer Configuration [27]

As infrared light passes through the heated sample cell it is altered by the light chopper, the characteristic wavelengths of each constituent are filtered and then measured by detectors of corresponding wavelengths. Therefore, when exhaust gas containing $\mathrm{CO}, \mathrm{CO}_{2}$, and $\mathrm{H}_{2} \mathrm{O}$ passes through the heated sample cell, light is absorbed at each constituent's characteristic absorption wavelength and light intensity measured by each detector is decreased. Concentrations of $\mathrm{CO}$ and $\mathrm{CO}_{2}$ are proportional to the light intensity measured by the detector. 


\subsubsection{Hydrocarbon Analyzer}

Total hydrocarbon concentrations are measured by the OBS using a flame ionization detector (FID). The FID analyzer works on the phenomenon by which ions are generated by the heat energy produced when hydrocarbons are introduced in a hydrogen flame. The ions produced collect on an ion collector that is comprised of two electrodes that surround the FID flame. The ions collected are detected as a current which is proportional to the number of carbon atoms in the sample. A diagram of the FID configuration is displayed below in Figure 3-3.

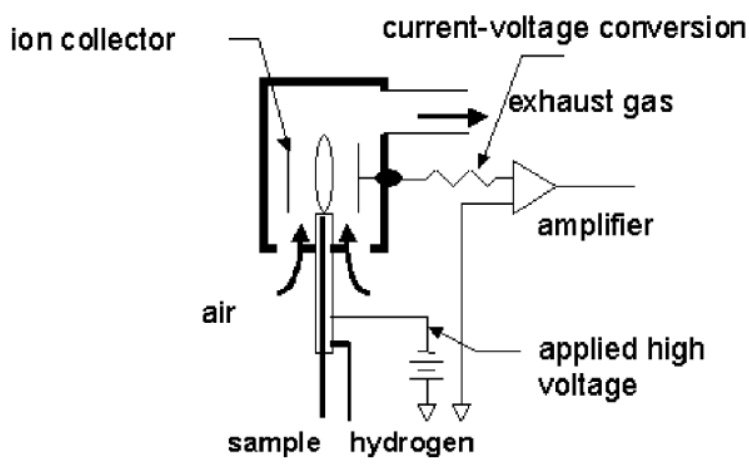

Figure 3-3: FID Analyzer Configuration [27]

\subsubsection{Oxides of Nitrogen Analyzer}

When analyzing the concentrations of the NOx in engine exhaust, the method of using a chemiluminescence detector (CLD) is often the method of choice. This is primarily due to its high sensitivity to nitric oxide (NO) while not being easily interfered with by other exhaust constituents. CLD analyzers work on the principle of mixing sample gas containing NO with ozone gas. In this reaction the $\mathrm{NO}$ is oxidized and transformed into nitrogen dioxide $\left(\mathrm{NO}_{2}\right)$. Part of the $\mathrm{NO}_{2}$ that is generated is in an excited state, meaning its energy levels are higher than normal. These excited $\mathrm{NO}_{2}$ molecules release this extra energy in the form of light. The amount 
of light emitted during this reaction is measured and is directly proportional to the concentration of NO molecules in the sample.

\subsubsection{Exhaust Flow Meter}

In order to calculate mass emissions of measured exhaust constituents, the OBS uses the provided exhaust gas flow meter. The flow meter uses directionally opposed pitot static tubes to measure exhaust flow. Exhaust gas temperature and the exhaust gas sample are also taken at the tail pipe attachment. A diagram of the tailpipe attachment is shown in Figure 3-4.

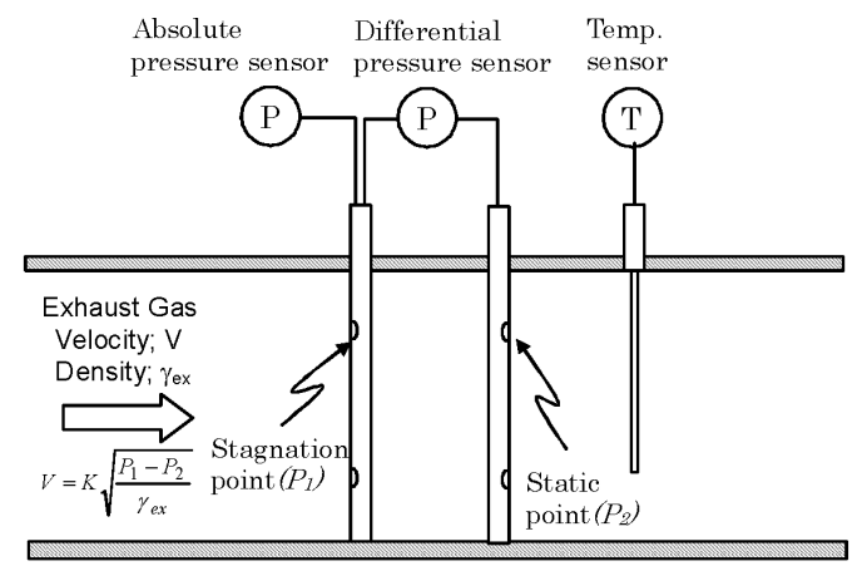

Figure 3-4: Tailpipe Attachment Cross-Section [27]

Exhaust flow is calculated automatically in real-time by the OBS main unit using the following equation.

$$
Q_{e x}(t)=K \times \sqrt{\frac{P_{e x}(t)}{101.3} \times \frac{293.15}{T_{e x}(t)} \times \frac{\Delta h(t)}{\gamma_{e x}}}
$$

Where: $\mathrm{Q}_{\mathrm{ex}}(\mathrm{t})=$ Exhaust gas flow rate at standard conditions $[\mathrm{L} / \mathrm{min}]$

$\mathrm{K}=$ Pitot calibration coefficient determined by Horiba at the factory 
$P_{e x}(t)=$ Measured pressure of exhaust gas $[\mathrm{kPa}]$

$\mathrm{T}_{\mathrm{ex}}(\mathrm{t})=$ Measured temperature of exhaust gas $[\mathrm{K}]$

$\Delta \mathrm{h}(\mathrm{t})=$ Differential pressure of pitot tube $[\mathrm{kPa}]$

$\gamma_{\mathrm{ex}}=$ Density of exhaust gas $\left[\mathrm{kg} / \mathrm{m}^{3}\right]$

\subsubsection{On-Board Diagnostic Interface}

The OBS system uses an on-board diagnostics (OBD) protocol adapter to transmit broadcast signals from the ECM to the OBS main unit to monitor engine parameters and calculate Not-toExceed data points. The OBD protocol adapter used for this testing was a Dearborn DPA-4 Plus [20]. The adapter read signals from the ECM using the J1939 interface protocol and relayed the information to the OBS. The signals broadcast from the ECM that were monitored by the OBS are displayed below in Table 3-4.

Table 3-4: OBD Output Signals

\begin{tabular}{|c|l|c|}
\hline OBD Channel & \multicolumn{1}{|c|}{ ECM Signal } & Units \\
\hline OBD_01 & Engine Speed & $\mathrm{RPM}$ \\
\hline OBD_02 & Wheel Based Vehicle Speed & $\mathrm{km} / \mathrm{h}$ \\
\hline OBD_03 & Actual Engine Percent Torque & $\%$ \\
\hline OBD_04 & Boost Pressure & $\mathrm{kPa}$ \\
\hline OBD_05 & Air Inlet Pressure & $\mathrm{kPa}$ \\
\hline OBD_06 & Engine Oil Pressure & $\mathrm{kPa}$ \\
\hline OBD_07 & Engine Coolant Temperature & ${ }^{\circ} \mathrm{C}$ \\
\hline OBD_08 & Intake Manifold 1 Temperature & ${ }^{\circ} \mathrm{C}$ \\
\hline OBD_09 & Fuel Temperature & ${ }^{\circ} \mathrm{C}$ \\
\hline OBD_10 & Throttle Position & $\%$ \\
\hline OBD_11 & Inlet Air Mass Flow Rate & $\mathrm{kg} / \mathrm{h}$ \\
\hline OBD_12 & EGR Mass Flow Rate & $\mathrm{kg} / \mathrm{h}$ \\
\hline OBD_13 & Fuel Rate & $\mathrm{L} / \mathrm{h}$ \\
\hline OBD_14 & Nominal Friction-Percent Torque & $\%$ \\
\hline OBD_15 & Reference Engine Torque & $\mathrm{Nm}$ \\
\hline
\end{tabular}




\subsubsection{Auxiliary Components}

Power to operate the OBS main unit and accessory equipment was provided via the PSU. The PSU inputs $110 \mathrm{~V} \mathrm{AC}$ and outputs $24 \mathrm{~V} \mathrm{DC}$ that is used to power the main unit and EIU. For this testing a $3 \mathrm{~kW}$ gasoline generator was also carried on board the vehicle to generate the 110 V AC to be provided to the PSU. Horiba also offers an alternative method of providing power to the OBS. By using the available power control unit (PCU) it is possible to provide power to the OBS and accessories without carrying an on-board generator. This unit used a combination of vehicle electrical power generation and two additional $12 \mathrm{~V} \mathrm{DC}$ automotive batteries.

The EIU is used by the OBS to interface the main unit and any analog inputs used during testing. LAN cables connect the OBS main unit and the control PC via the EIU. The vehicle protocol adapter used to record vehicle on-board diagnostic data received power from a $24 \mathrm{~V}$ DC output on the EIU. For the testing presented in this research, the EIU received Not-to-Exceed signals from the OBS and transmitted this signal to the OBS-TRPM system to trigger PM sampling.

Additional external sensors used by the OBS system include a relative humidity and temperature sensor and a GPS. The relative humidity and temperature sensor provides real time ambient humidity and temperature readings that are used in calculations by the OBS main unit. The GPS provides information on the vehicle's location in terms of latitude, longitude, and altitude as well as giving an additional method of determining vehicle speed. 
The OBS utilized a laptop PC to interface with the user. This laptop contained the Java software used to display and control the OBS functions and also inputs the OBD signals from the Dearborn Protocol Adapter.

The OBS required various fuel and analytical gases to be carried on-board with system in order to operate. The system required a bottle of FID fuel, ultra-zero air, and the necessary span gases for the $\mathrm{CO} / \mathrm{CO}_{2}, \mathrm{THC}$, and NOx analyzers. The FID fuel consisted of $40 \%$ hydrogen, $60 \%$ helium blend that was used by the FID analyzer to produce the hydrogen flame for ionization of hydrocarbons in the exhaust sample. The ultra-zero air was also used by the FID analyzer for generating the flame, however, it was also used as zero gas for calibration of all analyzers contained in the OBS. Since these bottles must be carried on-board while testing and space on a vehicle for the OBS is usually in short supply, it is common practice during in-use testing to use a bottle containing a blend of all span gases to be used for calibration by the OBS. Table 3-5 below displays the concentrations contained in the blend bottle used for this testing.

Table 3-5: Span Gas Concentrations

\begin{tabular}{|l|c|c|}
\hline Span Gas & Concentration & Unit \\
\hline $\mathrm{CO}$ & 1000 & $\mathrm{ppm}$ \\
\hline $\mathrm{CO}_{2}$ & 11.81 & $\%$ \\
\hline $\mathrm{NOx}$ & 1500 & $\mathrm{ppm}$ \\
\hline Propane & 100.3 & $\mathrm{ppm}$ \\
\hline
\end{tabular}

The span set point used for calibration of the THC analyzer is the propane concentration listed above multiplied by three due to the three carbon atoms in one molecule of propane $\left(\mathrm{C}_{3} \mathrm{H}_{8}\right)$. That is, the THC concentration is reported as a $\mathrm{C} 1$ equivalent value. 


\subsection{Horiba TRPM}

To measure the PM produced by the vehicles during this research, the OBS-TRPM system was used in conjunction with the OBS-2200 gaseous system. At the time the TRPM was a prototype system available from Horiba Instruments and is now commercially available. It was designed to be able to collect PM for about eight hours on a DPF equipped vehicle with moderate NTE operation. The TRPM consisted of four separate cabinets each containing various sampling, mechanical, and electrical components necessary for in-use gravimetric PM sampling [32].

\subsubsection{Software}

The OBS-TRPM operated using two software programs. The programs controlled the operation and data processing functions performed by the TRPM. The programs monitored all inputs from pressure and temperature sensors and controlled all output signals for the various motors, pumps, valves, relays, and displays. The first program was a Labview-based program and was used for service level operation such as daily tests and calibrations. The second, a Java-based program, was used to control the TRPM during actual tests. This program triggered the sampling for NTE events and logged the recorded data [32].

\subsubsection{Electrical Cabinet}

The electrical cabinet contained the rack mounted logic boards and all other necessary electronic equipment. A National Instrument's Compact Field Point module for digital and analog inputs and outputs was also contained in this cabinet. The TRPM used digital signals to control the NTE trigger during in-use testing. The internal valve relays were also controlled by the digital board. The TRPM was equipped with an analog input module capable of providing up to sixteen input channels. The input module collected signals from the transducers and mass flow 
controllers housed in the mechanical cabinet and converted them to digital values. External signals collected by the analog input module included a 0-10V DC signal for exhaust flow. The analog output board was used for controlling the set points of the mass flow controllers used for the partial flow dilution control system [32].

\subsubsection{Mechanical Cabinet}

The mechanical cabinet and electrical cabinet were designed to be installed side by side of each other. The two were connected through five serial connectors and one five-pin Amphenol connector. The mechanical cabinet contains all pumps, valves, and mass flow controllers used by the TRPM system to control dilution and sample flow to the heated enclosure. The total diluted sample flow rate was set at 30 liters per minute (lpm). Four pressure regulators control dilution air pressure supply to the various components in the mechanical cabinet [32].

\subsubsection{DCS Cabinet}

The DCS module was a real time PM detector manufactured by TSI Performance Measurement Tools Inc. The DCS bled off a small sample from the diluted exhaust stream and was passed through the DCS analyzer to create a transient response to apportion PM mass collected on the sample filter in the heated enclosure cabinet. In order to maintain the total diluted sample flow rate of $30 \mathrm{lpm}$, the sample that was taken by the DCS was replaced to the sample flow using dilution air by a dedicated mass flow controller located downstream of the PM filter [32].

\subsubsection{Sample Probe and Miniature Dilution Tunnel}

The sample probe for the TRPM system was mounted pointing upstream into the exhaust flow inside the stack of the vehicle. Attached directly to the sample probe on the outside of the stack 
was a miniature dilution tunnel. The dilution tunnel mixed HEPA filtered ambient air with the raw exhaust sample to provide the TRPM with a diluted sample of diesel exhaust to the sample filter. The dilution air was provided by either the vehicle's engine mounted air compressor or by an additional stand-alone $120 \mathrm{~V}$ AC air compressor carried on-board the vehicle alongside the TRPM unit. The dilution air was controlled by the mechanical cabinet described above based on exhaust flow rate. Dilution air temperature was measured using a resistance thermal detector (RTD) [32].

\subsubsection{Heated Enclosure}

The heated enclosure provided with the TRPM housed the system's cyclone, particulate filter holder, and by-pass filter. Figure 3-5 below displays the layout of the TRPM heated enclosure cabinet. When the TRPM was operating in measure mode, the diluted exhaust flowed through the systems cyclone where the larger particles of PM were removed from the sample flow. The remaining sample flow then flows through the filter holder where the PM was collected on a $47 \mathrm{~mm}$ Teflo filter [32]. 


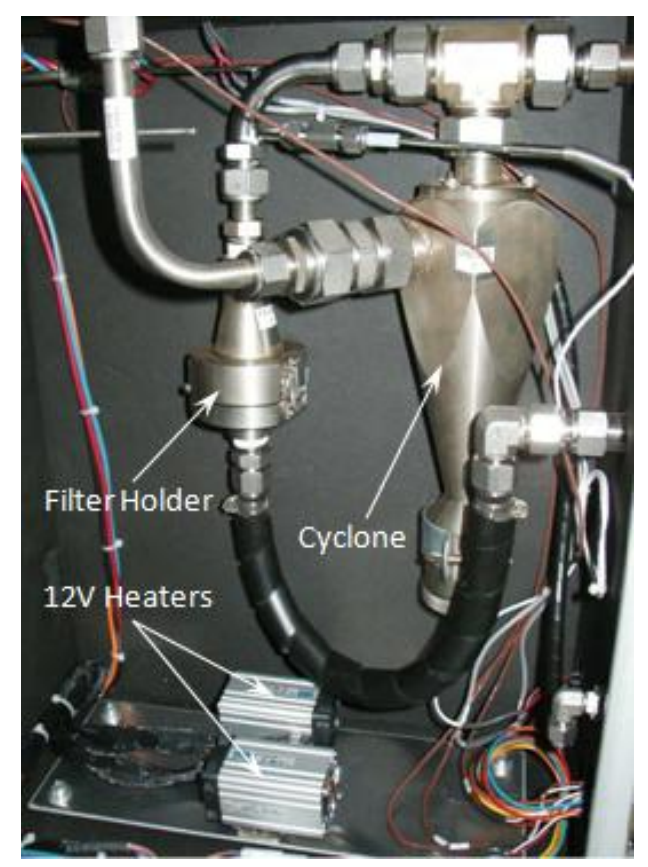

Figure 3-5: Internal Components of TRPM Heated Enclosure

\subsection{Test Procedure}

\subsubsection{Equipment Calibration and Maintenance Schedule}

In order to assure that the PEMS equipment being used for testing provided accurate measurement a set of calibrations and checks were performed on a regular basis. Contained in the operation manual of the OBS was the calibration and maintenance schedule recommended by Horiba. Table 3-6 below displays this schedule. 
Table 3-6: Horiba Recommended OBS Maintenance Schedule

\begin{tabular}{|l|l|}
\hline Check/Maintenance Action & Interval \\
\hline Filter Replacement & $\begin{array}{l}\text { Every 8 } \\
\text { measurement hours }\end{array}$ \\
\hline Cleaning of tail-pipe attachment & Every 6 months \\
\hline System Check & Monthly \\
\hline Amplifier adjustment for THC and NOx analyzer & Every 6 months \\
\hline H2O detector calibration & Yearly \\
\hline Leak and time delay check & Yearly \\
\hline Linearization check & Yearly \\
\hline NOx converter efficiency check & Yearly \\
\hline THC hang up check & Yearly \\
\hline Interference Check & Yearly \\
\hline Performance Check & Yearly \\
\hline
\end{tabular}

For data quality purposes during this research, the linearization check, NOx converter efficiency, THC hang up, and interference checks were completed on a monthly basis. Also, a system check was performed daily before each test to assure that all components of the OBS were operating properly.

The maintenance schedule for the TRPM was far less comprehensive. Horiba recommends no monthly or yearly calibrations or maintenance outside of the daily flow checks and pressure transducer calibrations that are outlined below in section 3.5.4 Daily System Checks.

\subsubsection{Equipment Installation}

Since this equipment was installed on a variety of different vehicle configurations ranging from Class 8 long-haul tractors to vocational bucket trucks, each installation of the PEMS system was different; however, the same set of guidelines was followed for each installation. The primary consideration when installing the PEMS on a vehicle was to be minimally invasive on the driver and vehicle operation. It was also important to protect the systems from adverse weather 
conditions. If it was possible, the system was installed inside the vehicle either in the sleeper, in the case of the long-haul tractors, or in place of the passenger seat for the vocational vehicles. The PEMS was also positioned such that the heated line was able to reach the exhaust stack. An example of the Horiba OBS and TRPM installed on one of the test vehicles was shown below in Figure 3-6. The figure shows the complete installation of the necessary PEMS equipment that was used to conduct this research. From left to right is the TRPM heated enclosure, DCS, mechanical and electrical cabinets, and the OBS system. Above the cab across the top of the "headache rack" is where the tailpipe attachment with sample probes was located. In the foreground are the calibration gases and the generator used for powering the PEMS equipment.

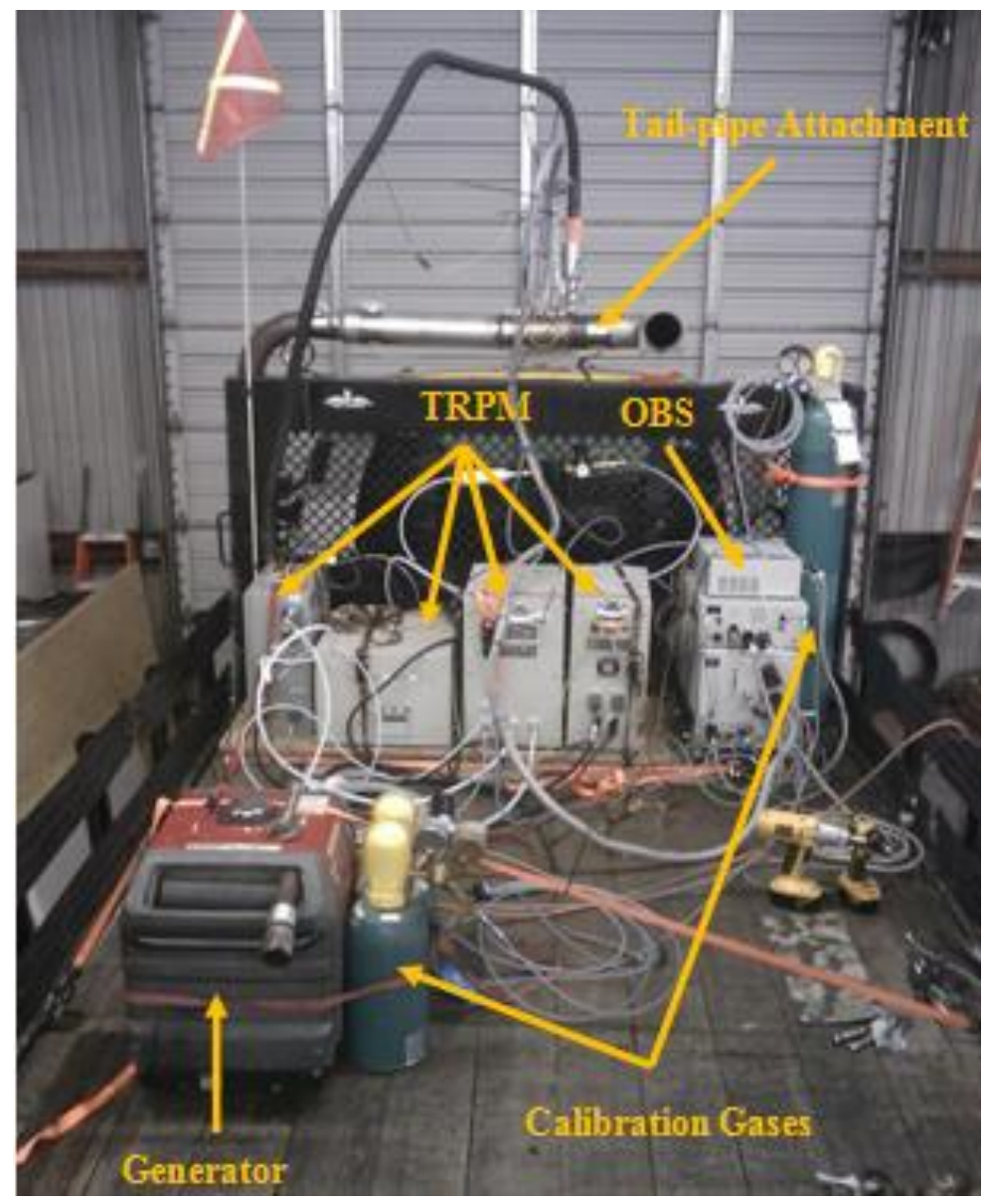

Figure 3-6: Equipment Installed on a Test Vehicle 


\subsubsection{Equipment Warm-Up}

After the equipment was installed on the test vehicle a certain time period was necessary for the equipment to warm-up before the test. The OBS usually required approximately one hour to reach operating temperatures before the test could begin. It was recommended that the TRPM be allowed to warm-up for a period of 15 minutes before the test began. This warm-up period was designed to allow the heated lines, heated analyzers, and heated enclosure to reach the minimum temperature required for operation.

\subsubsection{Daily System Checks}

The system check function of the OBS was the primary method of determining if all systems and analyzer in the OBS were performing correctly. This check was completed at the beginning of each test day. For this check, all calibration gases were connected and the warm-up sequence must have been completed. The system check was performed by accessing the maintenance screen and selecting the Check/Test button then the System Check option. An example of the results of a System Check is shown below in Figure 3-7. If an item was out of the proper range it would have been identified in flashing red. 


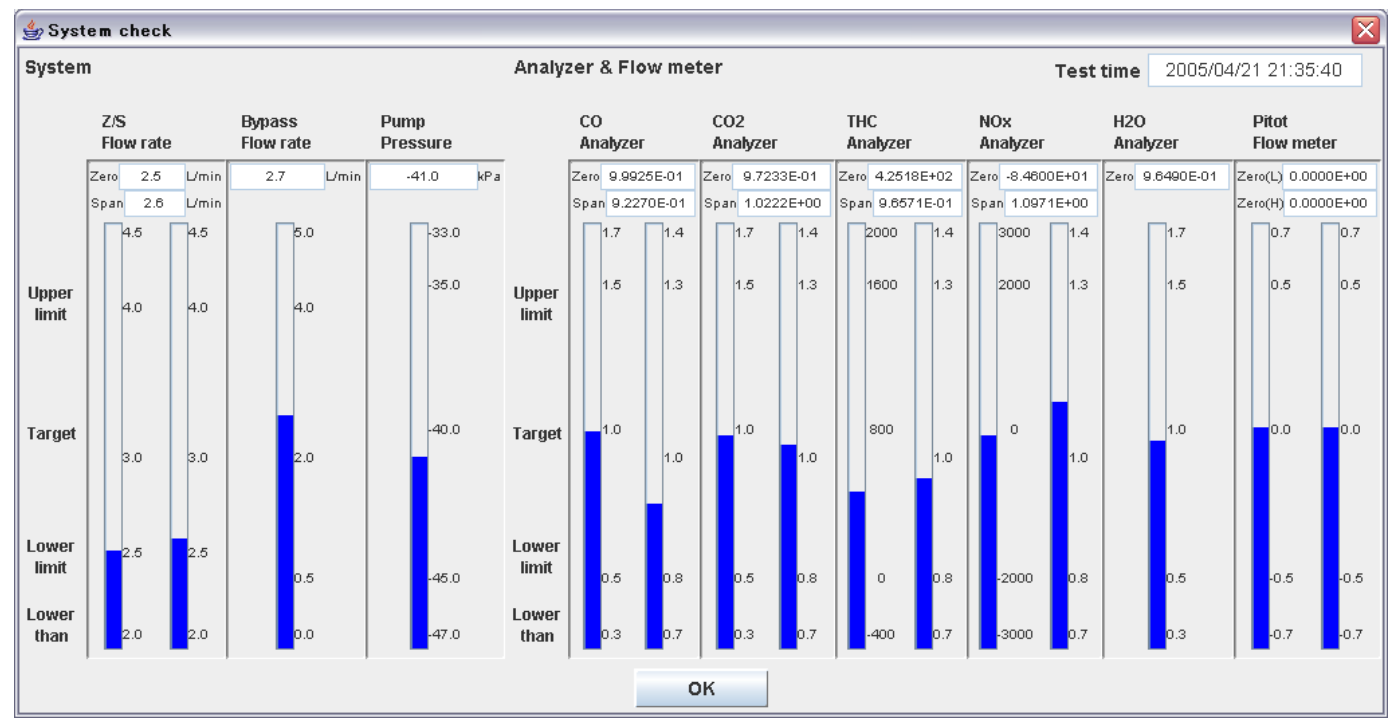

Figure 3-7: OBS System Check Result Window [27]

The TRPM required a daily sample flow rate check and pressure transducer calibration sequence to be completed before testing. These sequences were completed using the Labview program. The first sequence to be completed was the pressure transducer calibration. This was done by selecting the Diagnostics menu on the Labview program and then clicking the Analog Inputs button. This was done while the TRPM was in Idle mode before opening the Java software program, this insured that the sample pump was off and that the DCS was not drawing sample. The transducers were calibrated by entering the value for Dilute Pi into the Barometer value window in the PCAL start screen and selecting OK. This screen was accessed through the Cal menu. The windows used for the pressure transducer calibration sequence are shown below in Figure 3-8. 


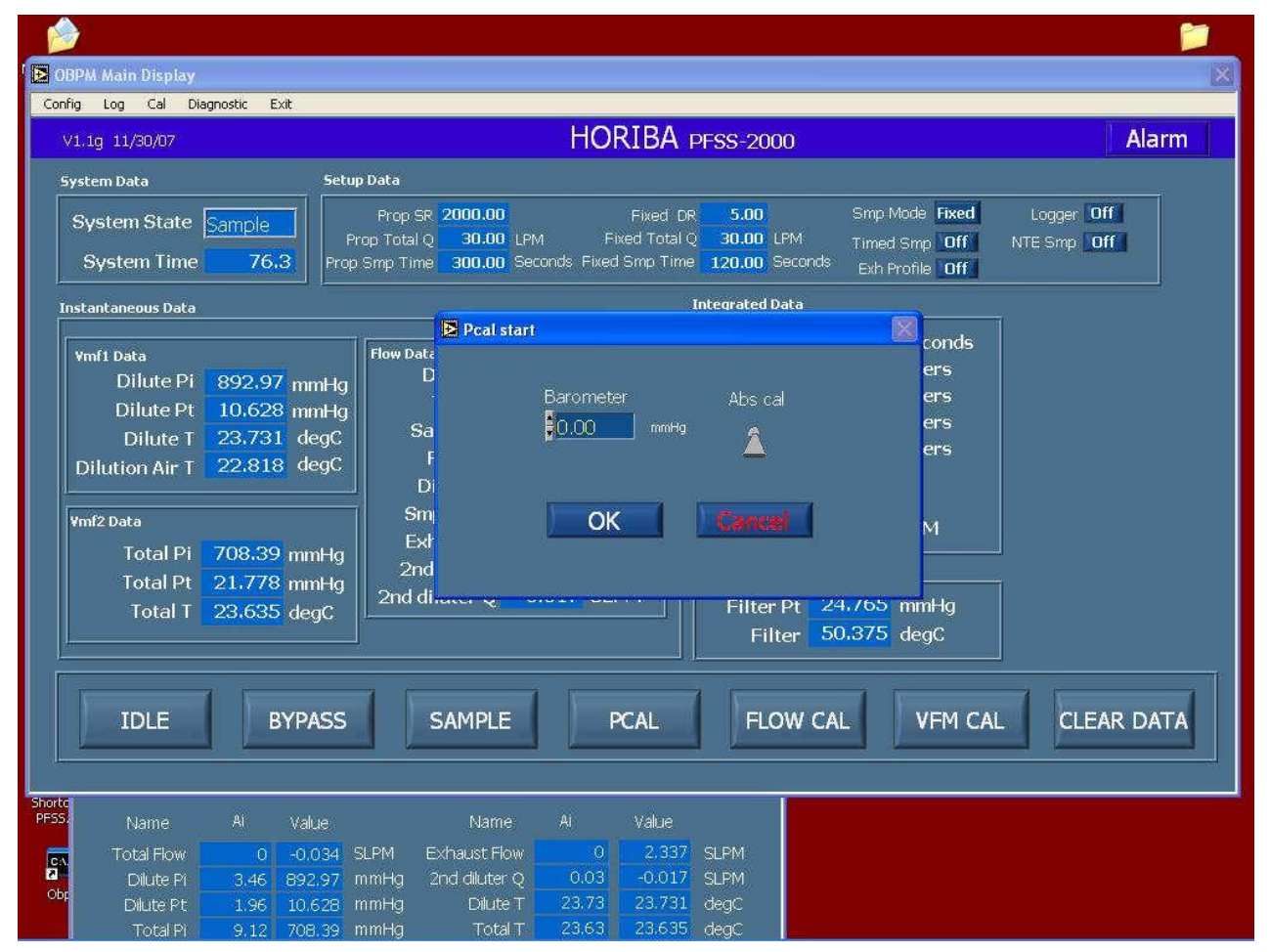

Figure 3-8: TRPM Pressure Transducer Calibration Sequence Window [32]

The sample flow rate check was intended to serve as a daily system leak check. This involved directly measuring the flow rate through the sample probe using an external laminar flow meter. The flow meter cable was first connected to the electrical cabinet, and then the outlet of the flow meter connected directly to the sample probe. This was done by removing the sample probe from the exhaust system. The system was then put into Bypass mode; once the Java software had been started the system could be switched into Ready mode. This caused the DCS to draw its sample flow. To verify the flow rate, a constant dilution rate was set to 5 and then 20 . The system passed the sample flow rate check if the sample flow reading in the software was within $3 \%$ of the dilution ratio of 5 and $5 \%$ of the dilution ratio of 20 shown by the laminar flow meter reading. The window used for the sample flow rate check is shown below in Figure 3-9. 


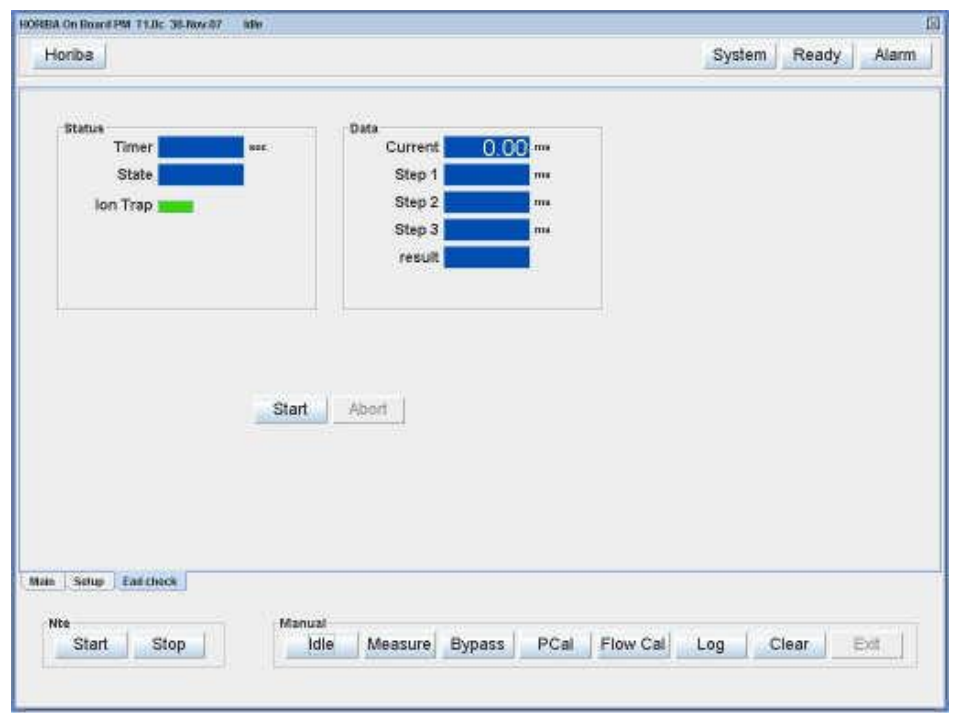

Figure 3-9: TRPM Sample Flow Rate Check Window [32]

\subsubsection{Test Set-Up}

Once the equipment had been installed on the vehicle and all necessary checks and calibrations had been completed it was possible to begin testing. On the OBS there were two variations of testing that can be conducted, a standard test or a NTE test. The standard test collected data continuously from the time that the test was started until the time it was ended by the user. The NTE test only collected data when all the criteria were met to be included in the NTE zone. For this research all tests were done using the NTE test option. 


\section{Discussion of Results}

Results from this research were divided into two separate sections consisting of work-window results and NTE results. The results from the two methods were then compared side by side in order to show the magnitude and variation in brake specific emissions of each method. The work-window results were obtained by using the reduced $1 \mathrm{~Hz}$ data files produced by the Horiba post-processor. These files were then reduced into individual windows using Matlab programming software. In order to reduce these files into individual work-windows the program identified the power data column of the file and integrated that value until a target work was reached. Once this value was reached, the rows of data contained in this integrated sum would consist of an individual work window. The program then identified specific columns of emission mass rate, in $\mathrm{g} / \mathrm{s}$, for $\mathrm{CO}, \mathrm{CO}_{2}$, humidity corrected $\mathrm{NOx}, \mathrm{THC}$, and PM and summed them to obtain a mass per window value using the below equation.

$$
X_{m a s s}(\operatorname{grams})=X_{i}\left(\frac{g}{s}\right) \times \Delta t(s)
$$

Where $\mathrm{X}_{\text {mass }}$ is the mass of the specific constituent in grams, $\mathrm{X}_{\mathrm{i}}$ is the instantaneous $\mathrm{g} / \mathrm{s}$ measurement of the specific constituent, and $\Delta \mathrm{t}$ is the time increment. The resulting mass was then integrated over the window and divided by the total work of the window.

$$
X_{B S}=\frac{X_{\text {mass }}}{W_{\text {window }}}
$$

In this equation $\mathrm{X}_{\mathrm{BS}}$ is the brake specific level of each constituent and $\mathrm{W}_{\text {window }}$ is the work done during the work-window. As discussed in Chapter 2, the NTE method usually incorporates engine family specific carve outs. The method also has various exclusion criteria based on 
certain parameters such as intake manifold temperature and engine coolant temperature. If these parameters are not met during a certain NTE event, then that data point is excluded from the final event. As this study is a simply a comparison between the two methods, no carve outs or exclusion criteria were applied to either method in order to maintain consistency in the results.

\subsection{Theoretical Work Calculation}

A Matlab program, see Appendix A- Matlab Program to Determine FTP Theoretical Work, was created to determine the theoretical work that would be produced for each engine lug curve as if it were operated on an engine dynamometer over the FTP cycle. This value would serve as the target work value to be reached when calculating the work-based windows for each test vehicle. Using the FTP cycle to generate the target work value allowed a closer simulation of emissions to reported levels. The program took the percent engine speed and torque setpoints of the FTP and used each engine's lug curves to interpolate engine speed and torque in RPM and $\mathrm{lb}_{\mathrm{f}}-\mathrm{ft}$, respectively. The following figures demonstrate the actual engine speed and torque setpoints of each engine for the FTP cycle. Figure 4-1 represents the FTP setpoints over the lug curve of Engine Family A. Figure 4-2 shows these points for Engine Family B while Figure 4-3 characterizes Engine Family C. 


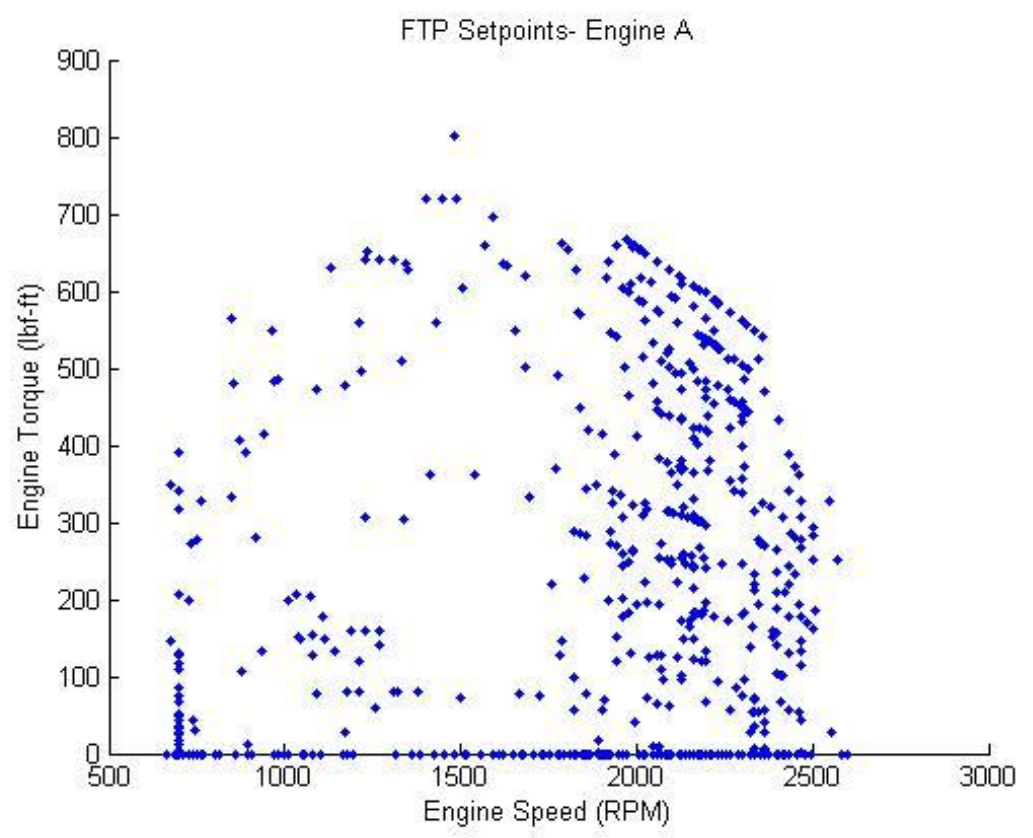

Figure 4-1: FTP Setpoints for Engine Family A

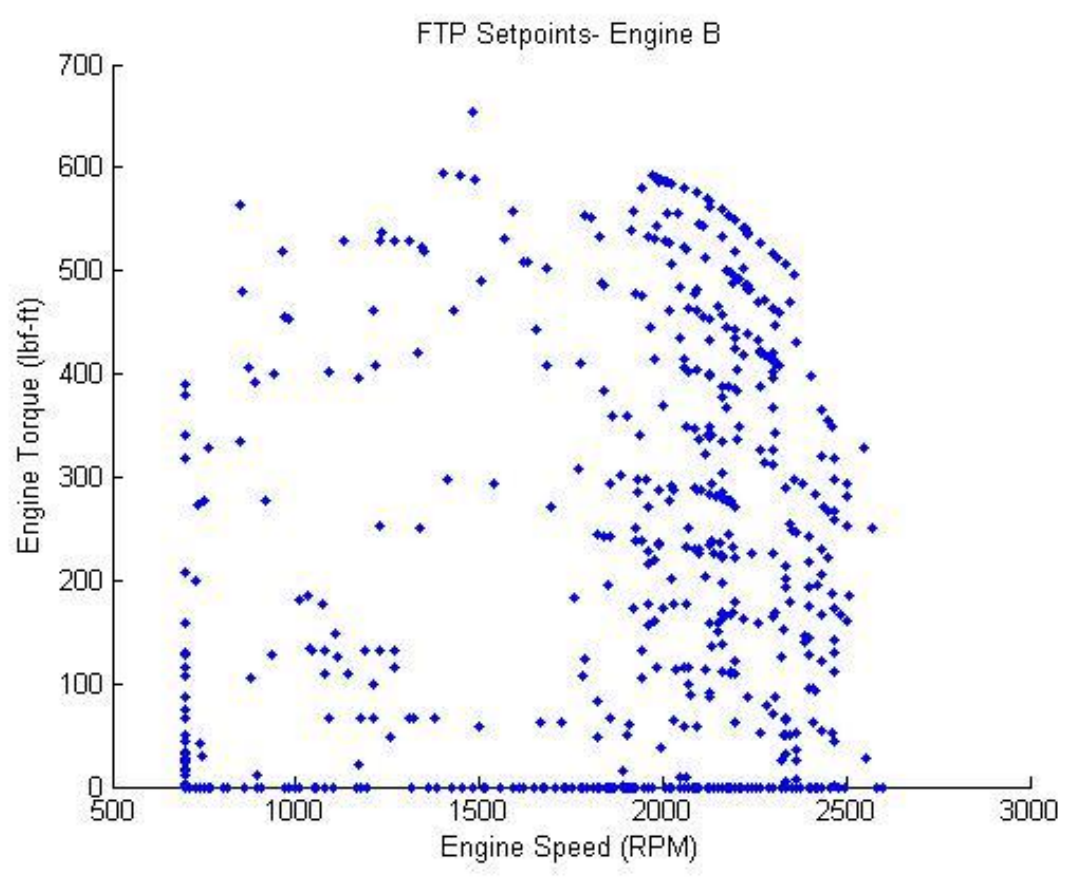

Figure 4-2: FTP Setpoints for Engine Family B 


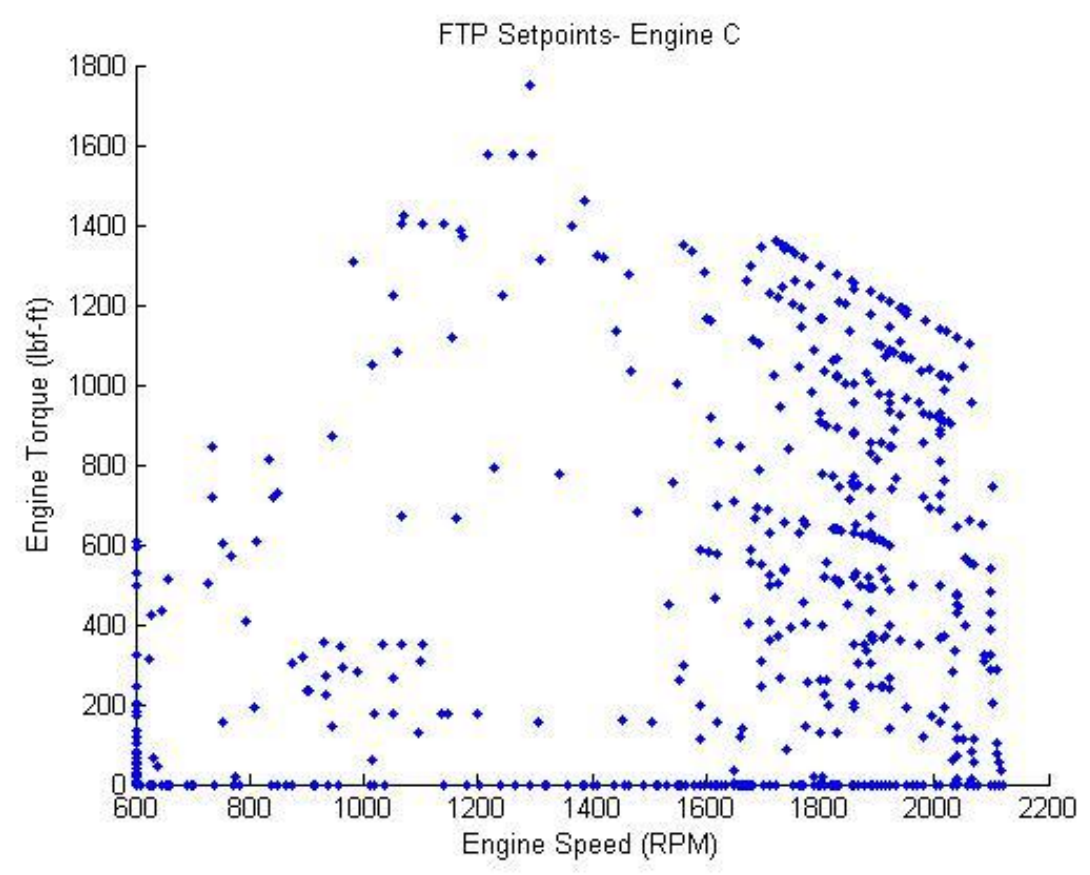

Figure 4-3: FTP Setpoints for Engine Family C

Power generated over the FTP cycle was calculated using the following equation for each speed/torque point.

$$
\operatorname{Power}(h p)=\frac{\text { Engine Speed }(R P M) \times \text { Engine Torque }\left(l b_{f}-f t\right)}{5252}
$$

Eqn. 8

The power for each point was then integrated over the cycle to determine the brake specific work done by the engine. Table 4-1 shows the calculated theoretical FTP work values for each of the three lug curves.

Table 4-1: Theoretical FTP Work

\begin{tabular}{|c|c|}
\hline Engine & Theoretical FTP Work (bhp-hr) \\
\hline A & 17.90 \\
\hline B & 16.16 \\
\hline C & 29.66 \\
\hline
\end{tabular}


A second Matlab program was created to integrate the actual work-windows, see Appendix BMatlab Program to Generate Work-Windows. This program read the power column of the input data file and integrated these values until the target was reached. The number of data points included in this integration comprised the work-window. The method for integrating the work window is shown below.

$$
\text { Work }_{i+1}=\text { Work }_{i}+\left(\text { Power }_{i} \times \frac{\Delta t}{3600 \mathrm{sec}}\right)
$$

Because of the variability in the instantaneous power generated by the engine, it is theoretically impossible to exactly generate a work-window exactly equal to that of the target value.

Therefore, a limit of $0.5 \%$ difference above the target was set as a tolerance to determine whether the variation was acceptable. Table 4-2 shows the accuracy of the work integration through various statistical variables. It shows that this method, according to the $0.5 \%$ limit, was an acceptable method for integrating work with a maximum percent difference from the target of $0.45 \%$.

Table 4-2: Window Work Calculation Statistics

\begin{tabular}{|l|c|c|c|c|c|}
\hline Test Vehicle & Average (bhp-hr) & $\begin{array}{c}\text { Std. Dev. } \\
\text { (bhp-hr) }\end{array}$ & Max (bhp-hr) & Min (bhp-hr) & \% Difference \\
\hline 1 (Gaseous) & 17.92 & 0.0143 & 17.97 & 17.90 & 0.39 \\
\hline 1 (PM) & 17.92 & 0.0158 & 17.98 & 17.90 & 0.45 \\
\hline 2 & 17.92 & 0.0152 & 17.97 & 17.90 & 0.39 \\
\hline 3 & 17.92 & 0.0126 & 17.97 & 17.90 & 0.39 \\
\hline 4 & 16.17 & 0.0112 & 16.22 & 16.16 & 0.37 \\
\hline 5 & 16.18 & 0.0153 & 16.22 & 16.16 & 0.37 \\
\hline 6 (Gaseous) & 29.69 & 0.0226 & 29.78 & 29.66 & 0.40 \\
\hline 6 (PM) & 29.70 & 0.0286 & 29.78 & 29.66 & 0.40 \\
\hline 7 (Gaseous) & 29.70 & 0.0295 & 29.78 & 29.66 & 0.40 \\
\hline 7 (PM) & 29.69 & 0.0216 & 29.78 & 29.66 & 0.40 \\
\hline
\end{tabular}


Figure 4-4 gives a graphical representation of the integrated window work for Test Vehicle 6. It shows the minimum work generated for the windows equal to the target FTP work of 29.66 bhp$\mathrm{hr}$ and the maximum never exceeds the upper bound of $29.8 \mathrm{bhp}-\mathrm{hr}$ established by the $0.5 \%$ limit.

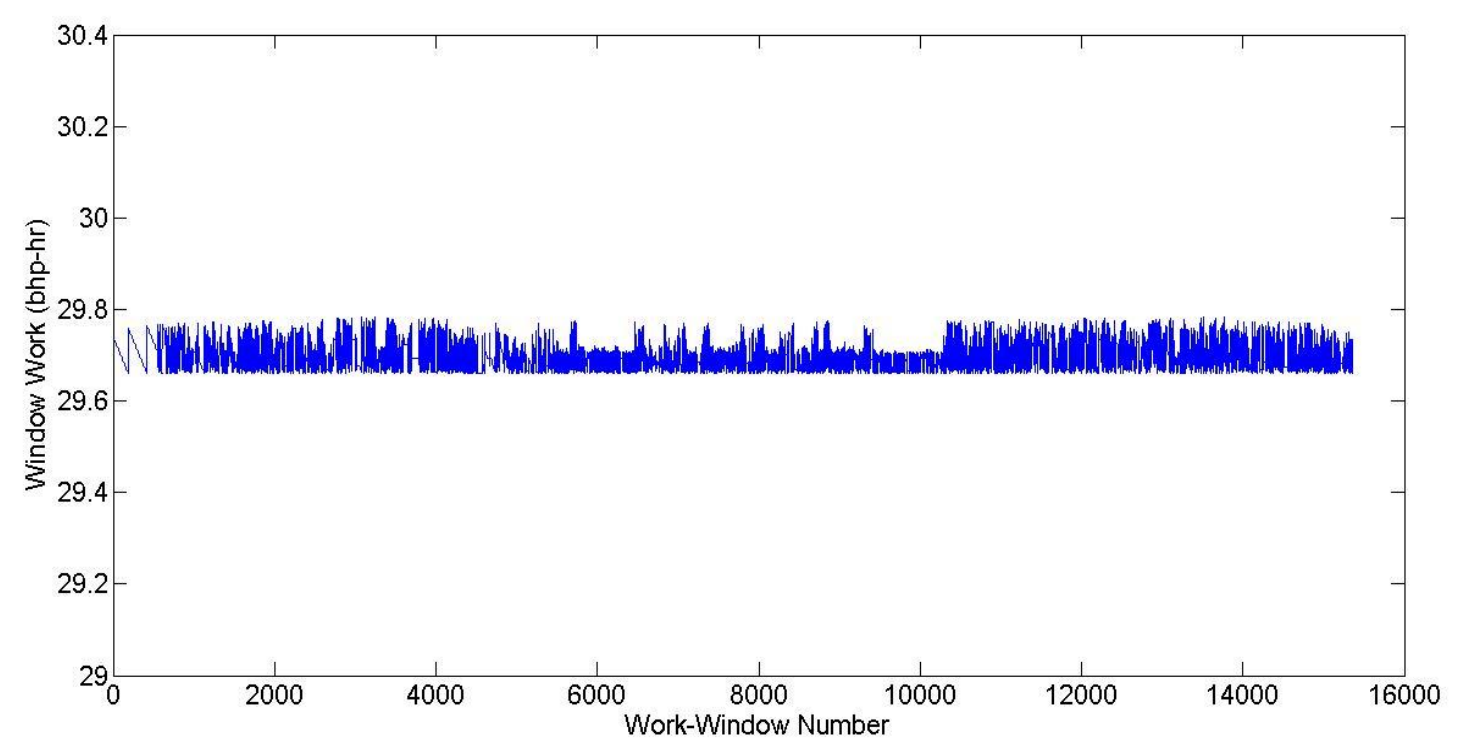

Figure 4-4: Test Vehicle 6 Window Work

\subsection{Work-Based Window Results}

The data files used for the work-window analysis were files generated by the Horiba OBS post processing software. This software compiled the $10 \mathrm{~Hz}$ data files that were created throughout the test day and reduced it into two separate $1 \mathrm{~Hz}$ files; with one being non-drift corrected and the other being drift corrected. The drift corrected files that were used for NTE determination were used to generate the work-window. This provided consistency between work-window data and NTE data. These files gave the emission measurement in mass rate $(\mathrm{g} / \mathrm{s})$ on an instantaneous basis $(1 \mathrm{~Hz})$ over an entire day of testing. This resulted in a large number of samples to be 
compiled into a large number of work-windows. Due to this large number of individual work windows, box and whisker plots were chosen to summarize the data. Box and whisker plots provide a graphical means to depict large data sets as they display five statistical summaries of the data in one plot. The box is used to show the upper and lower quartile of the data where the upper end of the box is $75^{\text {th }}$ quartile and the lower end is the $25^{\text {th }}$ quartile. The median of the data $\left(50^{\text {th }}\right.$ quartile) is shown as a single line between the upper and lower ends of the box. The whiskers are used to show the highest and lowest values contained within the data set that are within 1.5 times the inter-quartile range of the box. Data not contained within the whiskers are identified as outliers by marks the plot above and or below the whiskers.

Figure 4-5 provides a representation of a box and whisker plot showing the distribution of the work-window data. The figure shows the work-window emission data from Test Vehicle 3 in brake-specific mass units of $\mathrm{g} / \mathrm{bhp}-\mathrm{hr}$. For these plots $\mathrm{CO}_{2}$ was scaled by a factor of 1000 in order for it to be able to be plotted alongside the other exhaust constituents. The plot shows several outliers present for CO and THC as well as a few for PM. The numbers of outliers vary according to vehicle and are usually dependent on spikes in the brake specific concentrations. These spikes can most often be traced back to specific engine operation events or limitations in the analyzers themselves during periods of very low emission production. Examples of these events are described below in this chapter and help explain the reasoning behind the existence of these outliers in the data. 


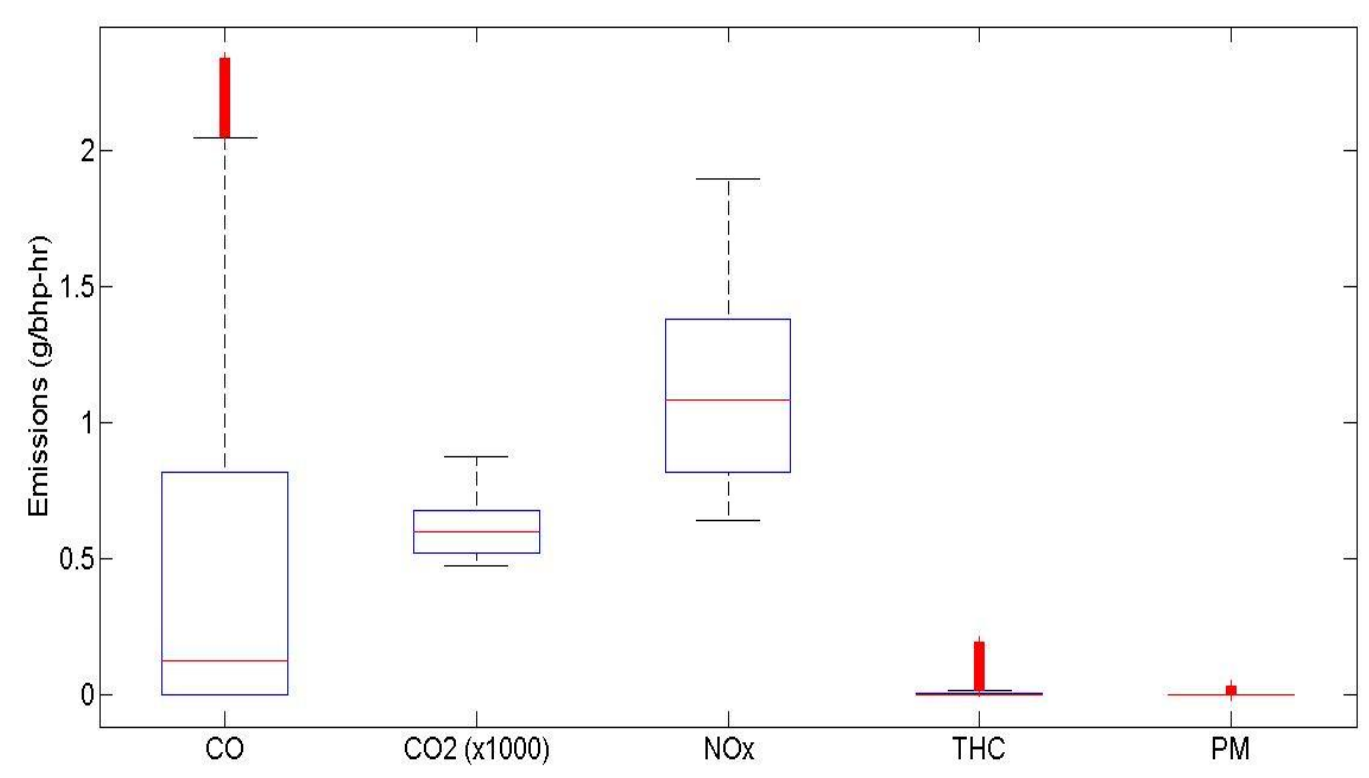

Figure 4-5: Test Vehicle 3 Work-Window Emission Distribution

By investigating the type of engine operation occurring during the work-windows that were deemed outliers, it was determined that the major cause was periods of extended idle. Idling for long periods of time is not the intended use for HDDEs and therefore the resulting emissions may not behave the same as if at full load or under normal on-road use. Fueling and combustion strategies may have been changed and certain emissions reduction systems may not operate as efficiently. Another problem with measurements during engine idle is the limitations of the sensors measuring the different characteristics of the operation. The OBS main unit receives data regarding power produced by the engine through OBD signals. During idle these vehicles produce a small fraction of rated power in order to run auxiliary components such as the alternator and air compressor. This power at idle was found to be $2 \%$ of the rated power of the 7 liter engines and less than $0.5 \%$ of rated power for the 13 liter engines. Therefore, accuracy of this measurement is greatly dependent on resolution of the engine's method of measuring engine 
speed and inferring torque. For instance, if actual power produced at idle is even slightly less than measured, this would result in a longer work-window duration and a higher integrated mass value. The following paragraphs show the effects that the engine idling for long periods of time has on emission reduction systems and gives explanation as to the reason behind the higher levels of emission formations.

Predominate outliers were found in the brake specific carbon monoxide emissions for the various test vehicles. This was especially true in the case of Test Vehicle 1 whose emission distribution is shown below in Figure 4-6. The figure shows a large number of outliers above the upper percentile approaching nearly ten times the magnitude of $\mathrm{CO}$ levels that would be expected of a DOC equipped vehicle under normal operation.

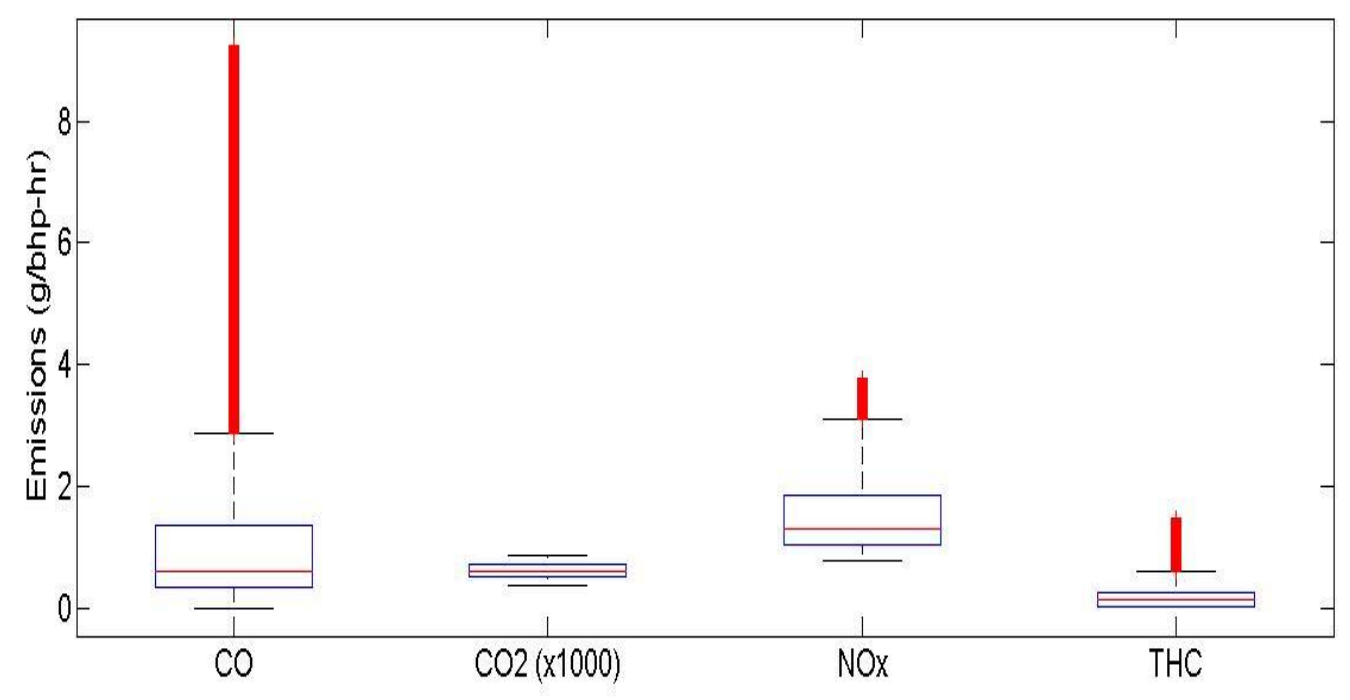

Figure 4-6: Test Vehicle 1 Work-Window Emission Distribution

Figure 4-7 is a graph of the brake specific $\mathrm{CO}$ values versus the corresponding work-window. The figure shows a dramatic spike in bsCO near the end of the test day. When compared to other 
constituents, during this same time a similar spike is present in the bsTHC results as is a reduction in $\mathrm{bsCO}_{2}$ leading to the belief that the DOC is not operating efficiently during this period. Since DOC efficiency is highly dependent on the temperature of the catalyst media, exhaust temperature during this period was investigated and it was found that the exhaust had cooled down below $300^{\circ} \mathrm{F}$ for approximately one hour. This is shown in Figure 4-8 from approximately 20000 seconds until 24000 seconds. Also visible in Figure 4-8 are points located every 3600 seconds where the temperature reading falls to zero. This is caused by the OBS creating new data files on any hourly basis. At this time the OBS rezeroes the analyzers and saves the data from the previous hour and begins recording in a new file. When the data from the entire day is compiled trends such as this can be seen in many of the data channels and do not affect the results of the end data. It should be noted that long idle duration that is atypical of normal engine operation may need to be bounded using specific criteria to avoid erroneously high brake specific values because of potential measurement errors at low power operation.

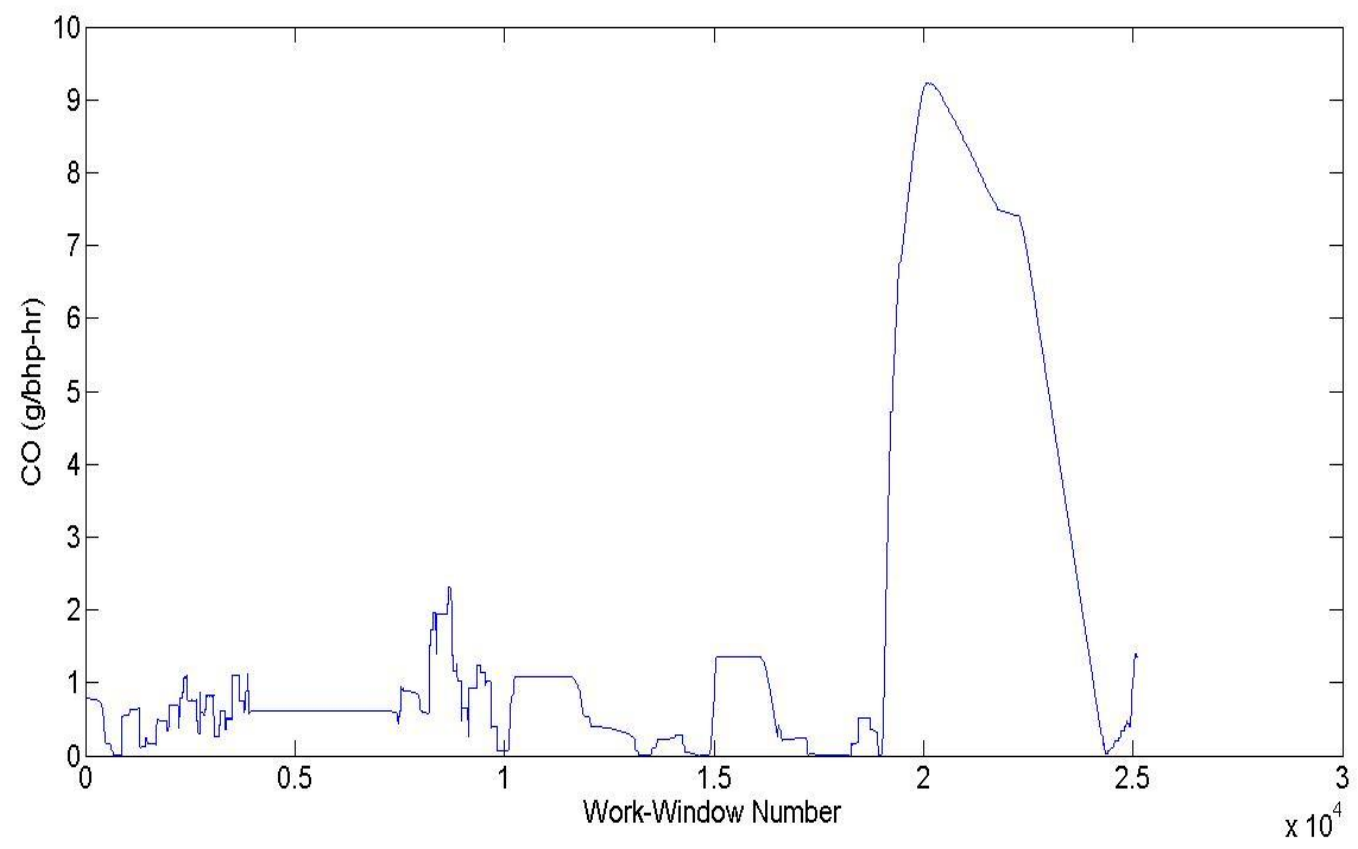


Figure 4-7: Test Vehicle 1 Work-Window bsCO

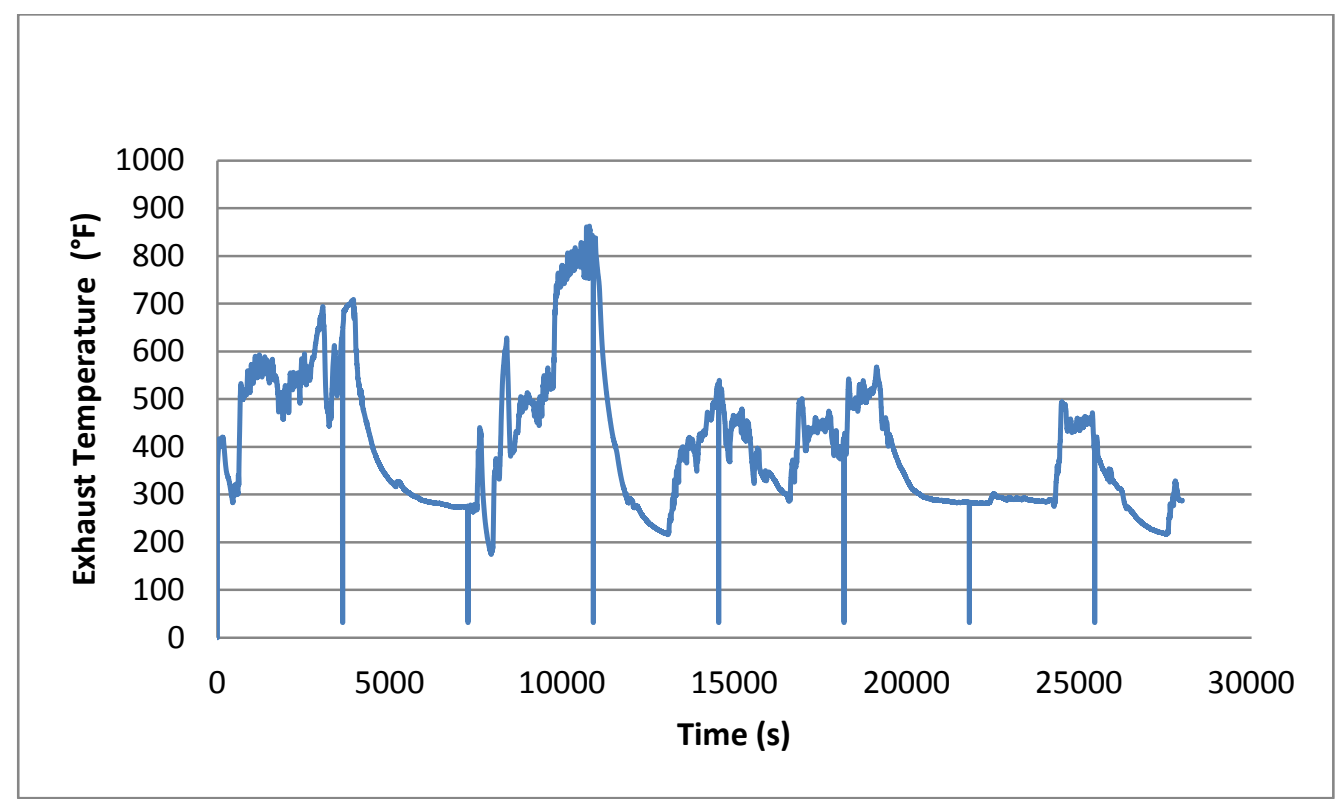

Figure 4-8: Test Vehicle 1 Exhaust Temperature

Another possible effect of long periods of idle can be seen on the brake specific NOx emissions results such as with Test Vehicle 6. It can be seen in Figure 4-9 that the major spike in NOx emissions directly corresponds to a period of extended idle. During this period the vehicle was at idle for just over 1 hour from time 11000-15000 seconds. The high levels of NOx emissions are verified by Figure 4-10 which shows the real-time NOx concentrations in ppm throughout the test day. Initially it would be expected to obtain lower NOx emissions at idle due to the lower in-cylinder temperatures which inhibit NOx formation; however, possible changes in engine control strategy at idle could lead to an increase in NOx levels instead. 


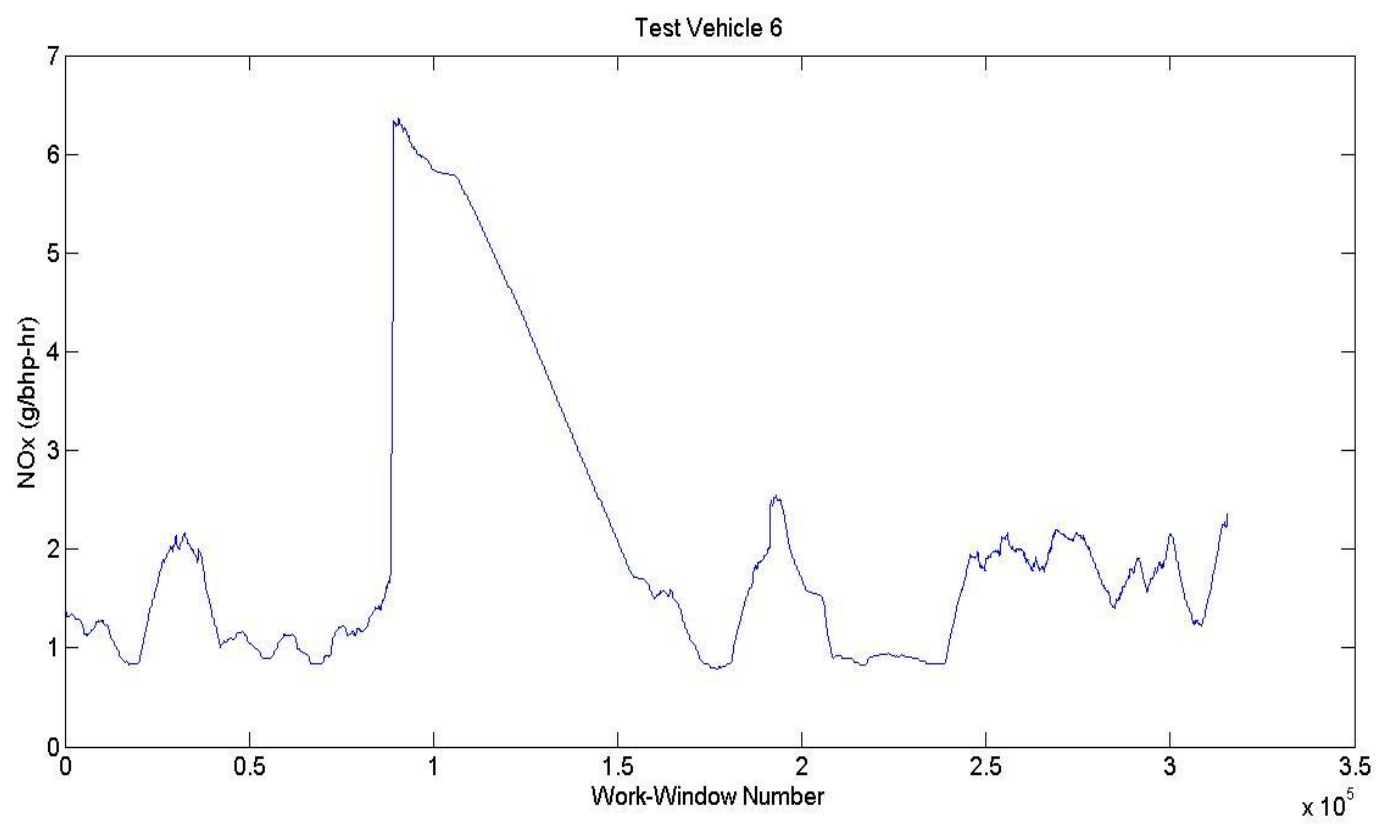

Figure 4-9: Test Vehicle 6 Work-Window bsNOx

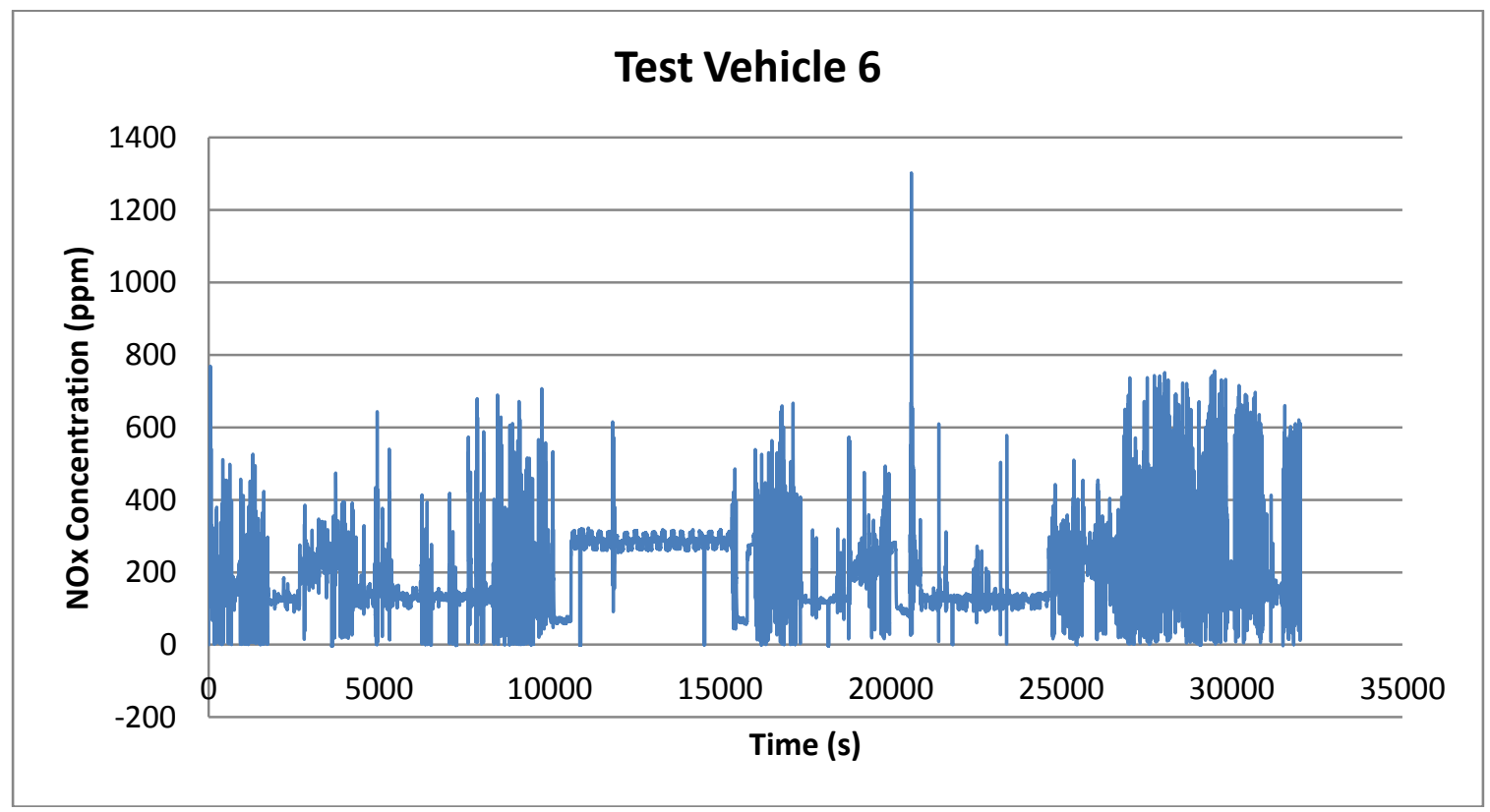

Figure 4-10: Test Vehicle 6 NOx Concentration

To find the root of this phenomenon, the characteristics of the emission reduction system which was intended to reduce NOx, known as exhaust gas recirculation (EGR), were explored. By 
examining the operating temperature of the EGR system during this period this theory is encouraged. During this time the intake EGR temperature remains constant at $100^{\circ} \mathrm{F}$ which was comparative to the outside ambient temperature. Also during this time, NOx concentration at idle increased, exhaust flow increased, and $\mathrm{CO}_{2}$ concentration decreased while power produced remained constant. This would lead to the inference that EGR was deactivated during periods of extended idle.

These effects of high idle on brake specific emissions are not present in the NTE emission data as that region of engine operation is not included in the NTE zone. However, HDDEs do operate, sometimes for long periods, in this region and this is where the work-window analyzes the full range of engine operation where the NTE method does not. This can be remedied by placing standards on the work-windows which would separate these periods of long idle into a category aside from medium and heavy engine operation. This could include categorizing the work-windows by window duration where emission limits could vary based on each category. One method to exclude long idle duration or low power operation is to limit the integration window to a finite time period. For instance, a maximum integration time window of 20 minutes could be used for the FTP cycle since this is the duration of the FTP.

The average results from the work-window method can be seen below in Table 4-3. Two rows of data are present for Test Vehicles 1, 6, and 7 because of technical difficulties with the TRPM system which required PM to be retested on a separate test day. It shows that with the exception of Test Vehicle 1 and Test Vehicle 4 the bsCO levels are within the reported levels outlined in Table 3-3. The high levels of bsCO for Test Vehicle 1 are subject to the large number of outliers 
in the window results and the high levels of all gaseous emissions from Test Vehicle 4 are due to the abnormally long periods of idle seen during the test. Brake specific $\mathrm{CO}_{2}$ values appear to be normal based on reported levels with slightly high values for Test Vehicles 5, 6, and 7. In comparison to the reported levels, Engines A and B produced consistently higher levels of NOx than the reported levels. For most of the test vehicles, bsTHC and bsPM were within acceptable limits of reported levels.

Table 4-3: Brake Specific Work-Window Results

\begin{tabular}{|l|c|c|c|c|c|c|c|}
\hline & & & \multicolumn{5}{|c|}{ Average (g/bhp-hr) } \\
\hline Test Vehicle & Work-Windows & Avg. Duration (s) & bsCO & bsCO2 & bsNOx & bsTHC & bsPM \\
\hline 1 (Gaseous) & 25117 & 1377 & 1.79 & 598.03 & 1.54 & 0.30 & \\
\hline 1 (PM) & 19383 & 1169 & & & & & 0.0002 \\
\hline 2 & 16807 & 1007 & 0.24 & 631.62 & 1.77 & 0.09 & 0.0086 \\
\hline 3 & 18747 & 914 & 0.52 & 613.95 & 1.13 & 0.01 & 0.0019 \\
\hline 4 & 32337 & 13164 & 4.99 & 1104.19 & 10.33 & 2.05 & 0.0003 \\
\hline 5 & 49935 & 3874 & 0.88 & 734.79 & 3.54 & 0.34 & 0.0026 \\
\hline 6 (Gaseous) & 31606 & 1545 & 0.53 & 615.66 & 1.88 & 0.03 & \\
\hline 6 (PM) & 15360 & 609 & & & & & 0.0409 \\
\hline 7 (Gaseous) & 39578 & 611 & 0.25 & 601.51 & 1.08 & 0.01 & \\
\hline 7 (PM) & 30213 & 776 & & & & & 0.0037 \\
\hline
\end{tabular}

\subsection{Not-To-Exceed Results}

The same approach for analyzing the NTE data was used as with the work-window data. Box and whisker plots were used to show the distribution of the emissions data during NTE events for each test vehicle. The NTE method utilized fewer events than the work-window method and therefore can be expected to contain fewer outliers. This can be seen in Figure 4-11 which shows the distribution of NTE event results for Test Vehicle 7. The outliers in this figure are fewer and more identifiable. An advantage of the NTE method is that this method is not 
susceptible to having the emissions data skewed by periods of long idle or engine control events that may occur in areas of low engine speed and torque. At the same time however, this could be viewed as a disadvantage of the NTE method as it does not take into account the full range of engine operation as the work-window method does.

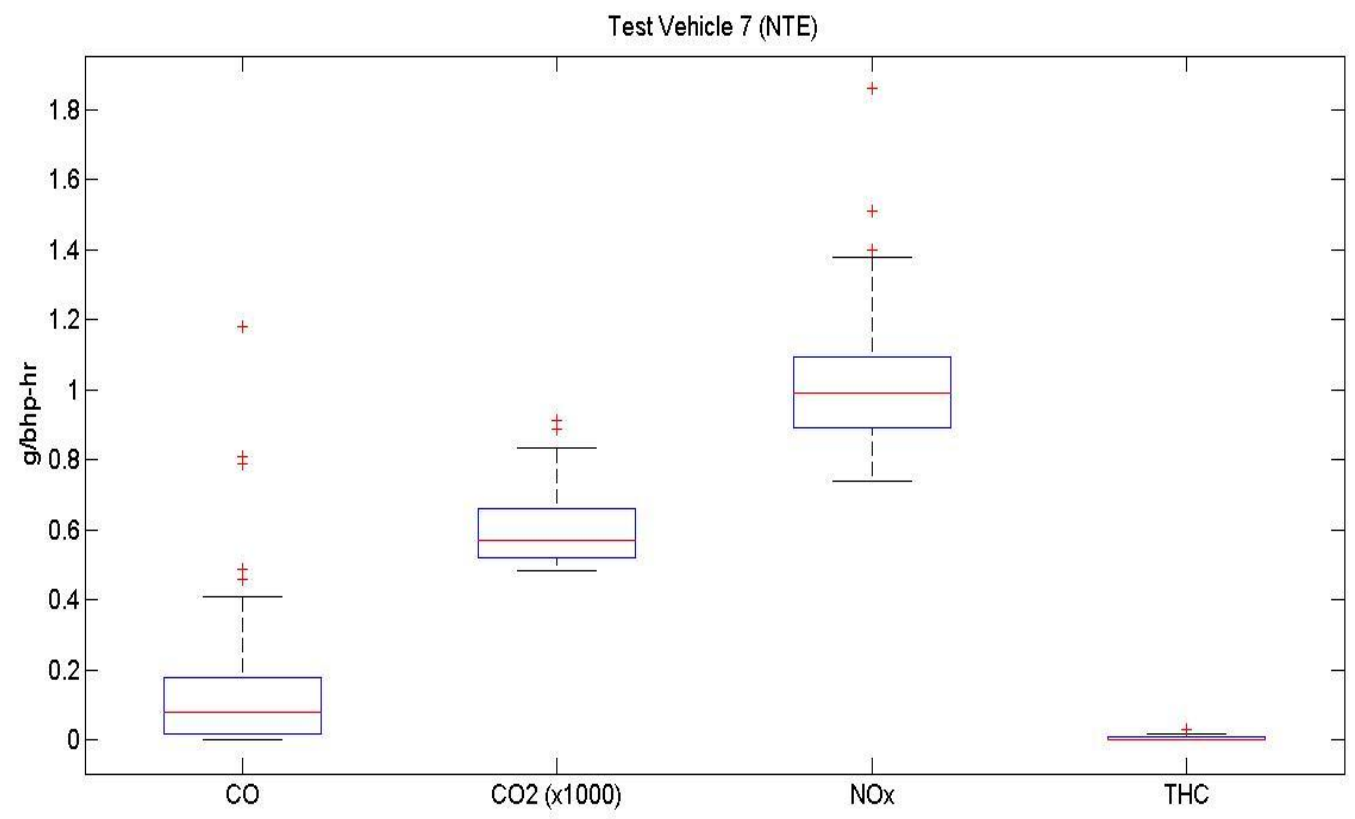

Figure 4-11: Test Vehicle 7 NTE Event Distribution

Table 4-4 gives a summary of the emissions data using the NTE method. When compared to the reported levels contained in Table 3-3 it shows that CO values were all below the $1 \mathrm{~g} / \mathrm{bhp}-\mathrm{hr}$ level for Engines A and B and well below the $2.125 \mathrm{~g} / \mathrm{bhp}-\mathrm{hr}$ level for Engine C. This was attributed to the implementation of Diesel Oxidation Catalysts (DOC) on the test vehicles which was used to oxidize the $\mathrm{CO}$, as well as gaseous phase hydrocarbons, and the solid organic fraction of $\mathrm{PM}$ into $\mathrm{CO}_{2}$ and $\mathrm{H}_{2} \mathrm{O}$. The $\mathrm{CO}_{2}$ emissions are a non-regulated constituent in $\mathrm{HDDE}$ exhaust; however, engine manufacturers may still certify the engine to a certain level of $\mathrm{CO}_{2}$. When compared to Table 3-3, it shows that only Test Vehicle 4 emitted substantially more than 
its reported level. NOx emissions were slightly higher than the reported level for Engines A and B, yet lower for Engine C. The average hydrocarbons and PM emissions were comparable to reported levels for all three engines.

Table 4-4: NTE Event Average Results

\begin{tabular}{|l|c|c|c|c|c|c|c|}
\hline & & \multicolumn{5}{c|}{ Average Brake Specific Emissions } \\
\hline \multicolumn{1}{|c|}{ Vehicle } & NTE Events & $\begin{array}{c}\text { Avg. NTE } \\
\text { Duration (s) }\end{array}$ & bsCO & bsCO2 & bsNOx & bsTHC & bsPM \\
\hline 1 (Gaseous) & 78 & 88 & 0.41 & 627.6 & 1.03 & 0.02 & \\
\hline 1 (PM) & 56 & 125 & & & & & 0.0004 \\
\hline 2 & 74 & 100 & 0.02 & 585.3 & 1.29 & 0.03 & 0.01 \\
\hline 3 & 120 & 79 & 0.19 & 620.4 & 0.99 & 0.01 & 0.00 \\
\hline 4 & 7 & 32 & 0 & 733.6 & 1.54 & 0.03 & 0 \\
\hline 5 & 22 & 68 & 0.09 & 650.0 & 1.35 & 0.01 & 0.00 \\
\hline 6 (Gaseous) & 138 & 86 & 0.21 & 580.4 & 1.05 & 0.01 & \\
\hline 6 (PM) & 68 & 82 & & & & & 0.04 \\
\hline 7 (Gaseous) & 239 & 52 & 0.15 & 594.7 & 1.02 & 0.00 & \\
\hline 7 (PM) & 196 & 95 & & & & & 0.18 \\
\hline
\end{tabular}

\subsection{Work Window-NTE Comparison}

In order to compare the data from the work-window results to the NTE results box and whisker plots were again utilized. In these plots the window results were plotted next to the NTE results of each test vehicle for the varying exhaust constituents in order to give a side-by-side comparison of the results from the two methods. In these plots the upper end of the teal-colored box represents the upper 75th percentile and the bottom of the purple-colored box represents the lower 25th percentile. The line between the two boxes represents the median or 50th percentile value. The whiskers contain the upper and lower 2.5 percent of the data. 
Figure 4-12 shows the comparison between the work-window method and the NTE method for CO. It shows that, on average, the work-window method resulted in higher bsCO results than was found using the NTE method. By looking at the length of the whiskers, it also shows a greater variation in the individual bsCO for each window when compared to the variation in the NTE method. The work-window data for Test Vehicle 4 is an order of magnitude greater than all other bsCO results and when examining the rest of the following comparison plots it can be seen that Test Vehicle 4 is a high emitter for all constituents with the exception of PM. This is attributed to the relatively long period of idle that was experienced by this vehicle during the test. The test day for this vehicle consisted of 1 hour and 20 minute idle period followed by a 20 minute drive at highway speeds to a staging yard where it idled for the remaining 11 hours of the day. During this test day only 7 NTE events were recorded compared to the work-window method which integrated over 30,000 individual windows. Due to the significant differences between the numbers of windows in the two methods, further statistical analysis is warranted but not conducted here. 


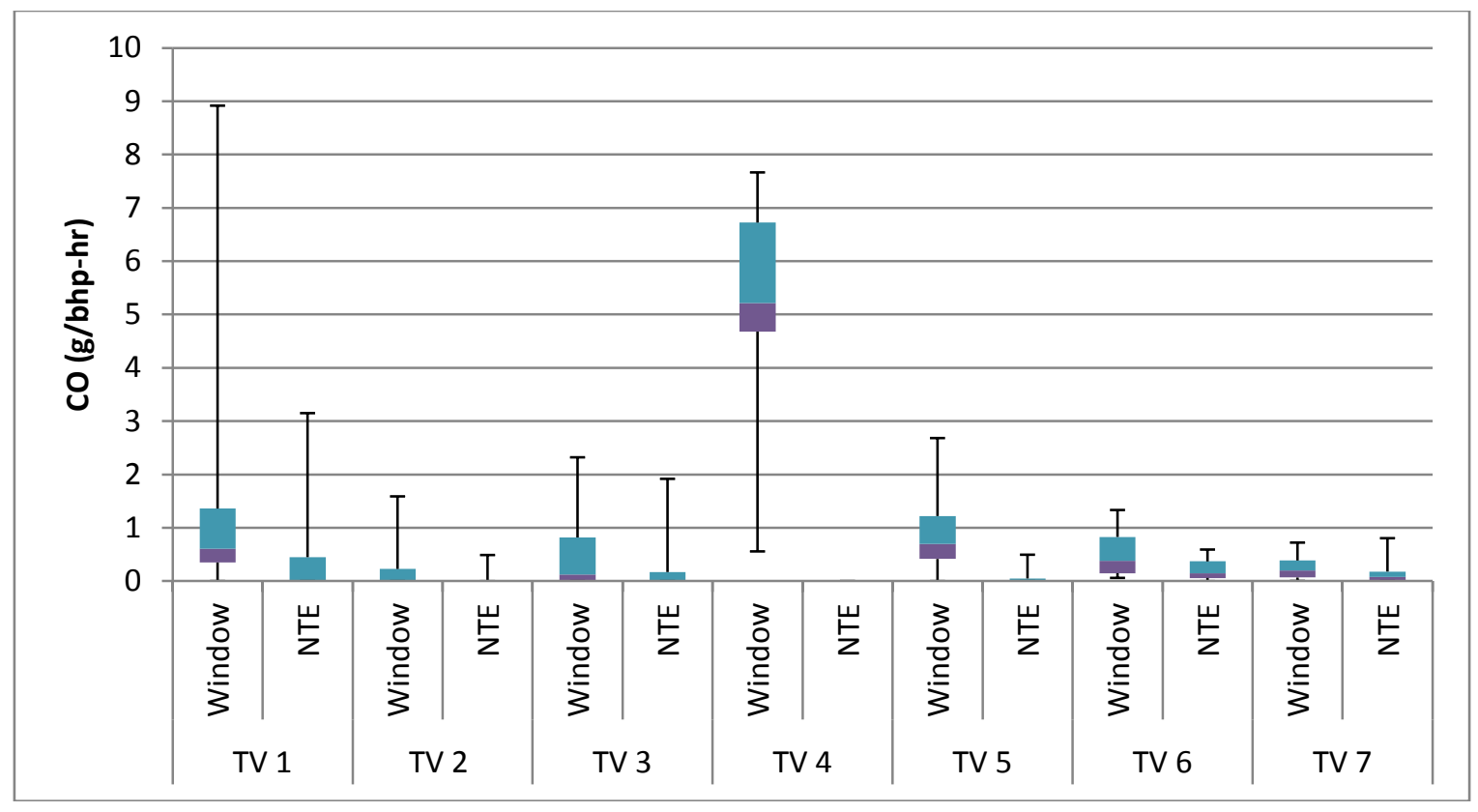

Figure 4-12: CO Comparison of Work-Window to NTE

The variation in brake specific $\mathrm{CO}_{2}$ results between the two methods is shown in Figure 4-13. It shows that the two methods, neglecting Test Vehicle 4, offer a much better comparison. Both methods show an approximate $\mathrm{bsCO}_{2}$ output of $600 \mathrm{~g} / \mathrm{bhp}-\mathrm{hr}$ with similar variation between work-windows and NTE events.

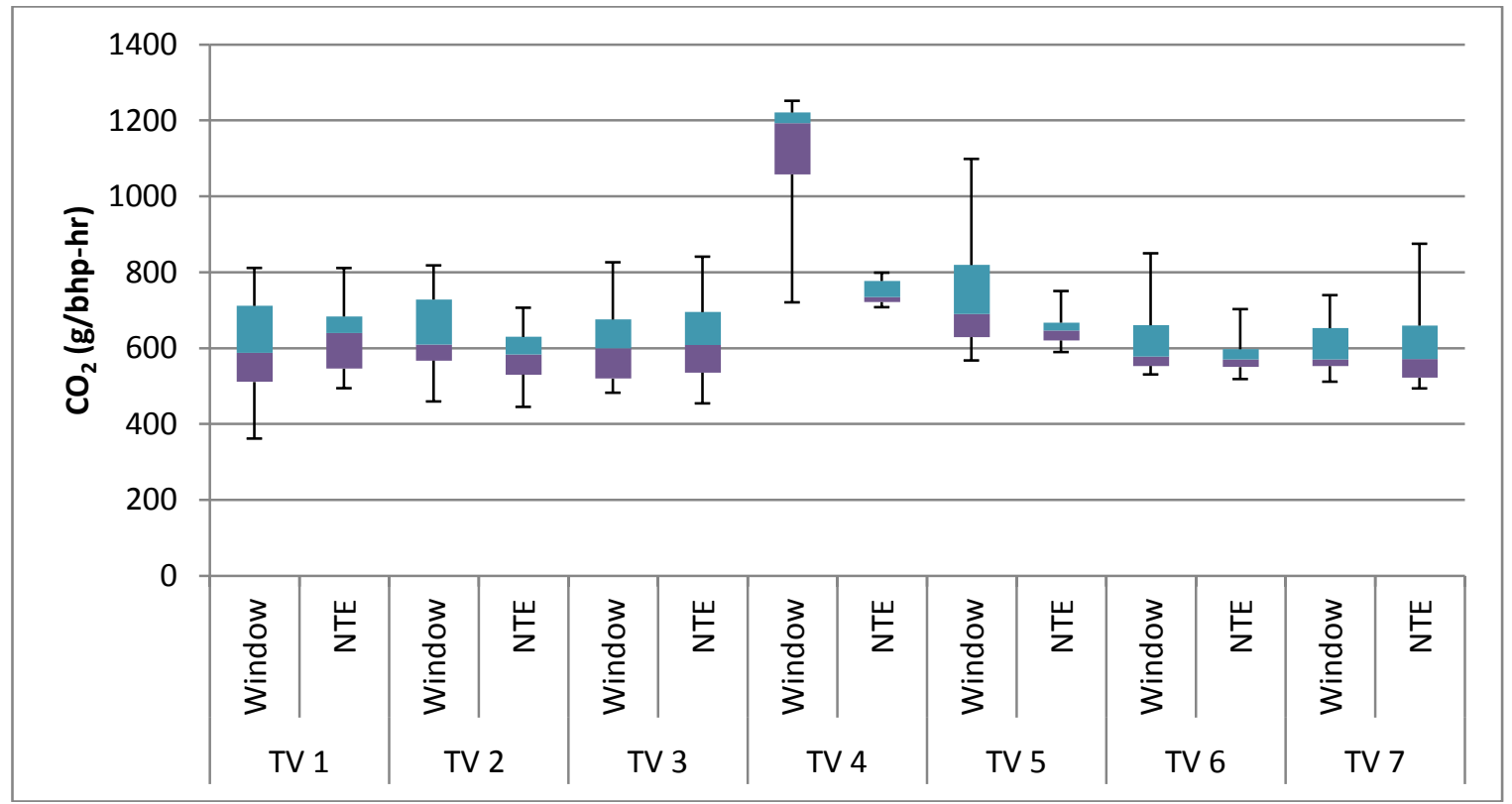

Figure 4-13: CO2 Comparison of Work-Window to NTE 
The comparison between the work-window method's and NTE method's bsNOx results is displayed in Figure 4-14. This figure also shows a good comparison between the two methods with an approximate bsNOx level of $1 \mathrm{~g} / \mathrm{bhp}-\mathrm{hr}$. Test Vehicle 4 again shows higher level of NOx emissions due to the effects of long idle on EGR operation. It also shows an elevated level in bsNOx in the window data for Test Vehicle 5. This vehicle also idled for a relative long period of time during the test day and could be subject to varying EGR operation.

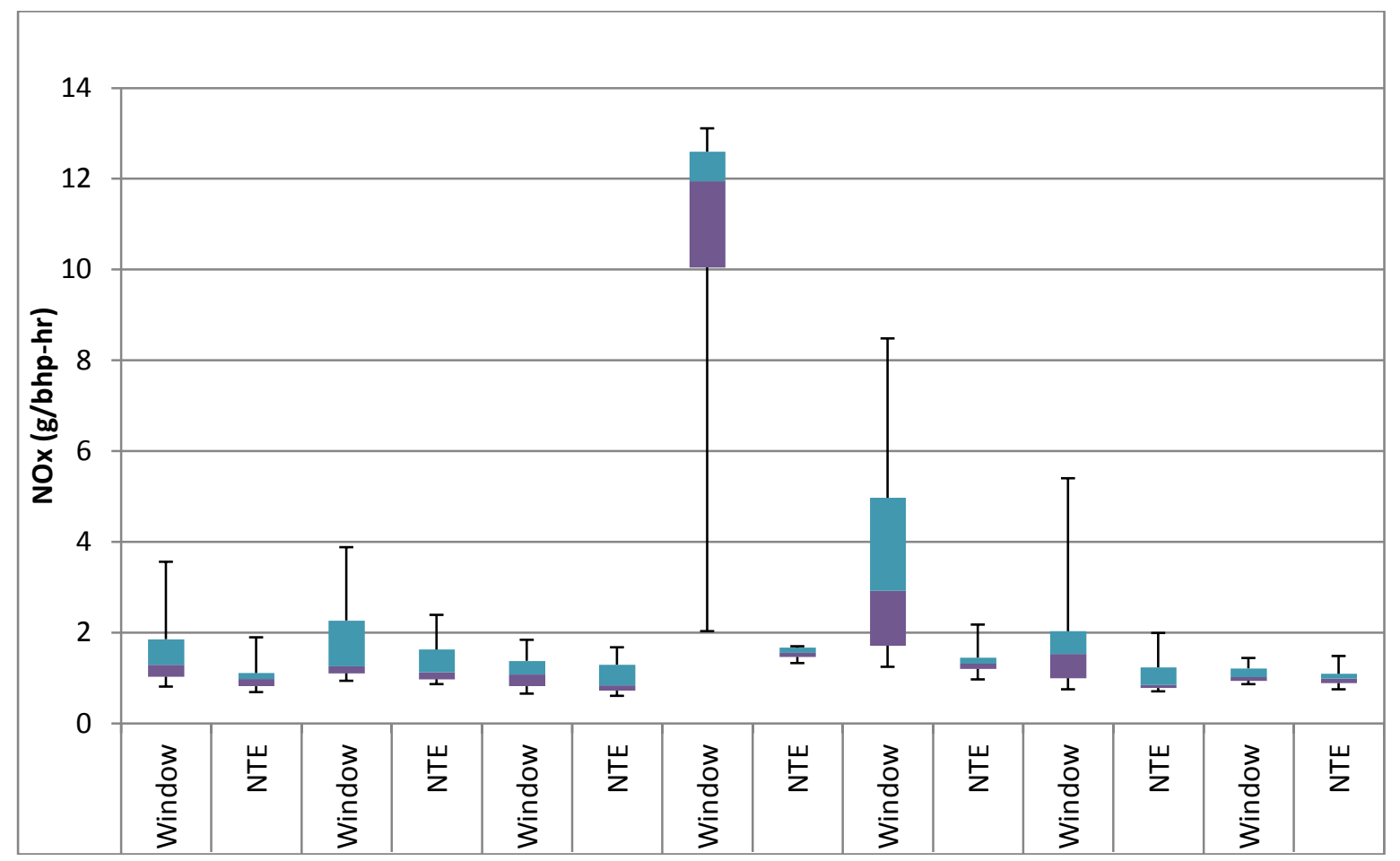

Figure 4-14: NOx Comparion of Work-Window to NTE 
Brake specific THC emissions are shown in Figure 4-15. Test Vehicles 4 and 5 again show high emission levels. Aside from these two vehicles the two methods show good agreement with bsTHC levels being close to zero. These levels are to be expected from DOC equipped vehicles under normal operation.

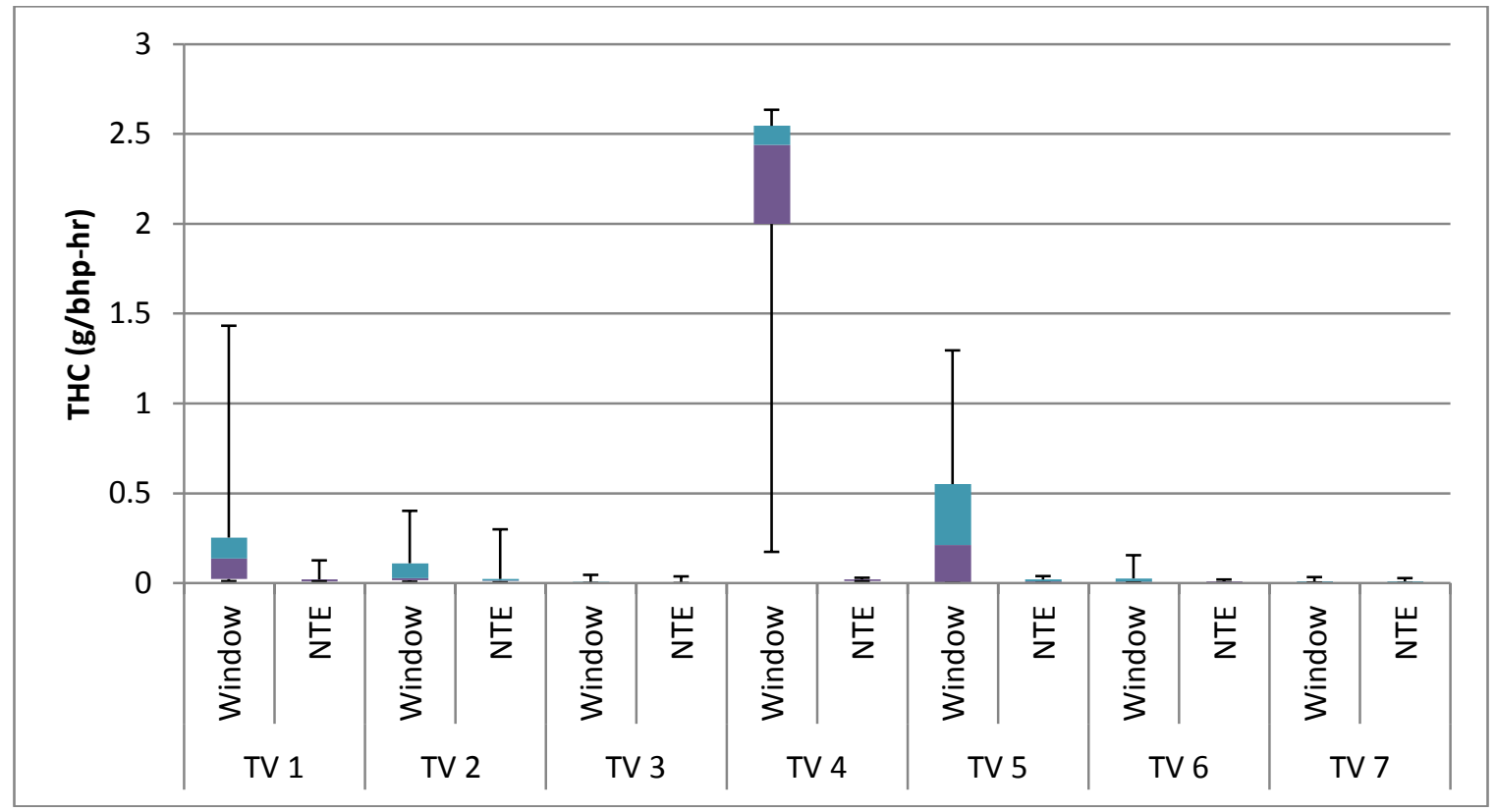

Figure 4-15: THC Comparison of Work-Window to NTE

The brake specific PM results for the work-window and NTE methods are shown below in Figure 4-16. The figure shows a relatively close comparison between the two methods. The average bsPM value for Test Vehicle 7 is shown to be an order of magnitude higher than the rest of the test vehicles. Reviewing specific engine operation data proved inconclusive, however, ambient temperatures were much lower during this test day, average $30^{\circ} \mathrm{F}$, than with the other test vehicles and due to temperature exclusion criteria all NTE events would be excluded for compliance testing. 


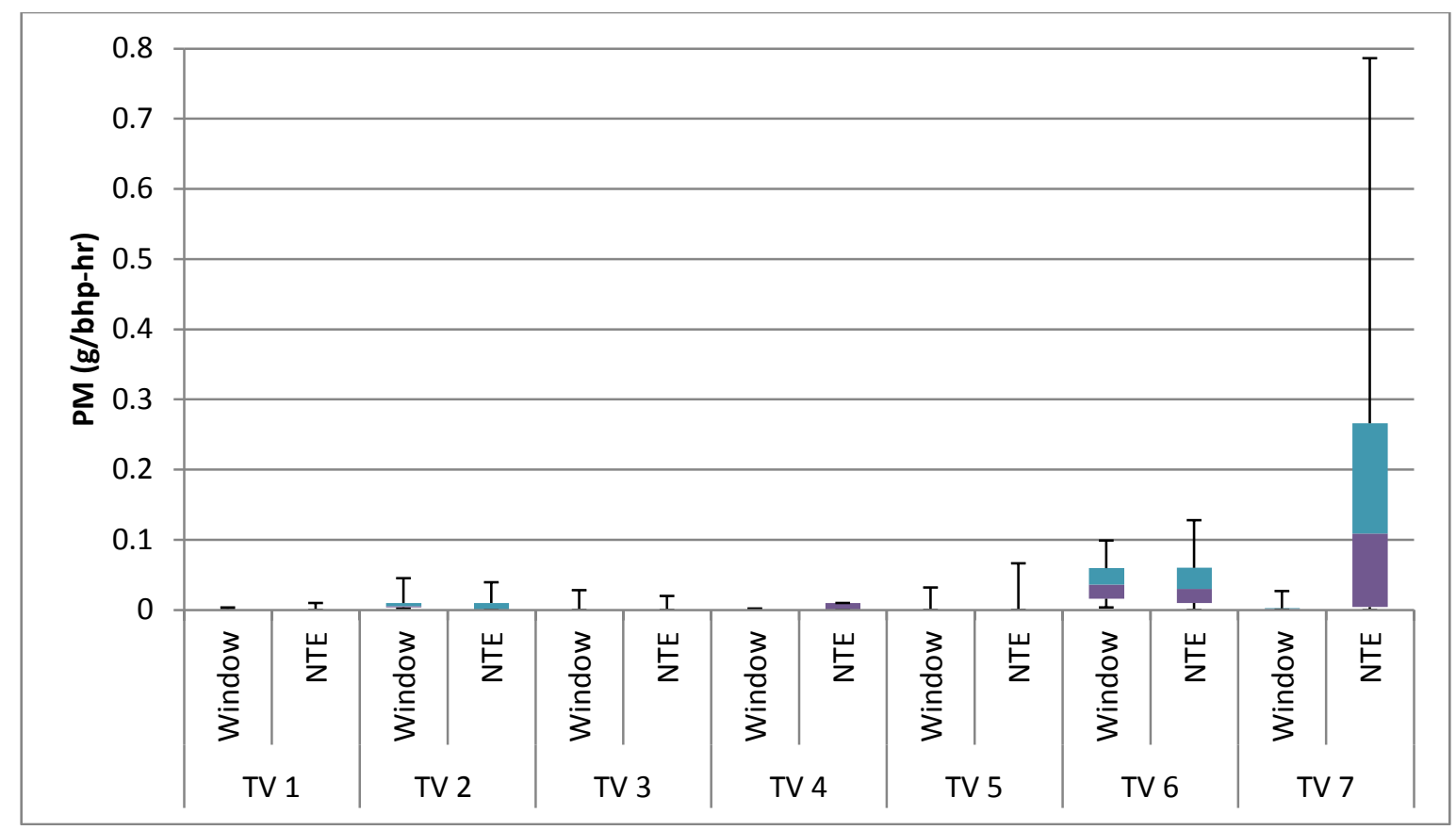

Figure 4-16: PM Comparison of Work-Window to NTE

Table 4-5 below represents the percent difference between the average NTE method and the average work-window method for each vehicle. Note that the average values only provide limited statistical information and that additional information could be obtained using a method such as the Student t-test but the purpose of this analysis was to provide a brief comparison between the two methods. Positive numbers in the table represents a work-window emissions value greater than the NTE method and negative numbers represent work-window emissions values less than the NTE method. It shows that the work-window method consistently calculated higher brake specific emissions than the NTE method. The large percent differences associated with $\mathrm{CO}$, THC, and PM are due to the small concentration of these constituents. On the order of magnitude of these emissions, a small difference in calculated result will lead to a large percent difference. While overall average levels for the work-window method are higher, this method does include the full range of engine operation including periods of idle which have been shown to increase brake specific levels. It should also be noted that while reading higher values with 
the work-based method, the majority of the brake specific emissions still compared to the reported levels for each constituent.

Table 4-5: Percent Difference (\%) Between Work-Window and NTE Results

\begin{tabular}{|c|c|c|c|c|c|}
\hline \multirow{2}{*}{$\begin{array}{c}\text { Test } \\
\text { Vehicle }\end{array}$} & $\mathrm{bsCO}$ & $\mathrm{bsCO}_{2}$ & bsNOx & bsTHC & bsPM \\
\hline & \multicolumn{5}{|c|}{ Percentage Change (\%) } \\
\hline 1 & 125.4 & -4.8 & 39.4 & 170.8 & -41.5 \\
\hline 2 & 163.2 & 7.6 & 30.8 & 92.4 & 31.7 \\
\hline 3 & 93.7 & -1.0 & 13.8 & 31.0 & -65.3 \\
\hline 4 & 200.0 & 40.3 & 148.1 & 194.2 & 200.0 \\
\hline 5 & 164.5 & 12.2 & 89.5 & 188.1 & -18.7 \\
\hline 6 & 87.3 & 5.9 & 57.0 & 116.5 & 5.6 \\
\hline 7 & 49.3 & 1.1 & 6.4 & 69.3 & -191.8 \\
\hline
\end{tabular}

A comparison between the reported levels and the brake specific emissions from each test vehicle is made in the following tables below. As in Table 4-5 above, these positive values in these tables represent values above the FTP certification reported levels and negative values represent values below the FTP certification reported levels. Table 4-6 displays the percent change between the average brake specific emissions from each vehicle and the FTP certification reported levels of the corresponding engine. The table shows that the majority of $\mathrm{CO}, \mathrm{CO}_{2}$, and PM results were below reported levels. It also shows that NOx results were consistently higher with the exception of Test Vehicle 7 and that THC results were distributed above and below reported levels.

Table 4-6: Work-Window Percent Change from the FTP Certification Reported Levels

\begin{tabular}{|c|c|c|c|c|c|}
\hline \multirow{2}{*}{$\begin{array}{c}\text { Test } \\
\text { Vehicle }\end{array}$} & bsCO & bsCO $_{2}$ & bsNOx & bsTHC & bsPM \\
\cline { 2 - 6 } & \multicolumn{5}{|c|}{ Percentage Change (\%) } \\
\hline 1 & 79.1 & -24.1 & 14.2 & 98.9 & -98.4 \\
\hline 2 & -75.5 & -19.8 & 30.8 & -42.6 & -42.9 \\
\hline 3 & -47.7 & -22.0 & -16.2 & -94.5 & -87.0 \\
\hline 4 & 398.9 & 40.2 & 665.4 & 1267.2 & -97.8 \\
\hline 5 & -12.2 & -6.7 & 161.9 & 126.4 & -82.4 \\
\hline 6 & -75.2 & -12.4 & 8.0 & -83.9 & 172.7 \\
\hline 7 & -88.4 & -14.4 & -37.8 & -95.7 & -75.1 \\
\hline
\end{tabular}


Table 4-7 shows a similar comparison between the NTE method results and the FTP certification reported levels. This method shows consistently lower values than the FTP certification reported levels. The only exceptions that can be found are with the NOx results for Test Vehicle 4 and with the PM results for Test Vehicles 6 and 7.

Table 4-7: NTE Percent Change from the FTP Certification Reported Levels

\begin{tabular}{|c|c|c|c|c|c|}
\hline \multirow{2}{*}{$\begin{array}{c}\text { Test } \\
\text { Vehicle }\end{array}$} & bsCO & bsCO $_{2}$ & bsNOx & bsTHC & bsPM \\
\cline { 2 - 6 } & \multicolumn{5}{|c|}{ Percentage Change (\%) } \\
\hline 1 & -58.9 & -20.3 & -23.4 & -84.4 & -97.6 \\
\hline 2 & -97.5 & -25.7 & -4.1 & -78.9 & -58.6 \\
\hline 3 & -81.1 & -21.2 & -27.0 & -96.0 & -74.4 \\
\hline 4 & -100.0 & -6.8 & 14.1 & -80.0 & -100.0 \\
\hline 5 & -91.5 & -17.5 & 0.0 & -93.0 & -78.8 \\
\hline 6 & -90.3 & -17.4 & -39.9 & -95.8 & 157.8 \\
\hline 7 & -93.0 & -15.3 & -41.6 & -97.9 & 1093.3 \\
\hline
\end{tabular}




\section{Conclusions and Recommendations}

\subsection{Conclusions}

After the implementation of the Consent Decrees which established the in-use testing program, the NTE method was set as the standard method for reporting in-use emissions from on-highway HDDEs in the United States. While this method is accepted to provide a reasonable representation of emission characteristics of engine during actual operation it is not without limitations. The NTE method uses a region of the engine map that excludes any operation under $30 \%$ rated power and torque as well as under certain speeds. This excludes any low speed, low load operation the engine may experience. While HDDEs may not be designed for extended operation in these ranges they do operate there and the emissions that are produced outside the NTE region are neglected with this method. Another limitation of the NTE method is the minimum 30 second time limit requirement imposed on engine operation to be in the NTE region to count as an NTE event. This requirement can reduce the amount of valid NTE data as the engine must be operating in this region continuously for a minimum of 30 seconds. This means that if the driver changes gears or reduces throttle position even momentarily then the previous 29 seconds of engine operation will not be analyzed by this method. A proposed alternative to the NTE method is a method based on the work produced by an engine without the 30 second time constraint on operation. This method creates a continuously moving integration window based on work done by the engine. Power produced by the engine is integrated over the frequency of the data sample rate until a target work done by the engine is accomplished. A benefit of basing in-use emisisons on a work basis is that the target work can be set to a value 
equal to that of test cycle's work value used in dynamometer certification tests. Specifically, a closer correlation between test cell results and in-use results may be obtained if the work done by an engine over the FTP cycle used for certification in a test cell is used as the target work. Another benefit of the work-window method is that this method fully encompasses all regions of engine operation. Since the work done during each window is the same, the only variable is the amount of time that it takes to achieve this work. This duration of the work window is dependent on the type of engine operation occurring during the window. An in-use engine at idle for long periods of time will still theoretically produce enough work through powering auxiliary accessories to eventually reach the target work. This allows the work-window method to give a representation of the type of engine operation that is occurring, something that is not possible with the NTE method. However, while it is beneficial to measure the complete range of engine operation, this can also be a disadvantage when calculating the actual brake-specific emissions. As shown by the data, long periods of idle operation can skew brake specific emission measurements. This is due to the limitations of the emission reduction systems or engine control strategy while the engine is operating at low power and low exhaust temperatures for long periods of time, as well as the possibly inaccuracies in power measurement due to resolution at low power.

Therefore, it was determined that with modifications the work-based window method could prove to be a viable alternative to the currently employed NTE method for reporting in-use emissions. It was found that because the work-window method incorporates operation at low power, that inaccuracies in power measurement can skew the brake specific calculations causing higher final results than the NTE method. Even by excluding certain windows containing 
extended idle, the work-window method still encompasses a more in depth collection of engine operation points by eliminating the 30 second time criteria that is in place with the NTE method.

\subsection{Recommendations}

It is recognized that both methods for analyzing in-use emissions have advantages and disadvantages. The NTE method is beneficial in that it is unaffected by engine operation at low speed, low torque regions where ECM-reported torque reporting may be inaccurate. However, when measuring the real world emissions production of HDDEs is the initiative; then the full range of engine operation should be analyzed. This is where the work-window method is advantageous. This method allows for the full range of operation to be measured and recorded. It can also closely simulate the work done during certification test cycles such as the FTP by using this value as the target work value for the windows. The disadvantage to the work-window is that it is subject to the low engine speed, low torque characteristics of engine operation which have been shown to produce larger brake specific emission concentrations. In order to make the work-window method a viable option for measuring in-use emissions simple additional parameters would have to be incorporated into the analysis procedure. By grouping the workwindows on the basis of duration and weighting these windows accordingly is one option. It was found that windows of a greater duration are typically windows with long periods of idle as it takes more time steps to integrate the target work. By grouping these windows separate from shorter windows consisting of higher load operation it would be possible to not exclude, but to perhaps permit higher levels of acceptable emission production. The windows could also be limited on duration based on the certification test duration. In the case of the FTP cycle, the work-window would be limited to 20 minutes maximum duration. This case was investigated 
using the data from Test Vehicle 1. It was found that by eliminating windows longer than 20 minutes, this resulted in a $66 \%$ reduction in $\mathrm{CO}$, a $28 \%$ reduction in NOx, and a $78 \%$ reduction in THC. Doing this also resulted in a percent increase of $\mathrm{CO}_{2}$ by $4 \%$ and $\mathrm{PM}$ by $40 \%$. However, the average values for these constituents still retained a percent change below reported levels of $21 \%$ and $98 \%$, respectively. The influence of extended idle duration could be evaluated by examining the modal data from the SET. The idle data from the SET could be compared to the idle data of the in-use test on a mass rate basis. This approach would eliminate the inaccuracies associated with reporting low torque or power from the ECM. An allowable error would need to be defined, but it is estimated that a 1.5 time the SET value may account for measurement errors and actual engine operation.

Another possibility would be to base acceptable brake specific work-window emission on test vehicle vocation. This option would permit vehicles whose vocation requires large amount of idle during day to day operation to produce higher levels of emissions. An example of this could be the aerial bucket trucks, Test Vehicle 4 and Test Vehicle 5, which use the power take-off (PTO) to power hydraulics while the bucket is being used by the operator.

By grouping these work-windows based on either duration or vehicle vocation allows for a complete measurement of engine operation and analysis of emissions over this entire range. Instead of excluding data from certain areas of operation the data can be analyzed and weighted accordingly. Further research in the effects of long periods of idle on the work-window method and an effective means of categorizing based on duration or vocation is recommended to perfect this method for in-use measurement of heavy-duty diesel engines. 


\section{References}

1. “United States v. Caterpillar, Inc.” Civil Action 98-02544. United States District Court for the District of Columbia. July 1, 1999.

2. “United States v. Cummins Engine Company, Inc." Civil Action. United States District Court for the District of Columbia. July 1, 1999.

3. "United States v. Detroit Diesel Corporation." Civil Action. United States District Court for the District of Columbia. July 1, 1999.

4. “United States v. Renault Vehicles Industries." Civil Action 98-02543. United States

District Court for the District of Columbia. July 1, 1999.

5. "United States v. Navistar International Transportation Corp." Civil Action. United States District Court for the District of Columbia. July 1, 1999.

6. “United States v. Volvo Truck Corporation." Civil Action 98-02547. United States District Court for the District of Columbia. July 1, 1999.

7. "CFR 40 Subpart N: Protection of the Environment: Emission Regulations for New OttoCycle and Diesel Heavy-Duty Engine; Gaseous and Particulate Exhaust Test Procedures." Office of the Federal Register National Archives and Records Administration. 2000.

8. “NTE (Not-To-Exceed Testing.” DieselNet. August 2011. August 29, 2011. <http://www.dieselnet.com/standards/cycles/nte.php>

9. Shade, B., Carder, D., Thompson, G., Gautam, M. "A Work-Based Window Method for Calculating In-Use Brake-Specific NOx Emissions of Heavy-Duty Diesel Engines." SAE Technical Paper No. 2008-01-1301. SAE International. Warrendale, PA. 2008.

10. "U.S. Automobile and Truck Fleets by Use." Research and Innovative Technology Administrations. August 30, 2011.

<http://www.bts.gov/publications/national_transportation_statistics/html/table_01_14.html>

11. "U.S. Ton-Miles of Freight." Research and Innovative Technology Administrations. August 30, 2011.

<http://www.bts.gov/publications/national_transportation_statistics/html/table_01_49.html>

12. "Emission Standards Reference Guide." U.S. Environmental Protection Agency. 2011. November 14, 2011. < http://www.epa.gov/otaq/standards/heavy-duty/hdci-exhaust.htm>

13. "Auto Emission Testing and Standards." Dictionary of American History. 2003. Encyclopedia.com. August 9, $2011<\mathrm{http}$ ://www.encyclopedia.com>.

14. "History of the Clean Air Act." U.S. Environmental Protection Agency. 2010. August 9, 2011. <http://epa.gov/oar/caa/caa_history.html>

15. "Clean Air Act Diesel Engine Cases." United States Department of Justice. November 2010. August 9, 2011. <http://www.justice.gov/enrd/4460.htm>

16. "What is a Dynamometer." Tech-FAQ. August 10, 2011. < http://www.techfaq.com/dynamometer.html>

17. Bougher, T., Khalek, I., Trevitz, S., Akard, M., "Verification of a Gaseous Portable Emissions Measurement System with a Laboratory System Using the Code of Federal Regulations Part 1065” SAE Technical Paper No. 2010-01-1069, 2010.

18. "Heavy Duty Transient FTP Cycle.” DieselNet. 1999. August 10, 2011. $<$ http://www.dieselnet.com/standards/cycles/ftp_trans.html>

19. "Heavy Duty Supplemental Emissions Test (SET)" DieselNet. 2010. September 3, 2011. $<$ http://www.dieselnet.com/standards/cycles/set.php> 
20. “CFR $40 \S 86.1370-2007$ Not-To-Exceed Test Procedures.” Office of the Federal Register National Archives and Records Administration. 2000.

21. "Horiba OBS-2200." Horiba Automotive Test Systems. 2011. October 24, 2011. $<$ http://www.horiba.com/us/en/automotive-test-systems/products/emission-measurementsystems/on-board-systems/details/obs-2000-877/>

22. "SEMTECH-DS." Sensors Inc. 2011. September 7, 2011. <http://www.sensorsinc.com/ds.html>

23. “AVL M.O.V.E. Gas PEMS.” AVL. 2011. October 24, 2011.< https://www.avl.com/gaspems>

24. Gautam, M., Thompson, G., Carder, D., Clark, N., Shade, B., Riddle, W., Lyons, D. "Measurement of In-Use, On-Board Emissions from Heavy-Duty Diesel Vehicles: Mobile Emissions Measurement System.” SAE Technical Paper No. 2001-01-3643. SAE International. Warrendale, PA. 2001.

25. "New on-board emission measuring system from Sensor's Inc.” DieselNet. July 29, 2002. August 31, 2011. <http://www.dieselnet.com/news/2002/07sensors.php>

26. Feist, M., Sharp, C., Spears, M. "Determination of PEMS Measurement Allowances for Gaseous Emissions Regulated Under the Heavy-Duty Diesel Engine In-Use Testing Program: Part 1-Project Overview and PEMS Evaluation Procedures.” SAE Technical Paper No. 2009-01-0940. SAE International. Warrendale, PA. 2009.

27. "On Board Emission Measurement System OBS-2200 Instruction Manual.” Horiba Instruments, Ltd. (C) 2005-2009

28. "Horiba OBS-TRPM: Operation Manual Version 1.1." Horiba Instruments, Inc. March 2008

29. Wei, Q., Akard, M., Porter, S., Nakamura, H. “The Development of an On-Board Instrument for On-Road Diesel Particulate Measurement." SAE Technical Paper No. 200836-0273. SAE International. Warrendale, PA. 2008.

30. Booker, D. R., Giannelli, R. A., Hu, J. "Road Test of an On-Board Particulate Matter Mass Measurement System.” SAE Technical Paper No. 2007-01-1116. SAE International. Warrendale, PA. 2007.

31. “SEMTECH PPMD.” Sensors Inc. 2011. September 7, 2011. <http://www.sensorsinc.com/ppmd.html>

32. Weiss, M., Bonnel, P., Hummel, R., Manfredi, U., Colombo, R., Lanappe, G., Lijour, P., Sculati, M. "Analyzing On-Road Emissions of Light-Duty Vehicles with Portable Emissions Measurement Systems.” JRC Scientific and Technical Reports EUR 24697 EN. JRC-IE. Ispra, Italy. 2011. 
7. Appendix A- Matlab Program to Determine FTP Theoretical Work 


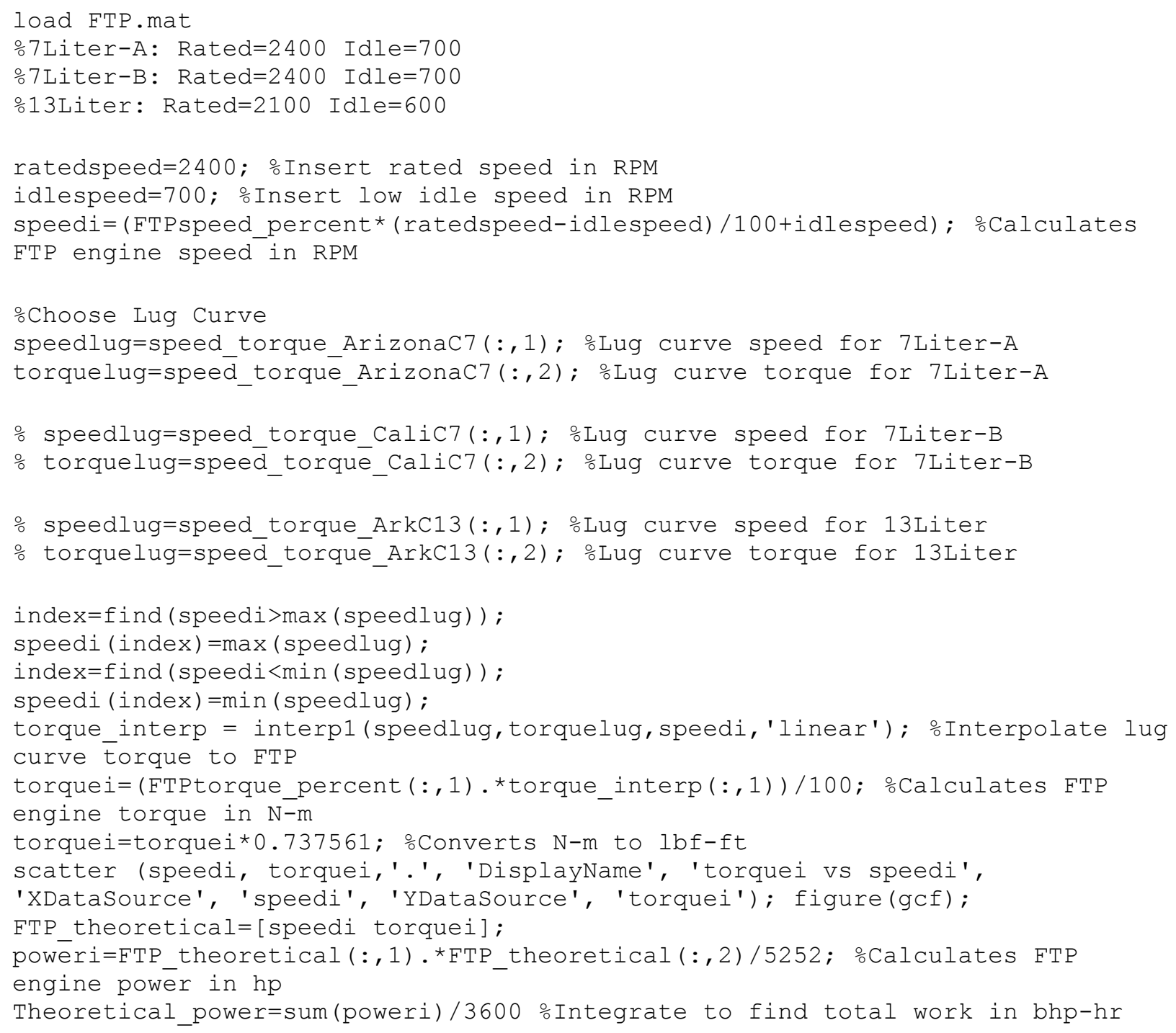


8. Appendix B-Matlab Program to Generate Work-Windows 


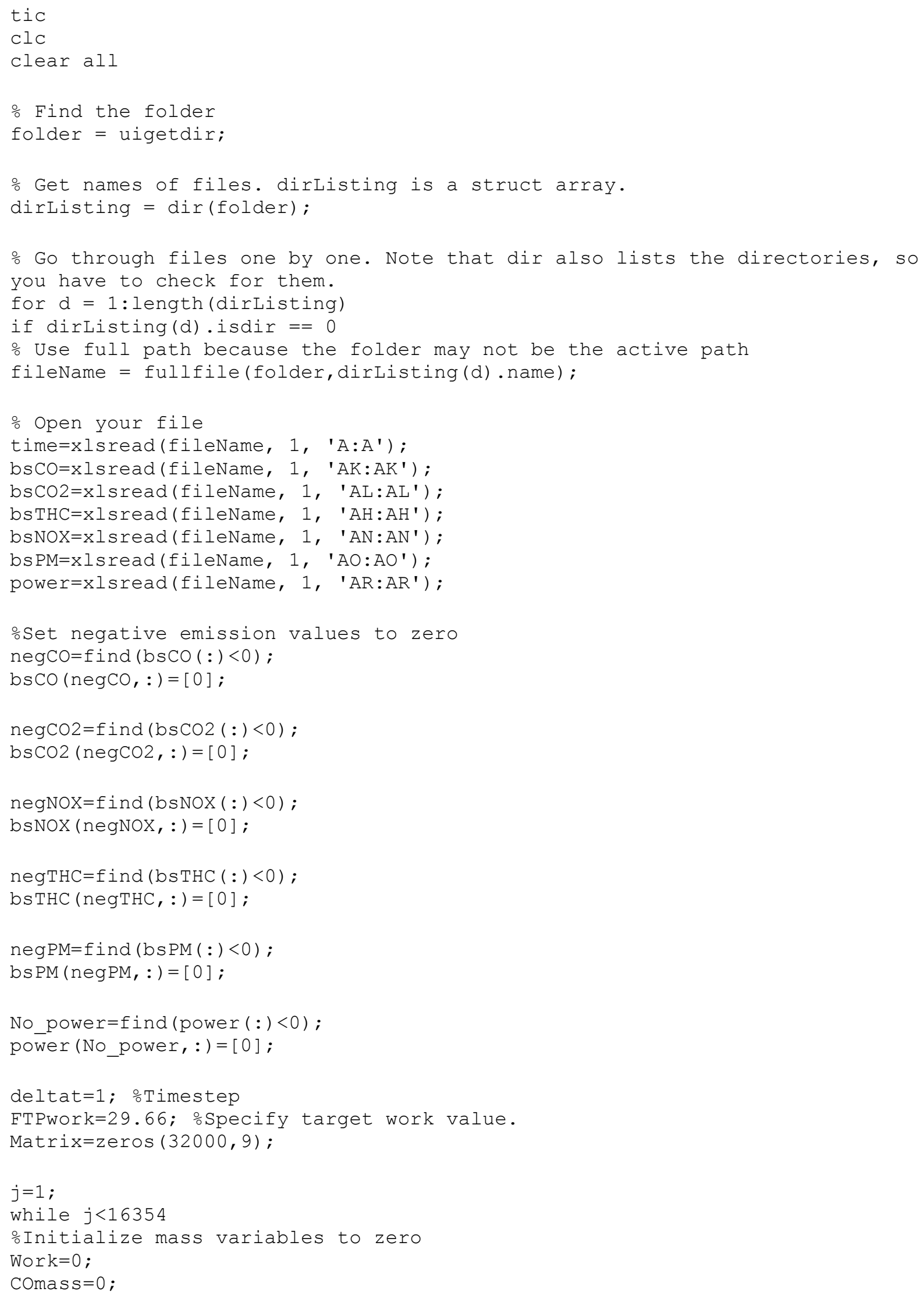




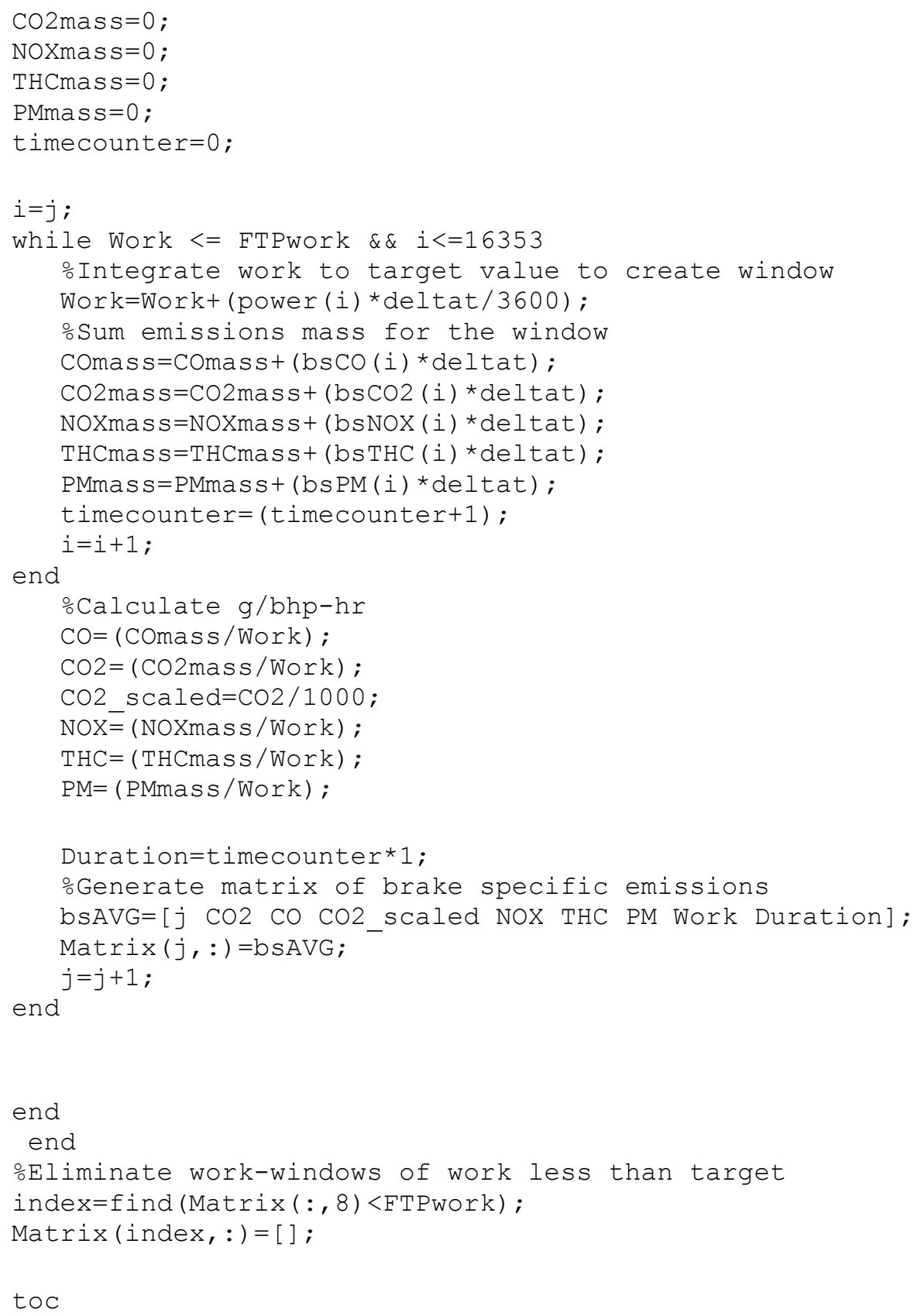




\section{Appendix C-Work-Window Plots and Graphs}

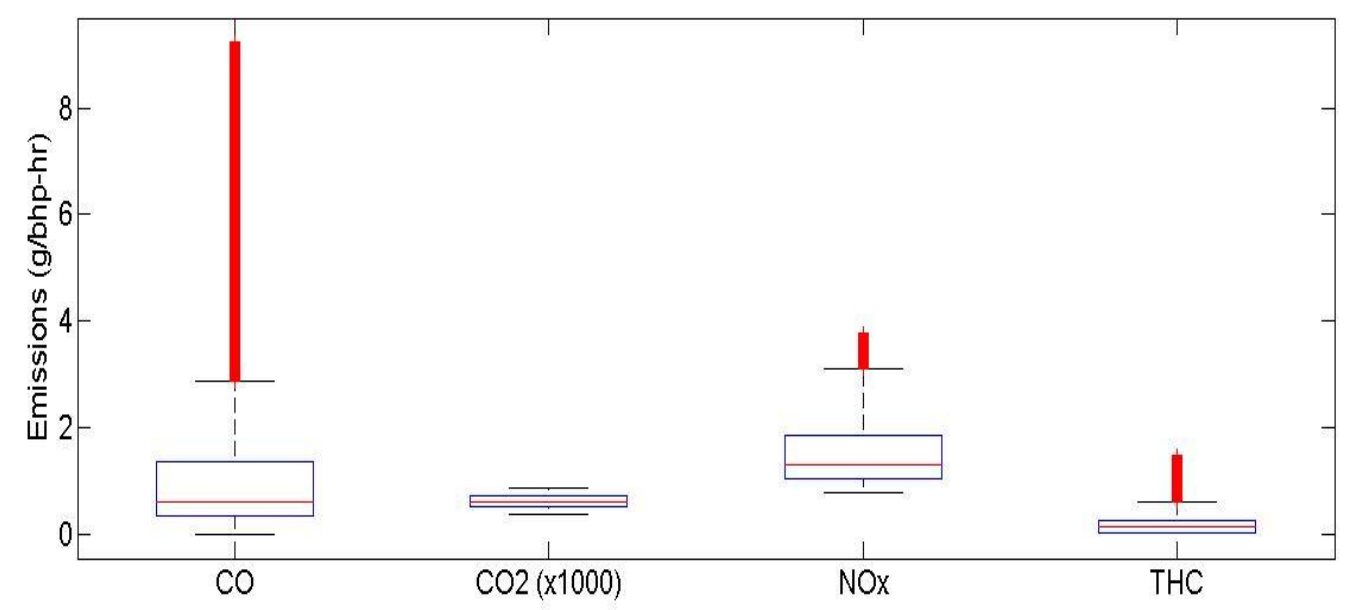

Figure 9-1: Work-Window Gaseous Emission Distribution for TV 1

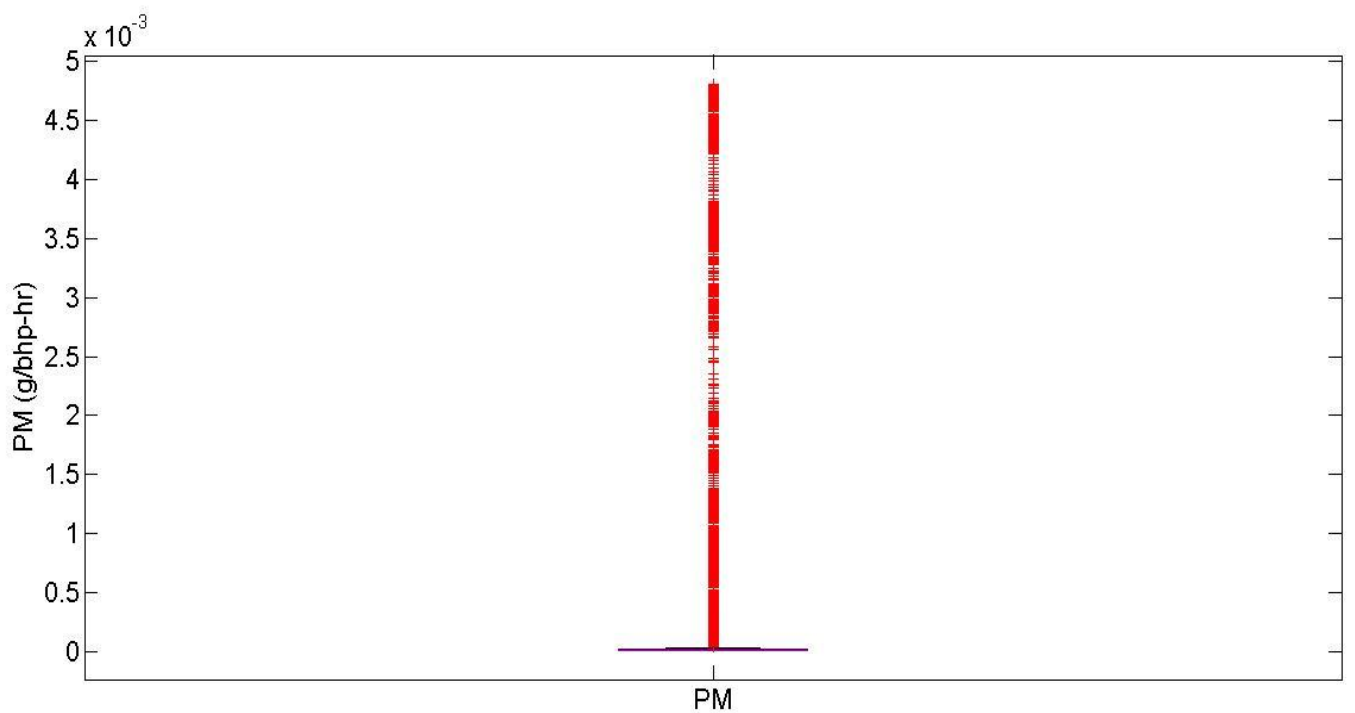

Figure 9-2: Work-Window PM Emission Distribution for TV 1 


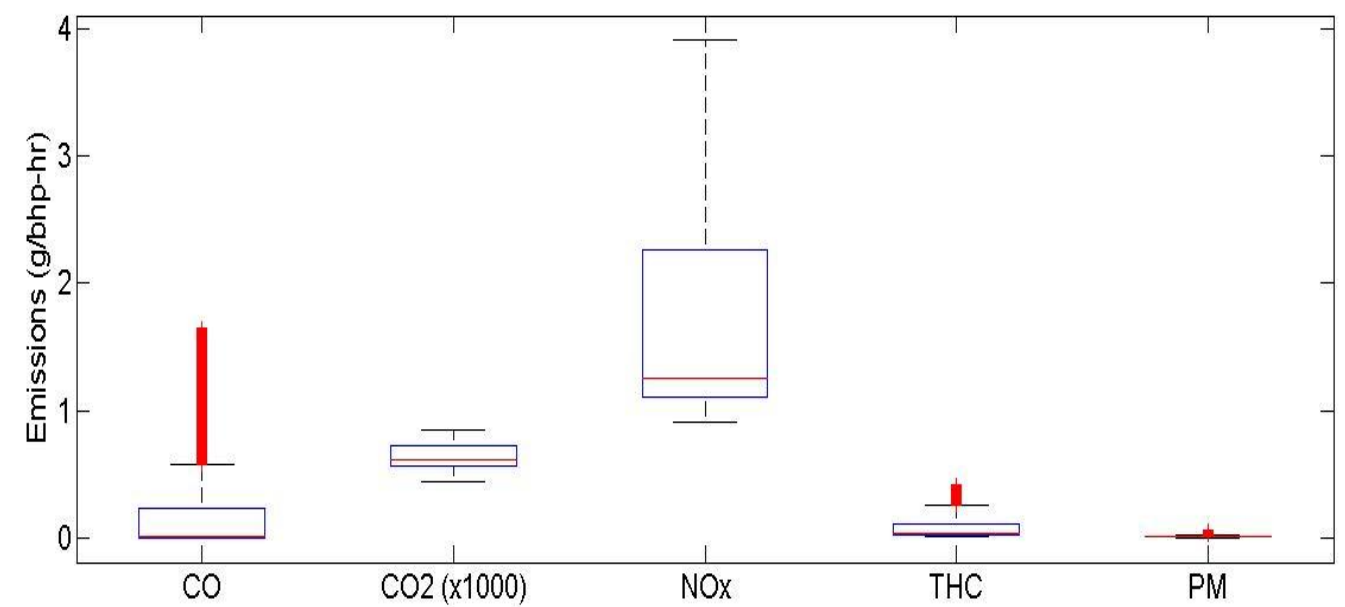

Figure 9-3: Work-Window Emission Distribution for TV 2

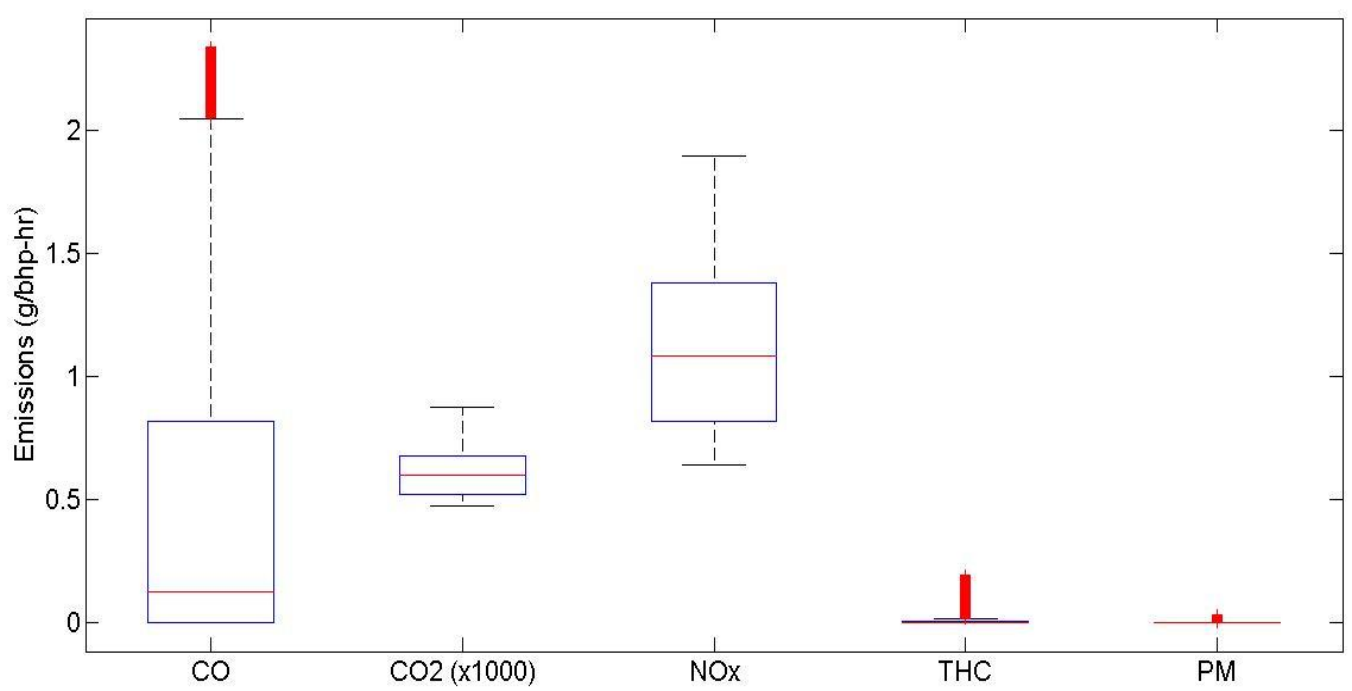

Figure 9-4: Work-Window Emission Distribution for TV 3 


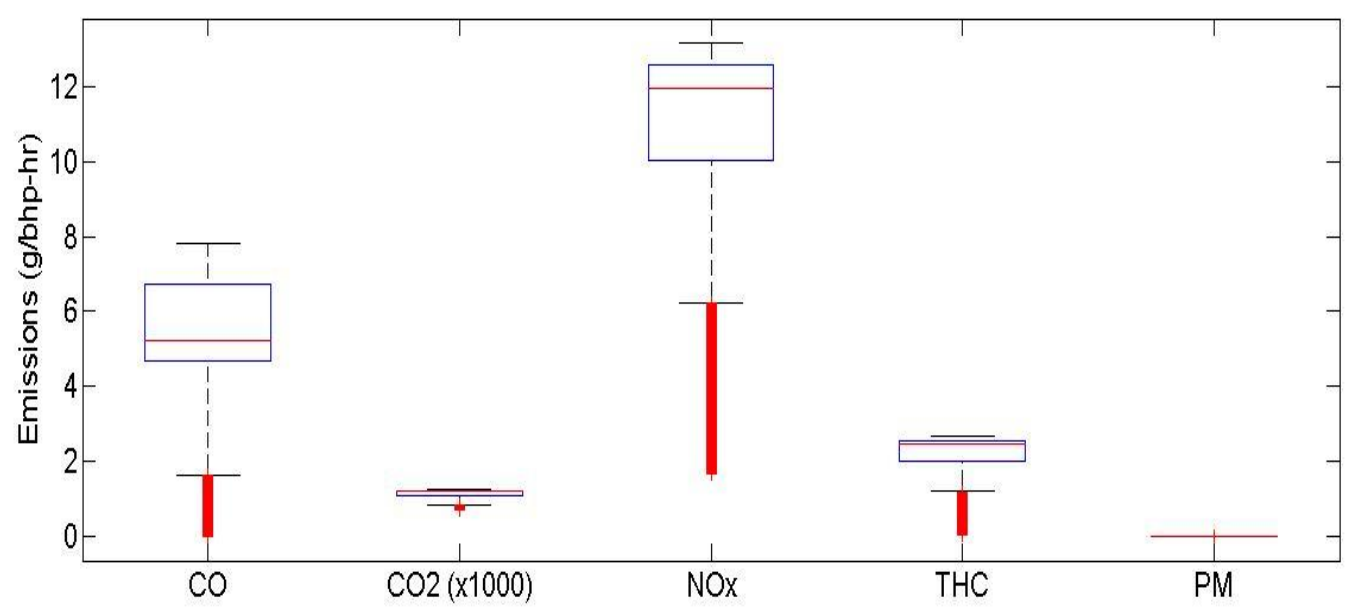

Figure 9-5: Work-Window Emission Distribution of TV 4

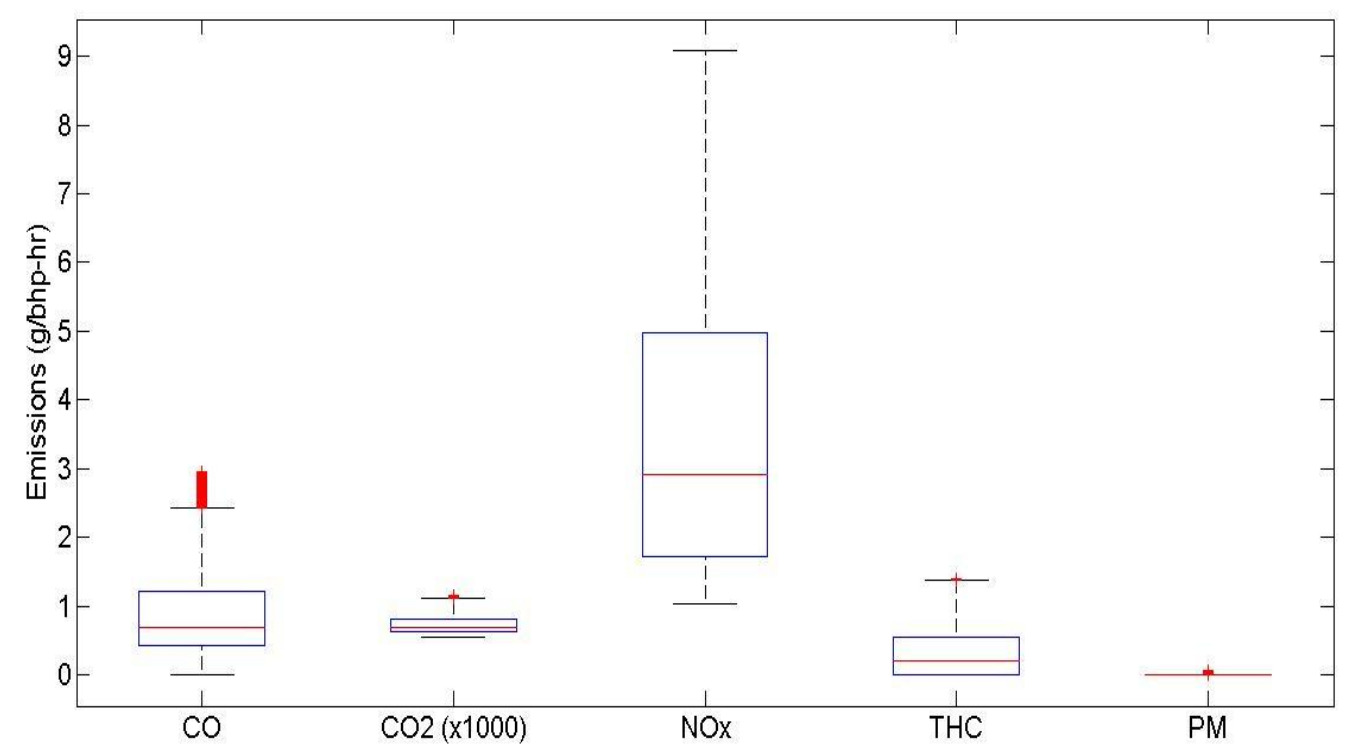

Figure 9-6: Work-Window Emission Distribution of TV 5 


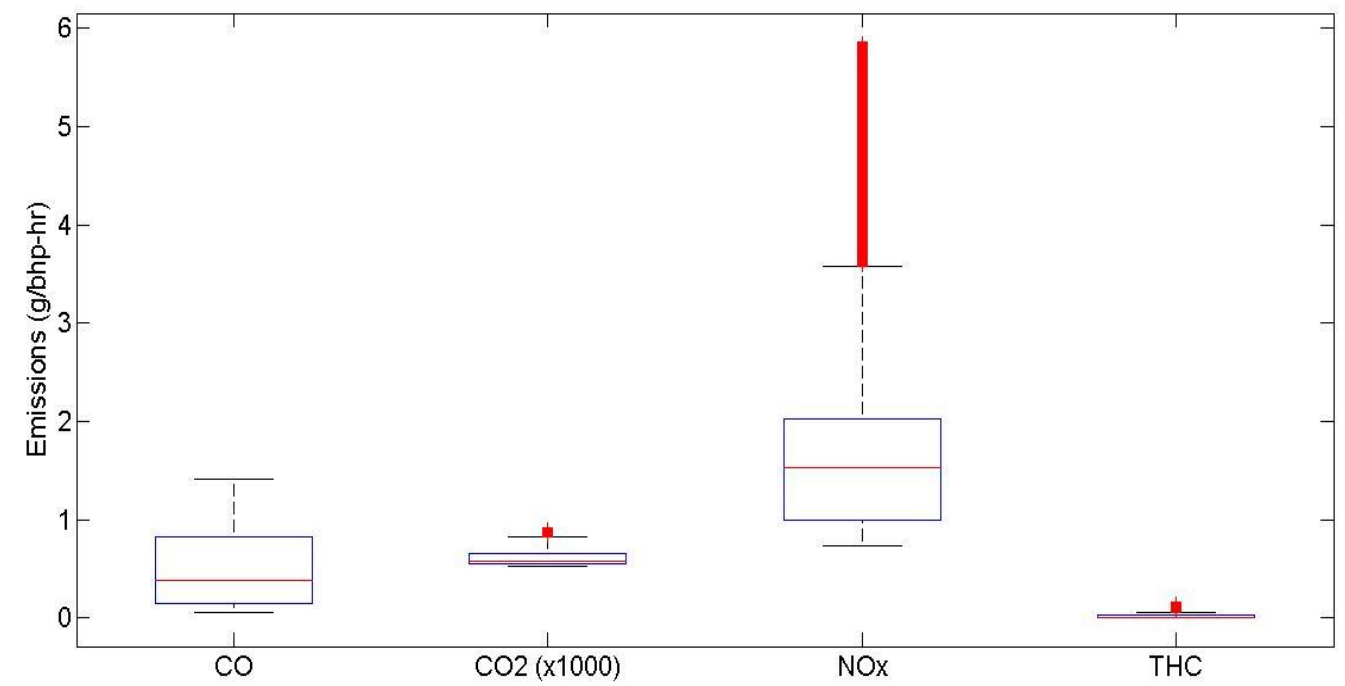

Figure 9-7: Work-Window Gaseous Emission Distribution TV 6

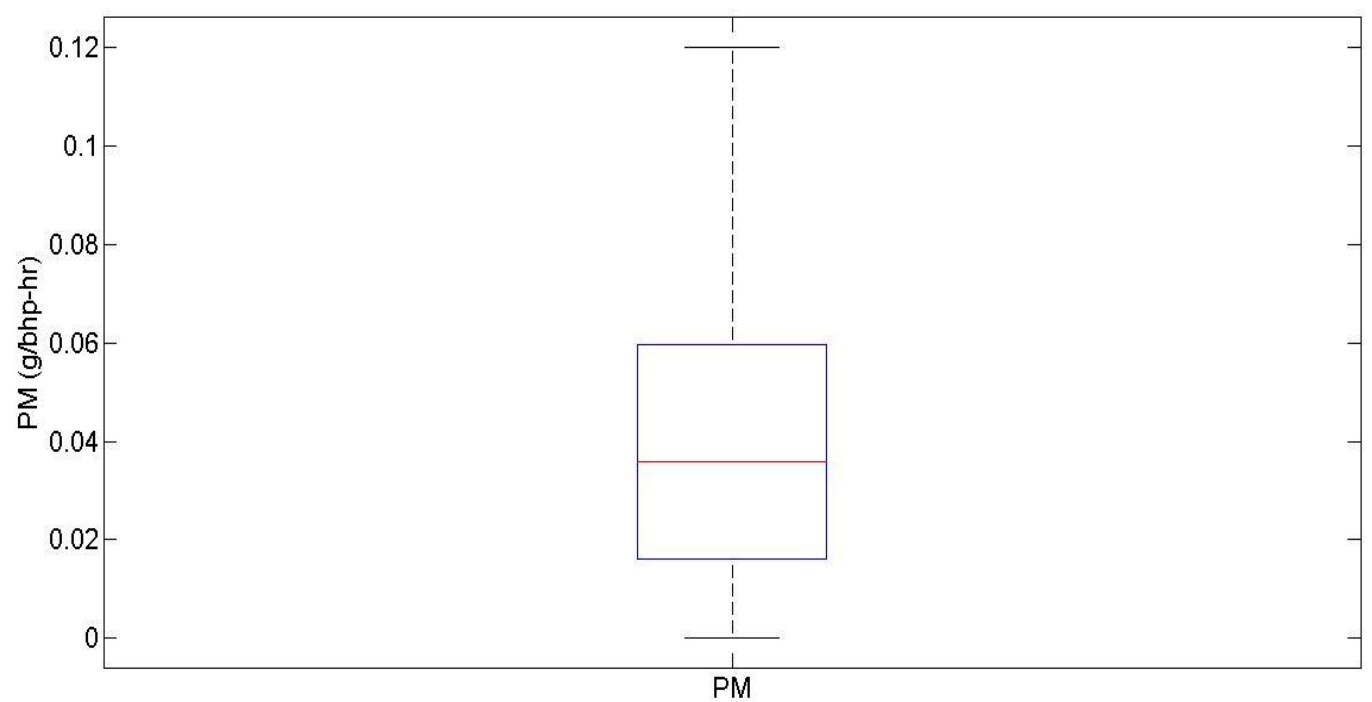

Figure 9-8: Work-Window PM Emission Distribution TV 6 


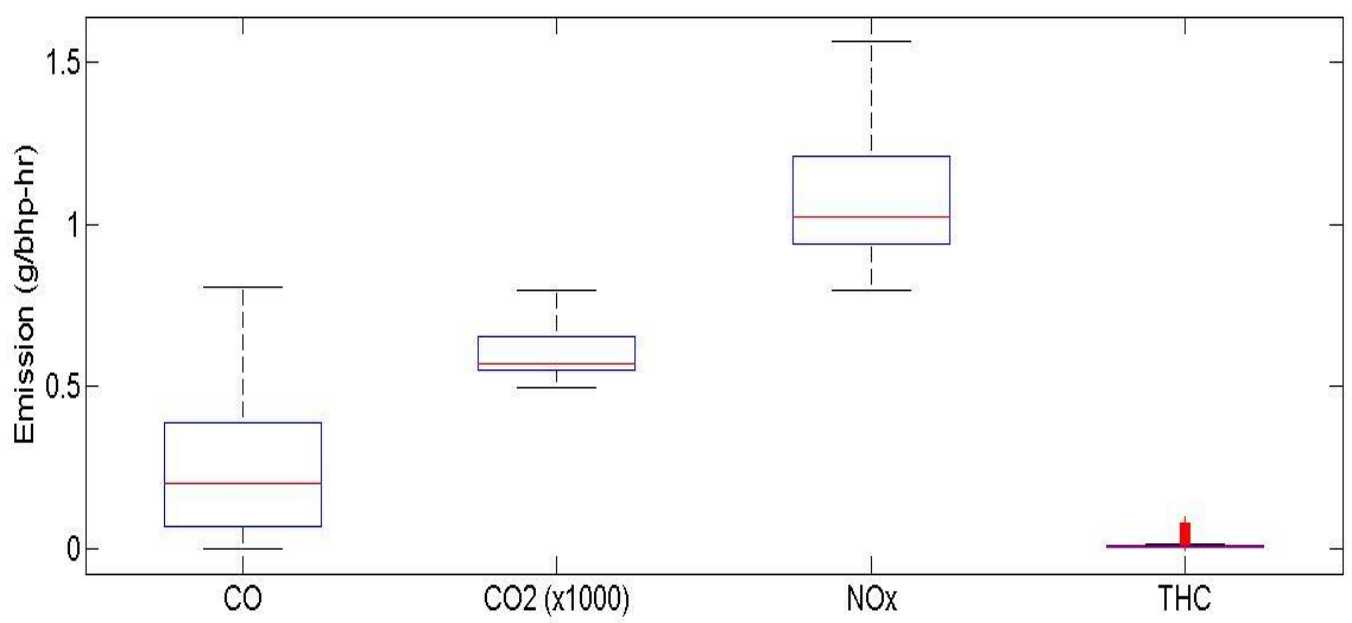

Figure 9-9: Work-Window Gaseous Emission Distribution TV 7

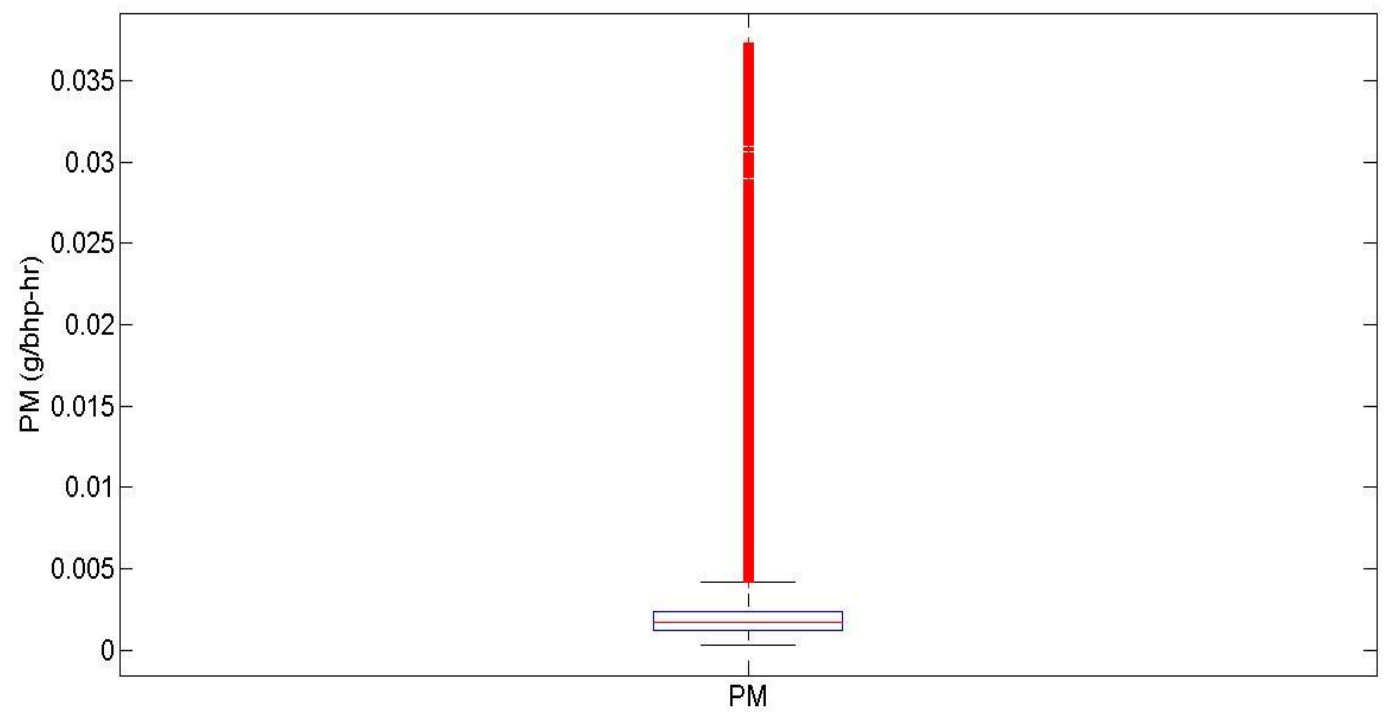

Figure 9-10: Work-Window PM Emission Distribution TV 7 


\section{Appendix D- NTE Plots and Graphs}




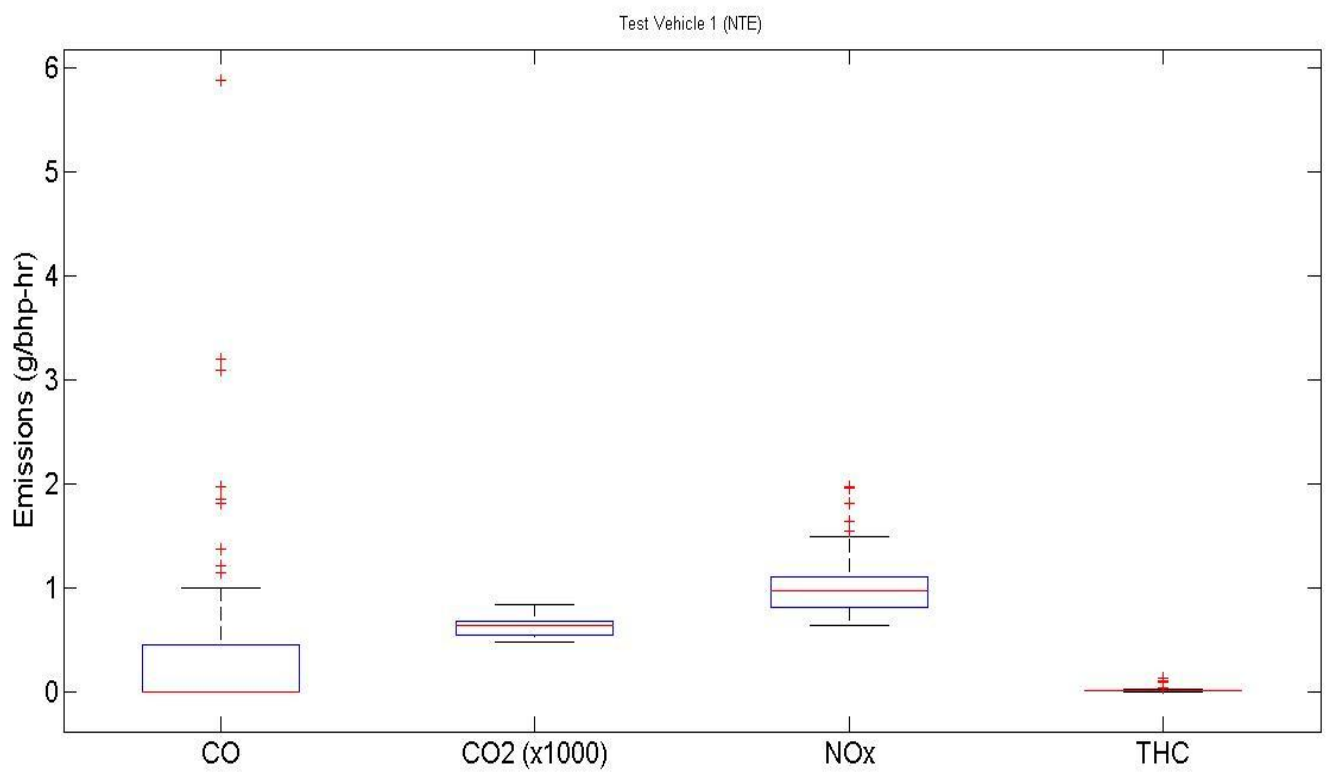

Figure 10-1: NTE Gaseous Emission Distribution for TV 1

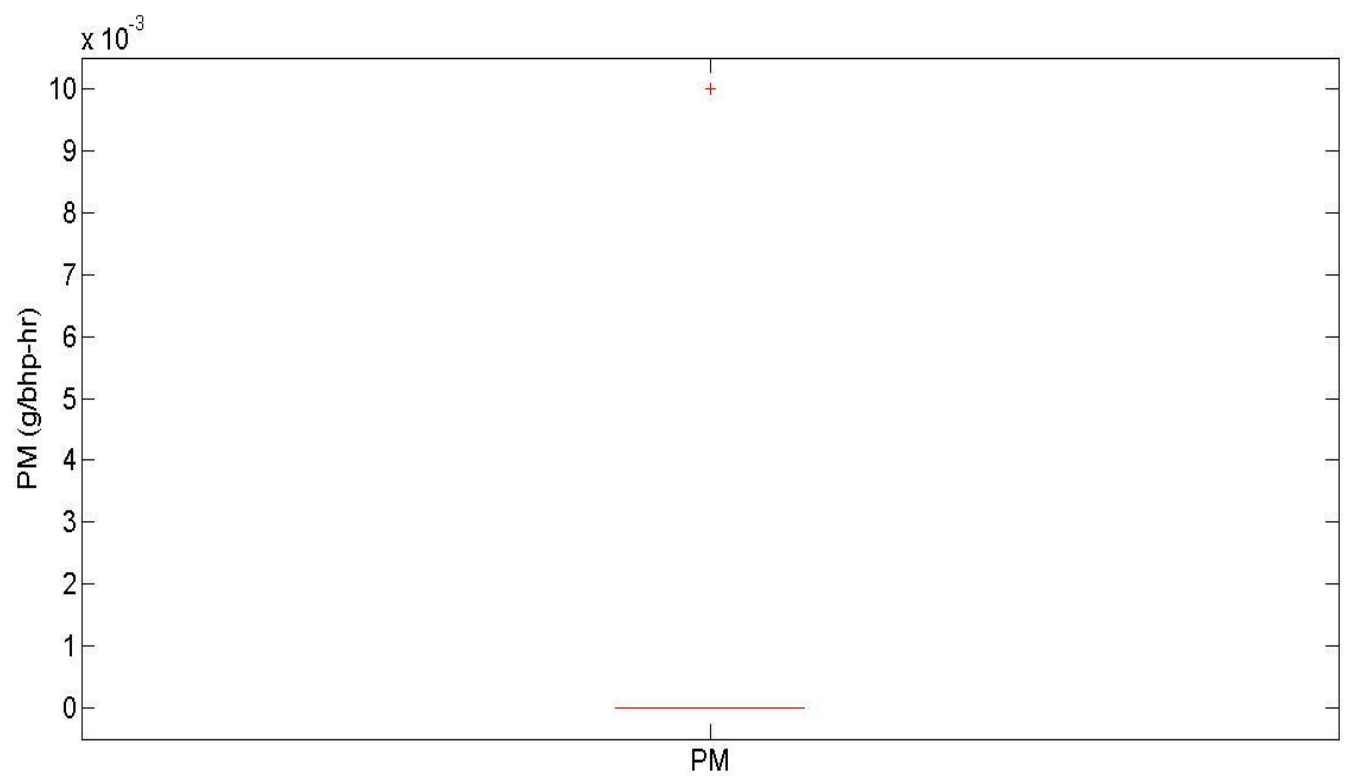

Figure 10-2: NTE PM Emission Distribution for TV 1 


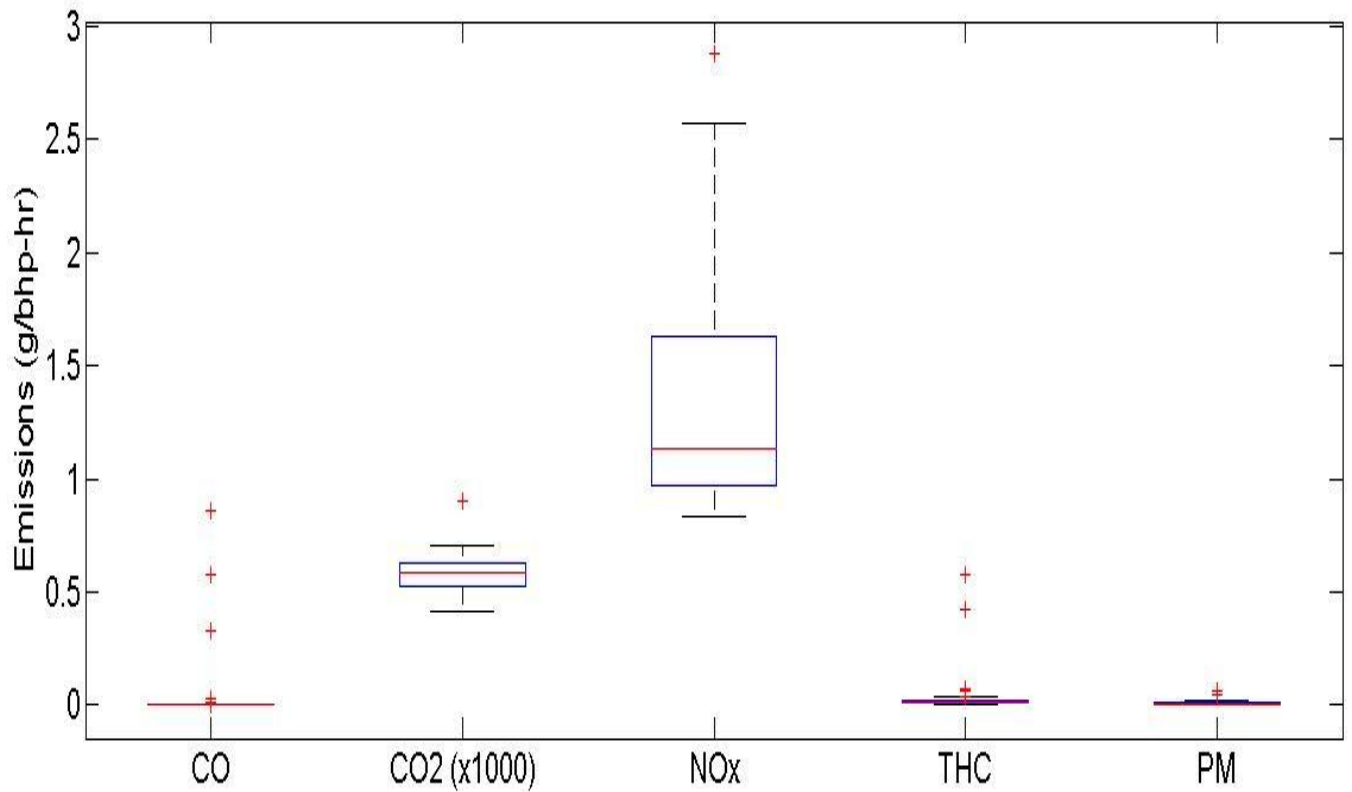

Figure 10-3: NTE Emission Distribution for TV 2

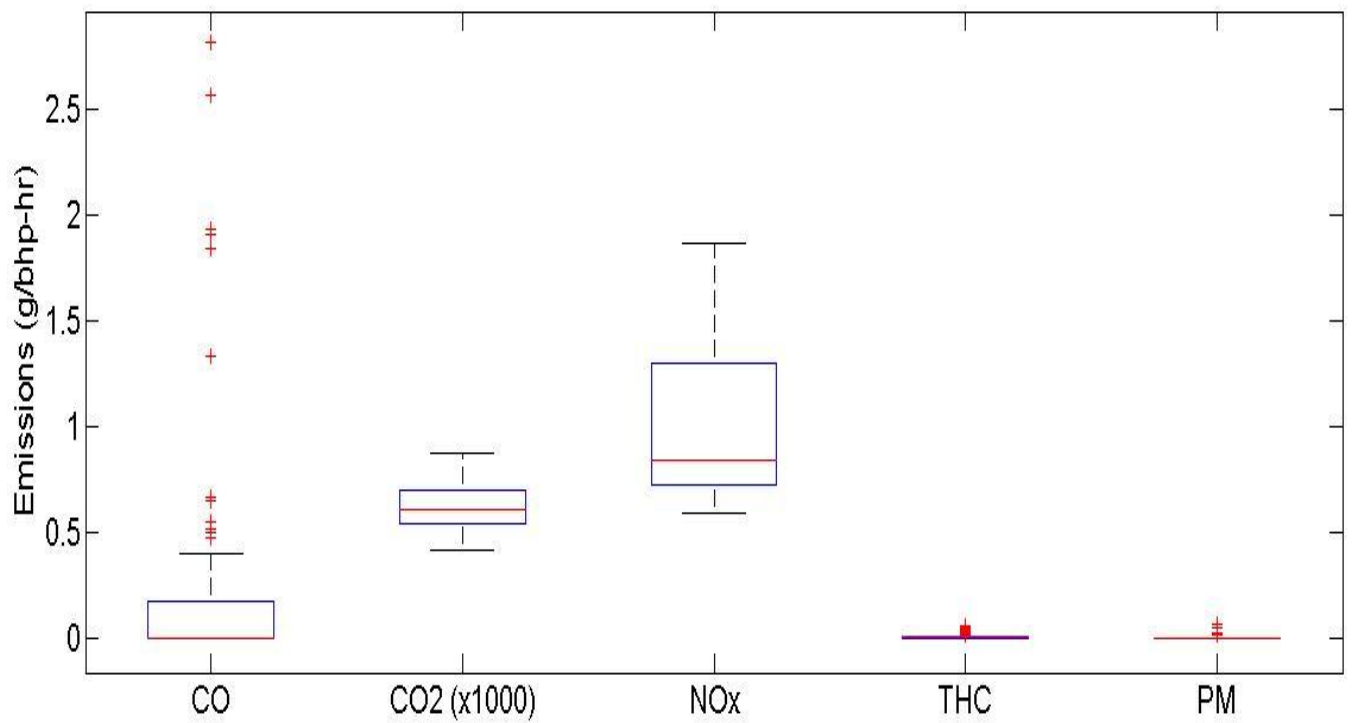

Figure 10-4: NTE Emission Distribution for TV 3 


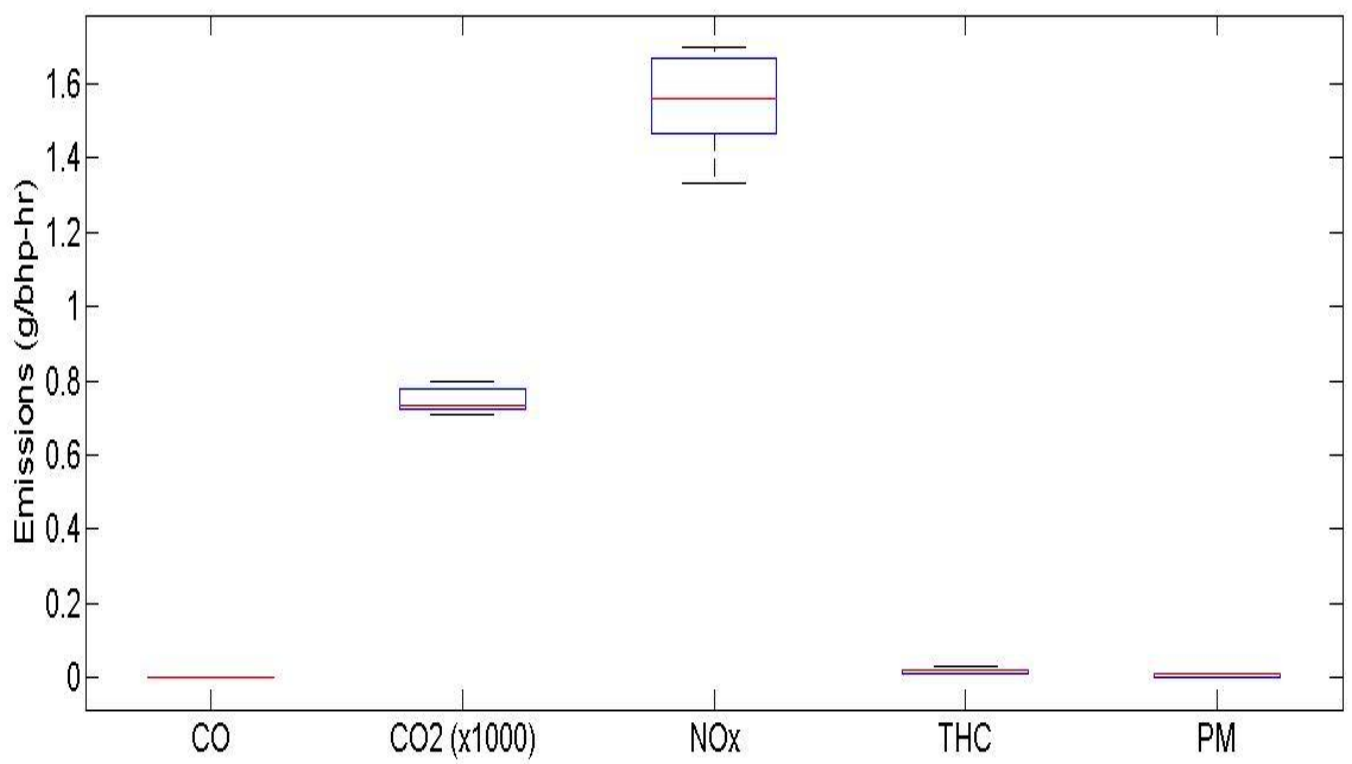

Figure 10-5: NTE Emission Distribution for TV 4

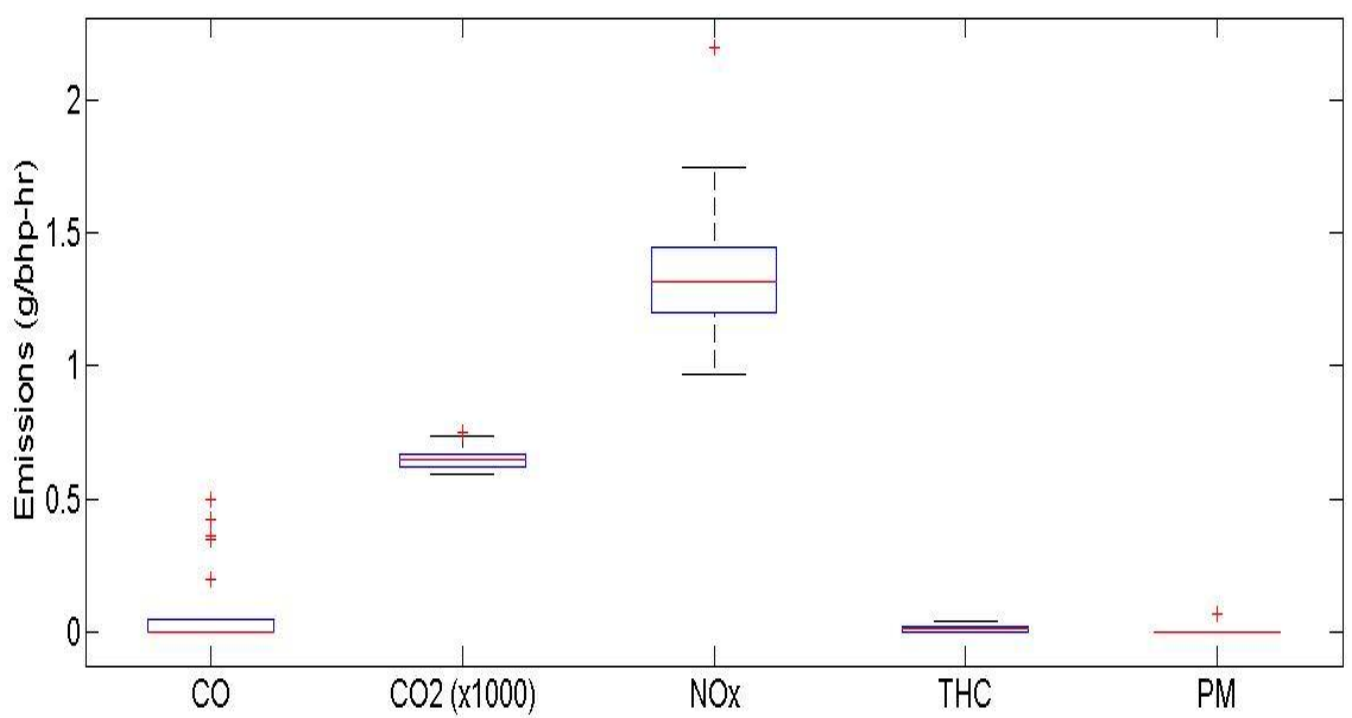

Figure 10-6: NTE Emission Distribution for TV 5 


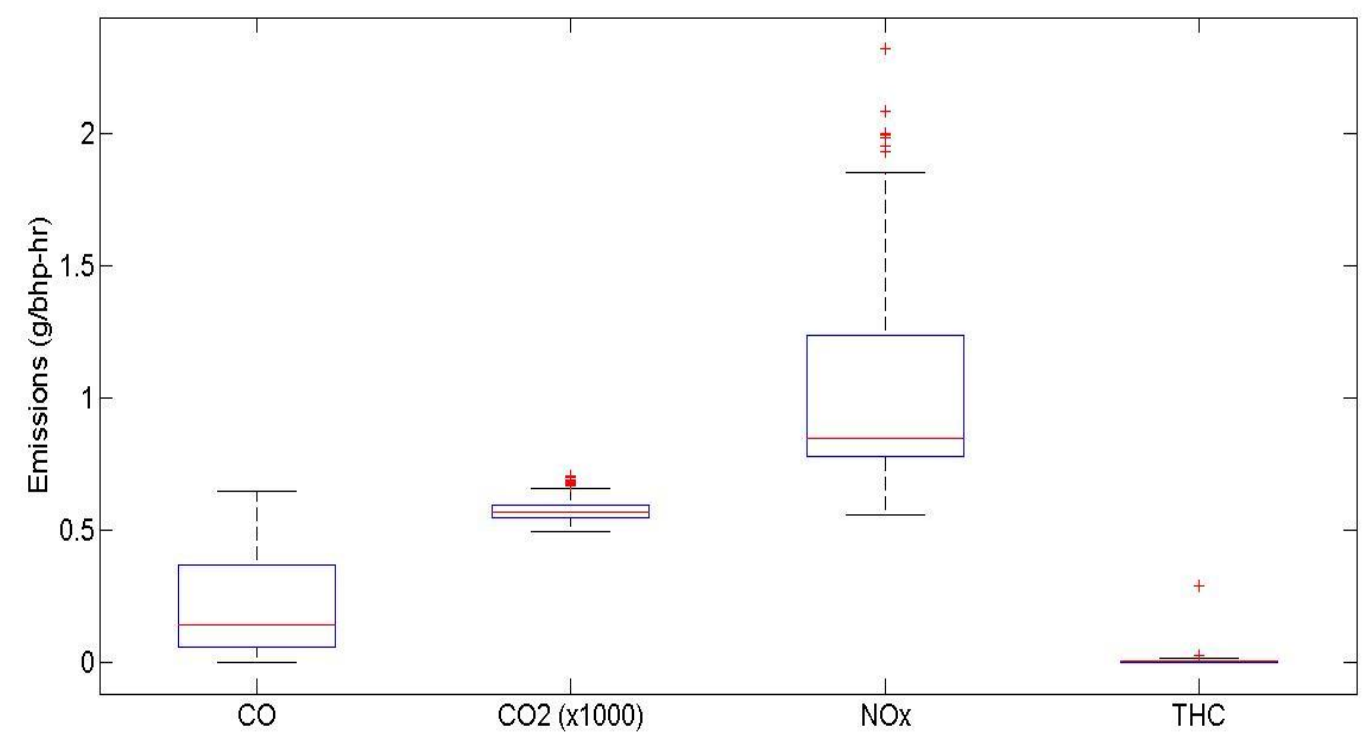

Figure 10-7: NTE Gaseous Emission Distribution for TV 6

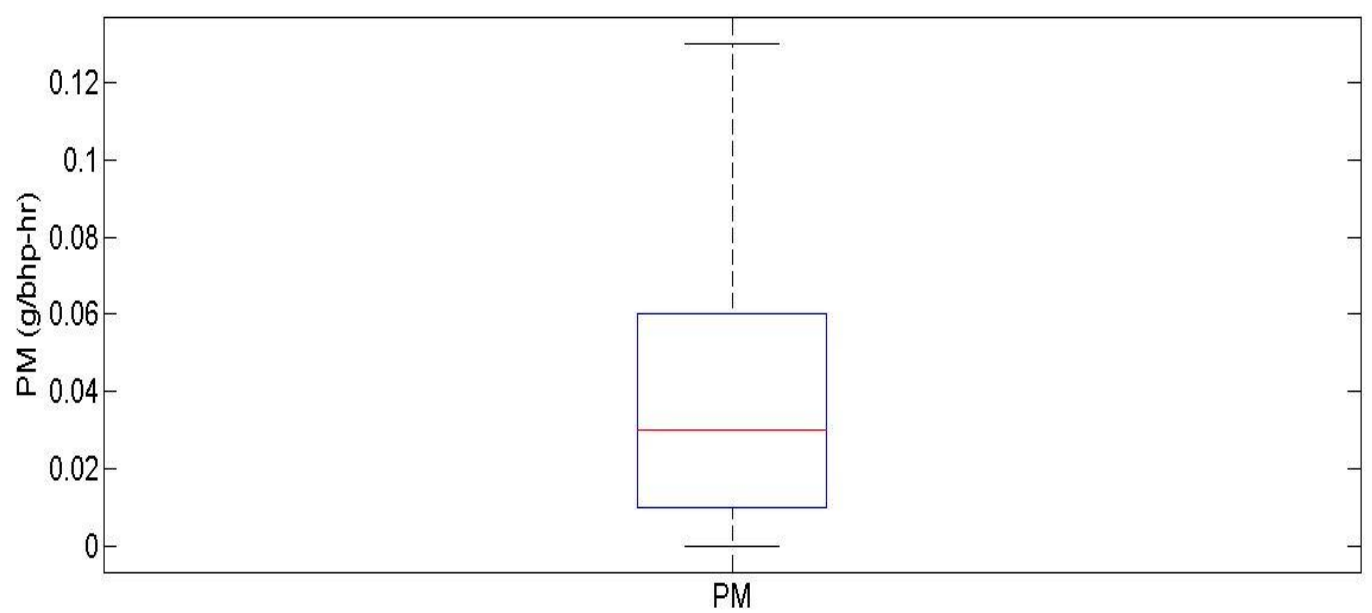

Figure 10-8: NTE PM Emission Distribution for TV 6 


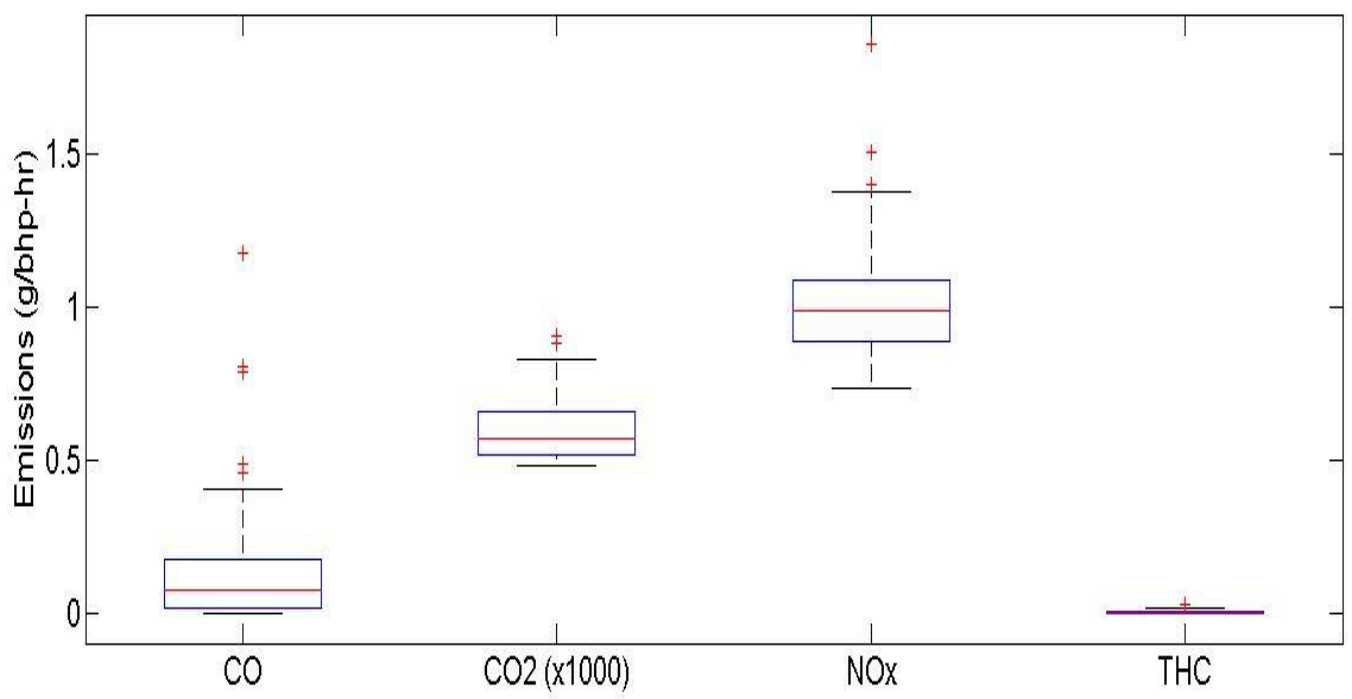

Figure 10-9: NTE Gaseous Emission Distribution for TV 7

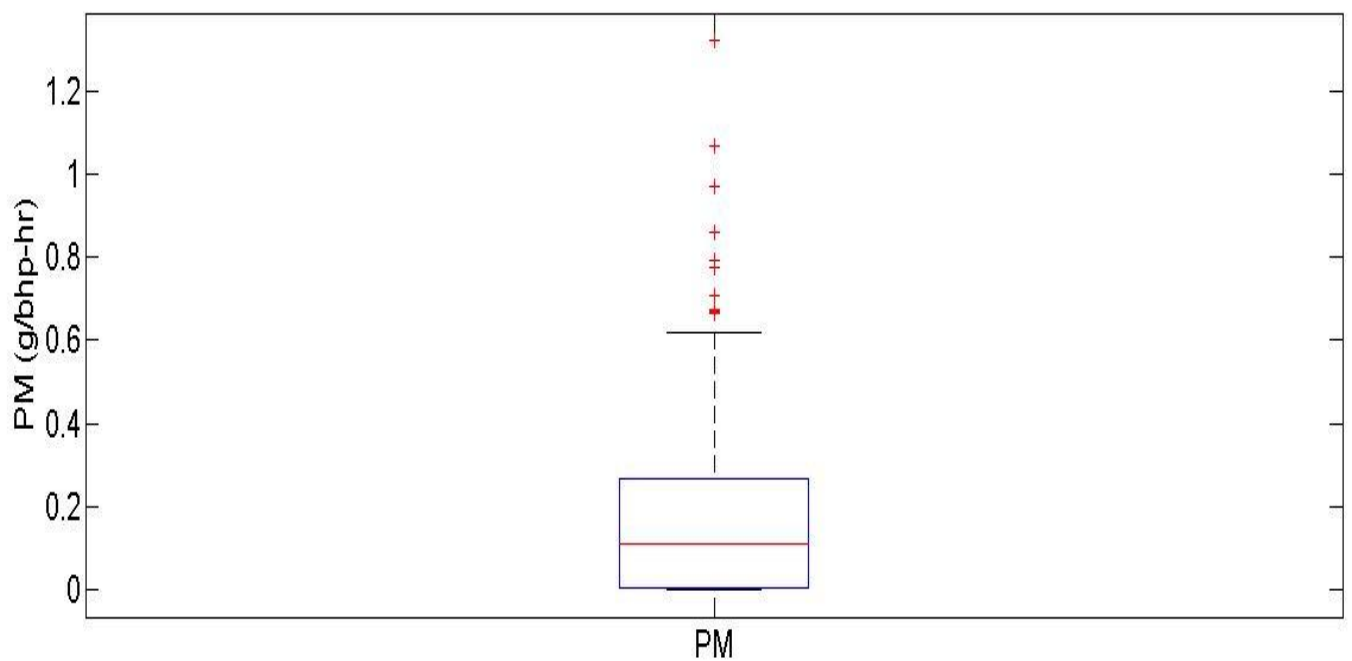

Figure 10-10: NTE PM Emission Distribution for TV 7

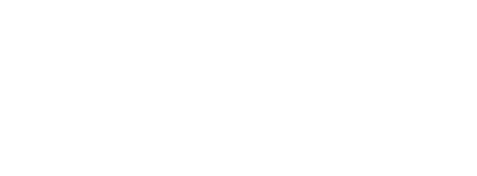

